\title{
Food Supplements in the Treatment of Ophthalmic Diseases: Preclinical and Clinical Studies
}

\author{
Dario Rusciano* PhD, Salvatore Pezzino PhD, Melania Olivieri PhD, Martina Cristaldi BSc and Giorgia Spampinato PhD \\ Sooft Italia SpA, Contrada Molino 17, 63833 Montegiorgio (FM), Italy
}

${ }^{*}$ Corresponding author: Dario Rusciano, Sooft Italia SpA, Research Center c/o Biologic Tower, University of Catania, Via Santa Sofia 89, 95123 Catania, Italy; Email: dario.rusciano@sooft.it

Received: July 24, 2020; Accepted: August 04, 2020; Published: August 10, 2020

\begin{abstract}
At least 2.2 billion people in the world suffer by vision impairment or blindness (World Health Organization, 2019). Apart from infective diseases amenable to antibiotic treatment, cataract and corneal diseases resolvable by surgery, or refractive defects treatable with spectacles, most of the remaining pathologies do not have a cure. They can be treated with drugs or by surgery to alleviate symptoms and to slow down progression, but the underlying cause of the disease is usually not fully resolvable. Therefore, the best strategy to limit the burden of these ophthalmic diseases is prevention. In fact, almost all ophthalmic pathologies have a known etiology and pathway of development (although often not all the elements in the different steps have been elucidated), so that they are amenable to possible preventive treatments. Aim of this review is to illustrate how food supplements might help in the prevention and treatment of these ophthalmic diseases.
\end{abstract}

\section{Introduction}

Among the 2.2 billion people in the world affected by any type of eye condition, the World Health Organization estimates 196 million with Age-related Macular Degeneration (AMD), 146 million with diabetic retinopathy (DR) and 76 million with glaucoma [1]. No clear estimate exists on the global presence of dry eye, though the English Agency known as Global-Data UK Ltd. in a document published on June 2018, considering the 8 more industrialised Countries (US, France, Germany, Italy, Spain, UK, Japan, and China), reports a prevalence of $267,680,785$ cases in 2016, destined to raise to $286,308,974$ cases in 2026 , therefore with an annual growth rate of $0.70 \%$ [2]. Approximately 200 million eyes globally are affected by cataracts causing a visual acuity less than $6 / 60$, which become 3-4 times more including cataracts causing an acuity below 6/18 [3], accounting for one third of the worldwide blindness [4]. Globally, over 300 millions adolescents (less than 19 years old) are affected by progressive myopia [1], which in older ages may bring serious complications, like glaucoma or retinal detachment. All these eye pathologies pose a serious threat to vision, and have a strong social and economic impact. It has been estimated in 2014 by the National Eye Institute that the annual economic burden of vision loss, eye diseases and vision disorders in the U.S. amounted to 139 billion \$ [5]. Now, what all these pathologies have in common is that there is no efficient pharmacological treatment for any of them. Resolutive surgery is possible in the case of cataract, but it is not devoid of although minimal - side effects [6]. Surgical approaches are routinary applied also to the other pathologies, but most often they are not curative, and can at best attenuate their progression $[7,8]$. However, for all of them there is a link with lifestyle and alimentary habits, which becomes more evident in older ages $[9,10]$. This opens a space for prevention, early treatment and association of dietary habits or use of food supplements with pharmacological or surgical treatments. Aim of this review is to illustrate the scientific evidence supporting the use of food supplements in the management of eye pathologies.

\section{GLAUCOMA}

Glaucoma is an optic neuropathy, including a group of similar pathologies affecting the retinal ganglion cells (RGC), the optic nerve $(\mathrm{ON})$ and the connected visual structures, causing vision loss and eventually blindness [11]. Primary open angle glaucoma (POAG) is the most common form of glaucoma (around $90 \%$ of the cases). It may occur in association with elevated intraocular pressure (IOP), in which case it is described as hypertensive glaucoma, or with normal IOP, in which case it is designed as normal tension glaucoma (NTG) [12]. In either case, the common pathological marker is the death of RGC by apoptosis, which eventually leads to the degeneration of the whole visual pathway, including the lateral geniculate nuclei and the visual brain cortex through the mechanism known as trans-synaptic degeneration $[13,14]$. This mechanism is present in other neurological diseases such as Alzheimer, Parkinson and Amyotrophic Lateral Sclerosis [13]. Therefore, also POAG is considered a slow progressing neurological disease [13]. Both extrinsic and intrinsic mechanisms contribute to RGC apoptotic death. Among the first, there are mechanical and metabolic factors. The compression of the $\mathrm{ON}$ at the lamina cribrosa (the structure present at the optic disk through which the ON leaves the eye) due to IOP elevation, leads to a decreased axoplasm flow and neurotrophins circulation between the periphery and the nucleus of the cell, necessary for RGC survival [15]. Endothelial dysfunction and decreased blood perfusion of the $\mathrm{ON}$ head $(\mathrm{ONH})$ is a common finding in POAG [16], and may become a dominant trigger in NTG [17]. These events may activate or aggravate the intrinsic mechanisms, like glial 
cell activation and neuroinflammation, glutamate excitotoxicity and calcium release from dying cells, oxidative stress, starting a domino effect of RGC death, and further aggravating the pathology [18-20]. More recently, mitochondrial dysfunction has been added as a main mechanism among the different causes that can possibly lead to RGC death and glaucoma [21]. However, from the clinical perspective, the only pharmacologic therapeutic approach is based on the reduction of the IOP, both for hypertensive POAG and for NTG [22]. However, several clinical studies have shown that IOP reduction is a necessary, but not sufficient condition to arrest POAG progression [23]. Moreover, due to the structure of the retina, and the redundance of the cell network system carrying light signals from the eye to the brain, usually more than $50 \%$ of RGCs are dead when the first visual field abnormalities are detectable [24]. Hence, a neuroprotective strategy is becoming more often associated with the classical IOP-lowering treatment to try and improve the therapeutic outcome of POAG patients [25]. We have already reported that neurodegeneration is caused by several different types of insult to RGC, therefore an effective neuroprotective treatment should be endowed with multiple effects on different targets [25]. To this purpose, a single molecule with pleiotropic effects, or an association of molecules joining together their therapeutic mechanisms, should be considered (Figure 1).

Brimonidine is a drug and it is an $\alpha-2_{\mathrm{A}}$ adrenergic receptor agonist, present in eye drops medications either alone, or in association with other hypotonizing drugs (timolol or dorzolamide). It is a paradigm of a multipurpose molecule, being active both on the hypotonizing and the neuroprotective side, and has clearly demonstrated that neuroprotection and hypotonizing effects can be dissociated. In fact, brimonidine, beside the hypotonizing effect on IOP [26], has also shown several neuroprotective effects, such as improved perfusion pressure at the ONH [27]; rescue of RGC from apoptosis by increasing the ratio bcl2/BAX [28]; prevention of the release of pro-apoptotic intracellular calcium [29]; blunting of the excitotoxicity due to excessive glutammate release [30] and upregulation of the neurotrophin BDNF expression by RGC [31]. Brimonidine neuroprotective effects in POAG have been demonstrated both in preclinical animal model systems [32] and in a seminal clinical trial of several years, showing that the neuroprotective effects achieved by brimonidine were indipendent from the hypotonizing effects that could be equally achieved by timolol [33].

\section{Food Supplements}

Epigallo-catechin-gallate (EGCG) is the main catechin of green tea, and also displays several activities with neuroprotective value. It has no effect on IOP, but it improves vascular perfusion by stimulating the expression of the endothelial form of nitric oxide synthase [34]; it is an iron chelator and a potent antioxidant, reducing oxidative stress and lipoperoxidation of cell membranes, thus shielding RGC from oxidative damage [35], and it is easily absorbed and distributed throughout the body [36]; it has anti-apoptotic activities, contrasting the activation of proapoptotic genes and favoring the expression of antiapoptotic ones, thus defending RGC from traumatic apoptotic death $[37,38]$. Its antioxidant and neuroprotective effects on RGC have been demonstrated in a mouse model in which oxidative damage was induced by intravitreal injection of sodium nitroprusside. When EGCG was given together with SNP, apoptotic cell death of RGC was significantly blunted [39]. Accordingly, in a mouse model of retinal ischemia/reperfusion, resembling acute closed angle glaucoma, oral

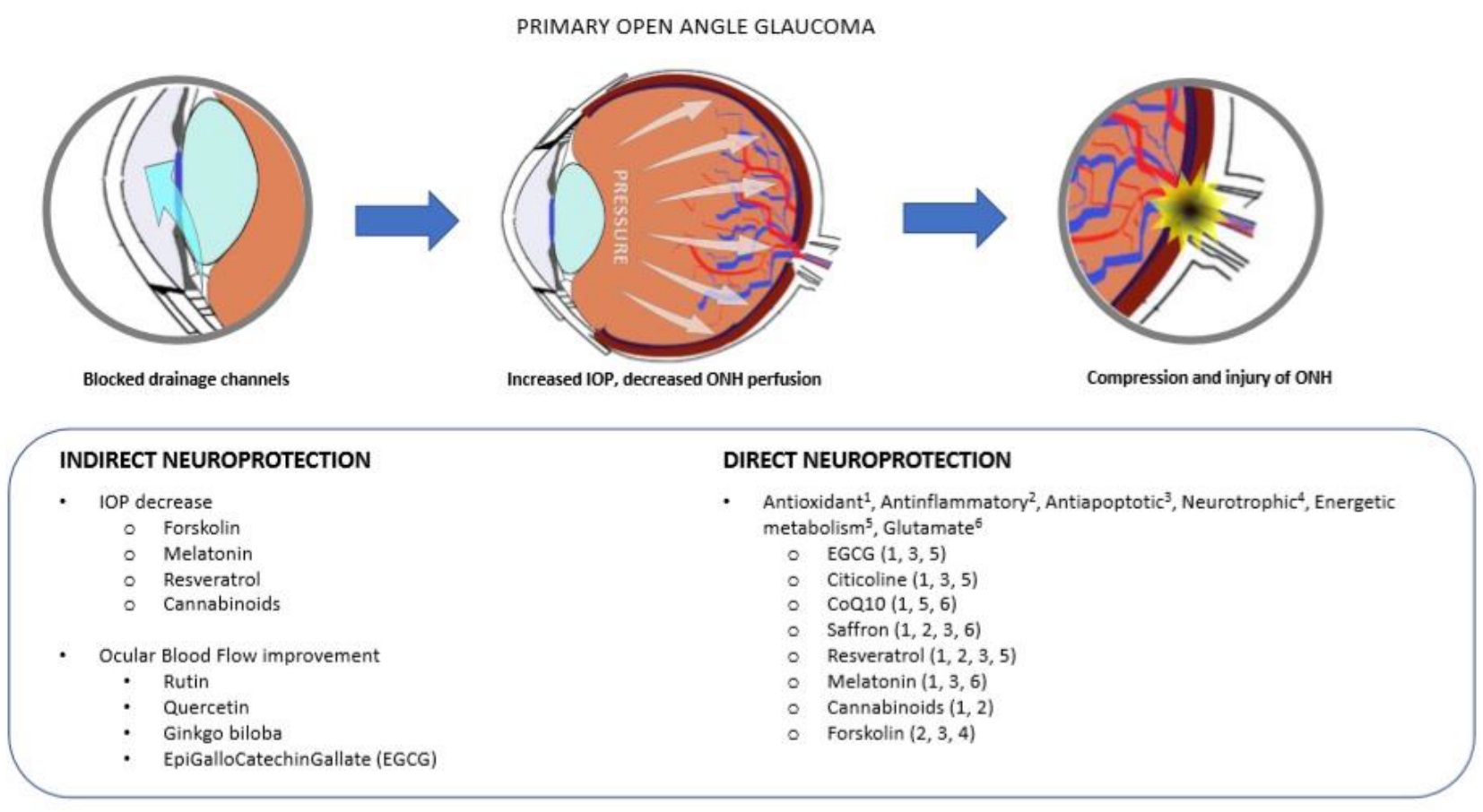

Figure 1: Neurodegeneration in POAG. The main recognized mechanisms of neurodegeneration in POAG are the excessive pressure at the level of the lamina cribrosa, where the optic nerve leaves the eye globe, and/or the decreased blood perfusion at the optic nerve head (ONH) (upper panel). These events may lead to injury and apoptosis of retinal ganglion cells (RGC), and the progressive loss of sight. Indirect neuroprotective agents are those mainly acting on the IOP decrease and the improvement of blood perfusion (bottom left). Direct neuroprotection works by blunting those events directly leading to cell injury and apoptosis (bottom right). 
administration of EGCG could rescue RGC from apoptotic death, as seen by the conserved electroretinogram (ERG) response and thickness of the ganglion cell layer, and by the decreased expression of apoptotic caspases [40]. The antioxidant activity of EGCG has been proposed as a possible remedy to blunt the effects of mytochondrial dysfunction on glaucoma progression [41]. A clinical trial on 18 patients with POAG established that EGCG oral supplementation could improve - although slightly, because of the short treatment time - their pattern electroretinogram (PERG), which is an early alteration detectable in glaucoma subjects [42].

Citicoline is the current name of cytidine-5'-diphosphocholine. Citicoline is naturally present in all cells, serving as an intermediate in the biosynthesis of phosphatidylcholine, a component of biological membranes [43]. Citicoline has been one of the first neuroprotectors proposed [44], and has shown neuroprotective effects in Alzheimer disease, stroke, and Parkinson's disease, as well as in glaucoma and amblyopia [45]. Some citicoline neuroprotective effects are mediated by the restoration of phosphatidylcholine levels and maintainance of sphingomyelin and cardiolipin levels (constituent of the inner mitochondrial membrane, involved in the cell energetic metabolism); by anti-oxidant effects, due to the increase of glutathione reductase (GR) activity and glutathione (GSH) synthesis and the decrease of PLA2 activity and lipid peroxidation; by the restoration of $\mathrm{Na}+/$ $\mathrm{K}+$ ATPase activity, essential for the proper functioning of neurons and glial cells. The choline provided by citicoline is used for the biosynthesis of the neurotransmitter acetylcholine, the stimulation of tyrosine hydroxylase activity and dopamine release [46]. Moreover, citicoline showed antiapoptotic effects by enhancing antiapoptotic bcl 2 expression in a rat model of partial ON crush [47], and by decreasing apoptotic caspases expression in explanted rat retinas cultivated in toxic high glucose cell culture medium [48]. Over the years, citicoline has been studied in several glaucoma clinical trials. Initially, it was given by intramuscular injection, with a notable improvement on both PERG (RGC function) and VEP (Visual Evoked Potentials: gives the function of the whole visual axis) response [49,50]. In a further study, it was shown that oral administration of citicoline to glaucoma patients gave the same protection as the intramuscular injection, thus improving patients' compliance [51]. Finally, also topical citicoline formulations as eye drops were shown to be effective in improving PERG and VEP of glaucoma patients over a period of 4 months [52].

Coenzyme Q (ubiquinone) neuroprotective activity also appears to be linked with its effects on mitochondria. In fact, coenzyme Q10 (CoQ10: the prevalent form found in humans) is a potent antioxidant, a membrane stabilizer and an important cofactor of the mitochondrial electron transport chain for the production of adenosine triphosphate (ATP) [53]. In the DBA/2J mouse model of spontaneous glaucoma, diet supplementation with CoQ10 significantly decreased the ratio between pro-apoptotic and anti-apoptocic genes in the retina, thus preventing apoptotic cell death. Moreover, mitochondrial DNA and the Tfam transcription factor of the oxydative phosphorylation system in the retina were functionally preserved. This resulted in increased RGC survival and preservation of ON axons, and blunting of astroglial activation in the retina and ONH [54]. Massive RGC death typically results in the release of an excess of glutamate, and a paroxystic activation of glutamate receptors. This leads to the opening of the mitochondrial permeability transition pore (MPTP) through which cytochrome $\mathrm{C}$ is released, signaling for the activation of caspase 9 and the apoptotic cascade. CoQ10 showed a further specific antiapoptotic effect by maintaining MPTP in the closed conformation thus preventing the triggering of apoptotic cell death [55]. In a rat model of mechanic ON injury a topical formulation of CoQ10 + vitamin E was administered as eye drops for 4 weeks. Decreased gliosis, increased anti-apoptotic gene expression, and preserved Tfam were observed in the retina of CoQ10 treated mice, which resulted in increased RGC survival [56]. Most recently, a multicenter, controlled clinical trial on 612 POAG patients has started, having visual field progression as the primary outcome, with the aim to evaluate the neuroprotective effects of an ophthalmic solution of CoQ10 and Vitamin E [57].

Saffron (crocus sativus) is a traditional medicinal plant containing in its stigmas many metabolites, among which the carotenoids crocin, crocetin and lycopene and the xantophyl zeaxanthin [58]. Crocin and crocetin are the main bioactive components [59], which can promptly be absorbed through the gastrointestinal tract, diffuse into organs and easily traverse the blood brain barrier (BBB) [60]. They have shown a protective effect on the integrity of the $\mathrm{BBB}$ during cerebral ischemia [61], which effect could likely be transposed also on the protection of the blood retinal barrier (BRB) during degenerative retinopathies, such as in AMD or DR [62]. The neuroprotective properties of saffron have been demonstrated in several ophthalmic pathologies and attributed to the important anti-inflammatory, antioxidant, and antiapoptotic properties of its bioactive components [63]. In glaucoma, retinal ischemia triggers neuronal cell death. Crocin and crocetin blunt oxidative stress and inhibit RGC death in mouse and rat models of ischemia/reperfusion [64-66]. Excitotoxicity by N-methyl-Daspartate (NMDA) released by dying RGC is a common event during glaucoma progression [19]. Oral administration of crocetin prevented the inner retinal damage induced by intravitreal injection of NMDA in mice, by inhibiting the caspase pathway [67]. Most recently, a mouse model of laser-induced ocular hypertension (OHT) has been used to show the anti-inflammatory and neuroprotective effects of a saffron extract titrated to 3\% in crocin. Both gliosis and RGC death were efficiently prevented by crocin oral supplementation in OHT eyes [68]. Clinical studies with saffron used so far IOP as the sole endpoint. Daily oral administration of $30 \mathrm{mg}$ of a saffron infusion for three weeks produced an IOP decrease in POAG patients [69], whilst a discontinuous (twice per week) oral treatment with an even higher amount of $1 \mathrm{gr}$ for a month gave no variation on the IOP [70], suggesting that continuity of treatment rather than dose could be the relevant strategy. The toxic effects of saffron become evident for daily doses higher than $5 \mathrm{~g}$ [71]. Therefore, since its human therapeutic use is in the range of milligrams, it has virtually no toxicity [72].

Resveratrol (3,5,4'-trihydroxy-trans-stilbene) is a natural phenol, a phytoalexin naturally produced by several plants (it can be found in foods such as grapes, peanuts, blueberries, and dark chocolate) in response to microbiological attacks [73]. It is endowed with potent anti-oxidant and anti-inflammatory properties, which are likely responsible for its cardioprotective [74], neuroprotective [75], and antiaging effects [76]. In fact, resveratrol has shown neuroprotective effects 
in neuroinflammatory and neurodegenerative diseases like stroke and Alzheimer's disease [77,78]. Most interestingly, resveratrol has been shown to blunt the damage of ischemic brain injuries [79], likely by preserving brain mitochondria function after ischemic/reperfusion damage [80], and extend the lifespan of organisms from yeast to mammals [81]. All these beneficial activities of resveratrol appear to be mainly mediated by its stimulating effect on AMPK [82], which in turn stimulates the activity of SIRT1 (the mammal homologue of Sir2), the longevity-associated gene [83]. Several preclinical evidence support the efficacy of resveratrol in controlling the glaucomatous disease. In primary trabecular meshwork (TM) cells subjected in vitro to chronic oxidative stress $\left(40 \% \mathrm{O}_{2}\right)$ resveratrol treatment blunted the production of free radicals and inflammatory markers (IL1a, IL6, IL8, and ELAM-1), also exerting antiapoptotic effects [84]. In a mouse model of glaucoma induced by clogging of the TM, intraperitoneal injections of resveratrol partially protected RGC from apoptotic cell death [85]. RGC dendrites protection by resveratrol was demonstrated in mice fed for one year with a resveratrol supplement, and then subjected to $\mathrm{ON}$ crush, which simulates the compression at the ONH further to acute IOP elevation. In this case the protective effect appeared to be associated with increased expression of the nuclear C/EBP homologous protein and the nuclear X-box-binding protein-1 [86]. Intravitreal injection of resveratrol could mitigate the retinal ischemic injury in a rat model system of ischemia/reperfusion obtained by a sudden elevation of the IOP, simulating an angle closure glaucoma. In this case the effect was related to the containment of the upregulation of matrix metalloproteinase- 9 , heme oxygenase-1 (HO-1), and inducible nitric oxide synthase [87]. Mitochondrial protection by resveratrol treatment was shown in hypertensive model systems in vitro with RGC5 neuronal cells, and in vivo in rats fed with a resveratrol supplement before artificial clogging of the TM. In both systems neuronal cells improved mitochondrial function and survival was dependent on the activation of the AMPK/SIRT1/ PGC-1 a signaling pathway, which is a critical pathway regulating mitochondrial biogenesis and function $[88,89]$. Finally, a critical process in the development of glaucoma is neuroinflammation, which is sustained by activated astrocytes producing cytotoxic mediators triggering RGC apoptosis. Resveratrol given in vitro to astrocytes under oxidative stress blunted their activation and improved their survival by decreasing caspases activation, toxic Tau processing, and neurofibrillar tangles formation [90]. Beside its direct neuroprotective activity on RGC, resveratrol may also work to decrease IOP. Topical administration of resveratrol eye drops in a rat model system of steroid-induced hypertensive glaucoma [91] could decrease by $25 \%$ the IOP via a mechanism involving adenosine receptors [92]. This hypotonizing effect was correlated with higher levels of metalloproteinase- 2 in the aqueous humour $(\mathrm{AH})$ and a decreased TM thickness beside a restoration of the retinal morphology and its redox status [92]. In the clinics, it has shown some degree of efficacy in neurologic pathologies such as Alzheimer disease and Friedreich ataxia [93], but no clinical data are available for glaucoma patients.

Melatonin is a very ancient molecule widely distributed in nature, in the vegetal and the animal world [94]. Melatonin is best known as a circadian regulator of sleep and other cyclical bodily functions
[95]. Accordingly, melatonin is not produced only by the pineal gland, but also by several other organs, thus influencing through paracrine signaling the physiological functions of the whole organism [94] by differential binding to its three receptors $\mathrm{MT}_{1-3}$ [96]. In the eye, it is made by the retina [97], the ciliary body [98] and the lachrymal gland [99]. Melatonin and its metabolites have antioxidant and free radical scavenger activities including both reactive oxygen and nitrogen species $[100,101]$, thus protecting from oxidative damage photoreceptors and other ocular tissues [102]. In preclinical studies melatonin showed clear neuroprotective effects. In a mouse model of ischemia/reperfusion of the retina after sudden IOP elevation, intraperitoneally injected melatonin prevented the toxicity due to the increased expression of the hypoxia inducible factor (HIF-1 $\alpha$ ) and Muller cells gliosis, thus improving RGC survival [103]. In a rat model of hypertensive glaucoma obtained by clogging of the TM, subcutaneous implantation of a pellet slowly releasing melatonin improved the antioxidant potential in the retina, decreased glutamate excitotoxicity with the final results of improving RGC survival and rescuing the retinal function as evidenced by the ERG [104]. In a rabbit model of intravitreal glutamate toxicity, simultaneous melatonin injection could blunt the oxidative stress and improve survival of RGC by decreasing their apoptotic cell death [105]. In a recent work with a rat model of hypertensive glaucoma obtained by episcleral injection of hypersaline solution, the intravitreal administration of Poly lactic-co-glycolic acid microspheres loaded with melatonin, CoQ10 and dexamethasone releasing the drugs for over 30 days, could preserve RGC from apoptotic cell death [106]. Interestingly, not only melatonin, but also agomelatine, the novel MT1/MT2 receptor agonist antidepressant, has shown significant neuroprotective features [107]. Melatonin not only shields RGC from apoptotic death, but also shows a direct effect on the IOP. Circadian changes of the IOP appear to be linked to melatonin [108], which has shown hypotensive effects on IOP [109], apparently mediated by the MT3 receptor [110,111]. Most recently, it has been shown that a nanomicellar formulation of melatonin and agomelatin given topically as eye drops is able to decrease by over $30 \%$ the IOP of normotensive rats, and by over $50 \%$ the IOP of hypertensive rats, after clogging of the TM [112]. Clinically, it has been reported that oral treatment with agomelatine could further decrease by $30 \%$ on average the IOP of 10 glaucomatous patients under maximum tolerated medical therapy (MTMT) with different hypotonizing drugs [113].

Cannabinoids are naturally present in our organism - including eye tissues and the retina - as endocannabinoids: anandamide, 2-arachidonoylglycerol and palmitoylethanolamide [114,115]. Phytocannabinoids (pCBs: agonists of the endocannabinoid receptors $\mathrm{CB} 1$ and $\mathrm{CB} 2$ ) are the active molecules found in cannabis (Cannabis sativa), and are mainly represented by $\Delta$-9-tetrahydrocannabinol (THC), cannabinol and cannabidiol. THC is the molecule mainly responsible for the psychoactive effect of marijuana, while cannabinol is much less a psychotropic agent, and cannabidiol is not psychoactive at all [116]. Phytocannabinoids (much of all THC) have shown efficacy both as modulators of the IOP $[117,118]$ and as neuroprotective agents [119]. It is likely the interaction of pCBs with the CB1 receptor that can lower the IOP by modulating production and outflow of 
AH $[120,121]$. The neuroprotective activity possibly depends on the antioxidant and antinflammatory effects of pCBs [122]. However, their psychotropic activity did not allow their free systemic use in ophthalmic diseases [123]. A valid alternative could be a topical formulation given as eye drops. Indeed, THC in nanotechnological formulations topically administered to normotensive rabbit's eyes could reduce the IOP by $30 \%$ of the baseline value [124]. In a case report observation, oily based galenic ophthalmic formulations of pCBs with different proportions of THC and cannabidiol were given to patients unresponsive to drug treatments, however with little effect on the IOP. Only one patient with open angle glaucoma secondary to Fuchs heterochromic iridocyclitis had a partial response, probably due to the antinflammatory effect of the formulation with a higher content of THC [125].

Forskolin is a labdane diterpene extracted from the roots of the plant Indian Plectranthus barbatum (Coleus forskohlii). It is a lipidsoluble molecule that can cross cell membranes, thus working as a receptor independent activator of adenylate cyclase, finally resulting in the intracellular increase of cyclic adenosine monophosphate (cAMP) and cAMP-mediated functions [126]. Forskolin lowers IOP [127] by two independent and original mechanisms, both triggered by cAMP elevation: it decreases net secretion of $\mathrm{AH}$ by the ciliary body by a mechanism that involves the chloride channels and a reabsorption of $\mathrm{AH}$ from the posterior chamber into the stroma [128,129]; and by enhancing $\mathrm{AH}$ outflow through the TM by a mechanism that involves cell actin cytoskeleton disassembly through PKA activation and Rho kinase inhibition [130]. None of the existing glaucoma drugs (carbonic anhydrase inhibitors, beta-blockers, alfa-agonists, prostaglandin analogs) has similar mechanisms of action, therefore it might be expected that forskolin effects add upon those of such drugs. In fact, a clinical study in which POAG patients under MTMT were treated with a food supplement containing forskolin and rutin - an antioxidant and vasoactive ingredient [131] - showed that the food supplement resulted in a further decrease of the IOP, independent of the drug that the patients were taking $[132,133]$. Moreover, forskolin is also endowed with direct neuroprotective activities, mediated by the activation of paracrine signaling, due to the induction of the neurotrophin BDNF (brain derived neurotrophic factor) expression by astrocytes and vascular endothelial cells $[134,135]$ and to the translocation of its receptor TrkB to the neuron cell membrane [136]. Preclinical data with a rat model system of hypertensive glaucoma obtained by clogging of the TM confirmed both the IOP control and the neuroprotective efficacy of oral forskolin [137]. Clinical data further corroborated the double efficacy of forskolin-based oral supplements. In a randomized, controlled clinical trial on 45 patients affected by POAG compensated by topical drugs, the 30 patients taking the food supplement with forskolin and rutin experienced during the 6 months of the trial a progressive decrease of the IOP and a concomitant increase of the PERG amplitude, suggesting an improvement of RGC survival [138]. Forskolin is also the basis of another association, with homotaurine - a neuroprotective compound used in Alzheimer [139] and Parkinson's [140] disease - and carnosine, a wide spectrum antioxidant neuroprotector [141,142]. Preclinical evidence on a rat model of retinal ischemia/reperfusion obtained by sudden barometric increase of the IOP has shown a clear neuroprotective synergistic effect of the association of the three compounds intravitreally injected [143]. Improved RGC survival was reported, correlating with the induction of PI3K/Akt, the inhibition of GSK-3 $\beta$ and the reduction of calpain activity, all known to be linked to neurodegenerative events [143]. Results from a randomized, controlled clinical trial on 22 patients affected by POAG with IOP compensated by topical drugs, showed that patients taking the oral supplement containing the three components had a significant further decrease of their IOP, an improvement of PERG amplitude at 6, 9, and 12 months, and of foveal sensitivity at 12 months, whilst all the above values remained stable in untreated control patients [144]. Most recently, a new association of forskolin with homotaurine and spearmint extract - rich in polyphenols and rosmarinic acid with antinflammatory and anti-oxidative effects, likely preventing neuron degeneration [145] - has been tested in a mouse model of ON crush, simulating the sudden compression at the $\mathrm{ONH}$ during acute glaucoma. The oral supplementation of forskolin, homotaurine, spearmint extract, and vitamins of the $\mathrm{B}$ group resulted in a significant improvement of RGC survival, correlating with a preservation of the ERG photopic negative response, which depends on the RGC health status, and with a decrease of inflammatory cytokines and pro-apoptotic markers [146]. Similar results were also obtained in a mouse model in which RGC degeneration depends on progressive IOP elevation, obtained by intracameral injection of polyetylen-glycol, which clogs the TM and decreases AH outflow [147].

Vitamins have been suggested as potential neuroprotective agents, and a recent metanalysis found relevant associations with vitamins A and C [148]. Deficiency of vitamins of the B complex has been reported in patients with glaucoma [148,149], which specifically showed significant lower serum levels of vitamins B1 and B12 $[150,151]$. Insufficient amounts of vitamins B6, B9 and B12 may lead to increased levels of homocysteine $[152,153]$, known to be toxic to RGC [154], and found in relevant amounts in the AH and plasma of POAG patients [155]. A recent meta-analysis showed a high prevalence of hyperhomocysteinemia in patients with pseudoexfoliative glaucoma [156], which another study associated with decreased levels of vitamin B6, B9 and B12 [157]. Accordingly, increasing vitamin B9 intake appeared to lower the risk of pseudoexfoliative glaucoma probably by reducing homocysteine levels [158]. Vitamin C is an antioxidant, and an important factor involved in tissue repair [159]. Biochemical analyses have shown that the glycosaminoglycan content of TM in healthy subject is different from that of POAG patients, which contains less hyaluronic acid (HA) and more chondroitin sulfate [160]. Vitamin $\mathrm{C}$ stimulates the synthesis and secretion of HA in TM cells, more in those cells derived from a glaucomatous eye than from a normal eye, thus re-equilibrating the production of extracellular matrix (ECM) glycosaminoglycans [161]. Addition of vitamin C supplements was found to be associated in a dose-dependent way with decreased prevalence of glaucoma in a population sample in the United States [162]. In a large cross-sectional study on Afro-American women, a correlation has been described between higher consumption of food rich in vitamins $\mathrm{A}$ and $\mathrm{C}$ and carotenoids and a decreased incidence of glaucoma [163]. In a different epidemiologic evaluation, NTG patients 
were found to have lower blood levels of vitamin $\mathrm{C}$ and increased levels of uric acid [164]. Vitamin C has a role in maintaining lysosomal function and correct protein turnover in TM cells; therefore, an insufficient concentration of vitamin $\mathrm{C}$ in plasma and $\mathrm{AH}$ may alter the physiological function of TM cells, resulting in a decreased outflow capability and an increase of the IOP [165]. Vitamin E is a strong antioxidant [166]. Several studies on glaucoma patients have reported low levels of vitamin E in their blood [162,167] or AH [168]. A low intake of Vitamin A as retinol equivalents appears to be associated with an increased risk of POAG [150]. Vitamin D plays a role in the signaling pathways related to bone and mineral metabolism, cellular proliferation, immune modulation, and oxidative stress [169,170]. A high prevalence of vitamin D deficiency is observed in patients with glaucoma, confirmed by low circulating amounts of vitamin $\mathrm{D}$ in these subjects $[171,172]$. Metabolomic analysis on plasma samples from 72 POAG patients compared to 72 healthy controls revealed alterations of vitamin $\mathrm{D}$ metabolic pathways correlating with vitamin D insufficiency in POAG patients [173]; moreover, the presence of specific vitamin D receptor polymorphisms were found to be relevant risk factors in the development of glaucoma [174]. Accordingly, other studies have reported low serum levels of vitamin D in POAG patients [175].

\section{OCULAR SURFACE DYSFUNCTION (Dry Eye)}

The most recent definition of the dry eye syndrome by "The Tear Film and Ocular Surface Society Dry Eye Workshop Report", defines the key points and possible therapeutic targets of the disease. Dry eye is "a multifactorial disease of the ocular surface" leading to tear film instability in which "hyperosmolarity, ocular surface inflammation, and neurosensory abnormalities play etiological roles" [176]. The etiology of dry eye is complex, and no cure for it is available. Artificial tears provide a way to blunt signs and symptoms of the disease, but with limited efficacy, both in terms of intensity and duration. Therefore, there is an increasing interest in the use of nutritional supplements as a complementary approach for the prevention and management of the dry eye syndrome [177]. Many scientific reports have highlighted an association between incidence and severity of dry eye disease and nutritional deficiencies [178-183]. The identification and appropriate use of nutraceuticals able to work on dry eye may provide insights into dry eye pathogenesis and increase the efficacy of conventional therapies.

\section{Polyunsaturated Fatty Acids}

Among dietary supplements, there is a growing interest in the use of polyunsaturated fatty acids (PUFAs) to prevent or alleviate signs and symptoms of dry eye $[184,185]$. PUFAs are involved in the synthesis of photoreceptor outer segment disks, and in ocular surface physiology; therefore, they are essential for proper visual development and retinal function [186]. PUFAs can be grouped into two main families: omega-3 and omega-6 [187]. The omega-3 include docosahexaenoic acid (DHA), eicosapentaenoic acid (EPA) and alpha-linolenic acid (ALA), while omega-6 include linoleic acid (LA), gamma-linolenic acid (GLA) and arachidonic acid (AA). Multiple clinical trials looked at the effect of omega- 3 and omega- 6 supplements in the treatment of dry eye syndrome. Miljanović et al., evaluated the association between the dietary intake of different ratios of omega- 3 and omega- 6 and dry eye syndrome occurrence in a large cross sectional study on women. Results showed that women with a higher dietary intake of omega-3 had a lower prevalence of dry eye symptoms and that a high ratio of omega-6/omega-3 (>15:1) was associated with a greater prevalence (more than 2-folds) of dry eye syndrome [188]. A meta-analysis of 9 randomized controlled trials (collected between 2002 and 2011) on PUFAs dietary supplements reported an improvement of the burning sensation and reflex lacrimation in dry eye patients assuming PUFAs [189]. A similar meta-analysis of other 7 randomized controlled trials collected from 2007 to 2013 reported not only the improvement of the above symptoms, but also an improvement of signs like Schirmer Test and Tear Break Up Time [190].

Meibomian gland dysfunction (MGD) is a chronic disease of the homonymous glands [191-193], leading to altered secretion of the tear film lipid layer, finally resulting in increased tear evaporation and tear osmolarity, a trigger for dry eye signs and symptoms [191-193]. One key factor of the potential benefits of systemic supplementation with PUFAs is the evidence that dietary fatty acids can be incorporated in lacrimal gland phospholipids [194-196]. Wojtowicz et al., explored the potential effect of dietary supplementation with omega-3 on lipid composition in a case-control trial, where treated patients received for 90 days fish oil, containing $450 \mathrm{mg}$ of EPA, $300 \mathrm{mg}$ of DHA, and $1000 \mathrm{mg}$ of flaxseed oil (rich in ALA). At the end of the study, most of the patients (about 70\%) became asymptomatic with an increment of tear secretion [197]. Another study recruiting a large sample of postmenopausal women, showed that high omega-3 consumption and moderate omega- 6 consumption were protective against MGD [198]. Tear film hyperosmolarity is a focal event in dry eye syndrome [199]. In a double-blind, randomized, parallel trial, consumption of sea buckthorn oil (high in omega-3 and omega- 6 fatty acids) for 3 months attenuated the increase in tear film osmolarity during the cold season and positively affected symptoms in dry eye patients [200]. Furthermore, a moderate daily dose of long-chain omega-3 PUFAs given over three months reduced tear osmolarity and increased tear stability in subjects with dry-eye disease [201]. In a different clinical study on patients with contact lens associated dry eye, 6 months of oral treatment with evening primrose oil rich in the omega- 6 GLA resulted in improvements in dryness symptoms at 3 and 6 months and in overall lens wearing comfort at 6 months [202]. Oleñik et al., evaluated efficacy and tolerability of a food supplement containing a combination of omega-3 and antioxidants (a mixture of DHA $1050 \mathrm{mg}$, EPA $127.5 \mathrm{mg}$, DPA $90 \mathrm{mg}+$ vitamins C/E and GSH + trace elements) on dry eye related symptoms in patients under treatment with artificial tears [203]. After 12 weeks, treated patients showed a significant improvement of symptoms with a lesser need of using artificial tears and a better tolerance to contact lens wearing. Comparable outcomes were achieved with treatment administered for shorter periods of time [204] or with lower concentrations of omega-3 PUFAs [205]. In another recent study, dietary omega-3 fatty acids administration showed efficacy in alleviating computer workrelated dry-eye symptoms, associated with altered tear evaporation rate (Figure 2) [206]. 


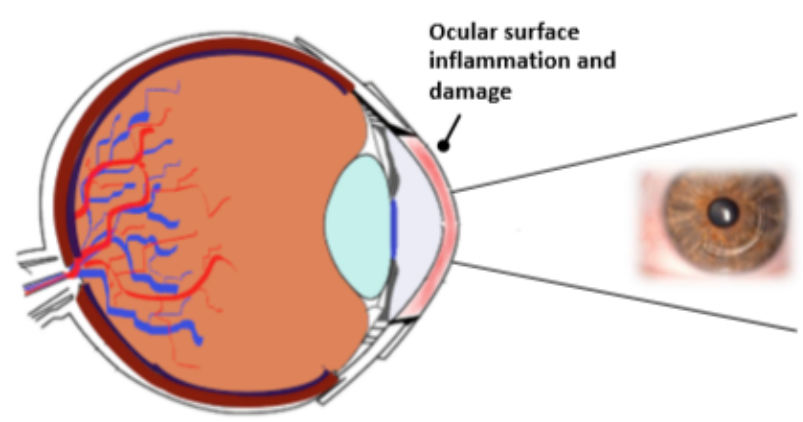

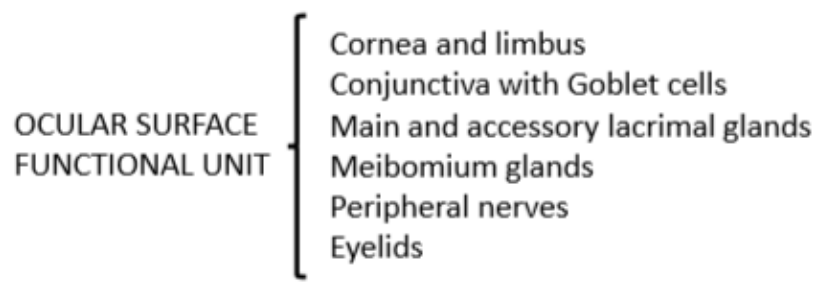

PUFAs:

Vitamin D:

Vitamin A:

Lactoferrin:

Aminoacids:
Tears quality and quantity (improved stability and osmolarity); antioxidant; antinflammatory. Antioxidant; antinflammatory; immune modulation; antalgic.

Antiapoptotic.

Antioxidant, antinflammatory, antimicrobial, wound healing promotion.

Antioxidant, antinflammatory, wound healing promotion.

Figure 2: Eye dryness and ocular surface dysfuntion. The malfunctioning of one ore more components of the ocular surface functional unit may lead to pathologic alterations of the ocular surface eventually causing eye dryness, discomfort and pain (upper panel). Some food supplements have been shown to prevent and/or alleviate symptoms and signs of dry eye (bottom panel).

Chronic inflammatory processes associated to immunologic activation have a pivotal role in dry eye pathogenesis [207,208] and PUFAs have been shown to have significant anti-inflammatory activity [209], which might turn beneficial in avoiding the excessive damage caused by chronic inflammation. In a mouse dry eye model induced by scopolamine injection in a dry environment, treatment with topical ALA for 9 days resulted in a significant decrease of inflammatory cytokines like TNF- $\alpha$, and a reduction of corneal fluorescein staining in comparison to untreated controls [210]. Barabino and colleagues investigated the efficacy and anti-inflammatory activity of oral supplements of systemic $\omega-6$ (LA and GLA) given twice per day for 45 days, on chronic ocular inflammation in patients with dry eye. They observed an improvement in symptoms and ocular surface inflammation in the study group patients when compared to controls [211]. A recent prospective case-control study showed that patients receiving an oral combination of antioxidants and omega-3 PUFAs for 3 months displayed reduced tear levels of inflammatory mediators such as the interleukins: IL-1b, IL-6, and IL-10 [212]. Brignole-Baudouin et al., in a multicentre trial, demonstrated that supplementation with omega- 3 and omega- 6 fatty acids can reduce the ectopic expression of the HLA-DR inflammatory marker and may help to improve dry eye symptoms [213]. Prostaglandins are well-known inflammatory mediators, playing a key role in the modulation of the inflammatory response in dry eye disease [214]. More specifically, tear levels of prostaglandin-E2 are known to be positively correlated with dry eye symptoms [215,216]. Black currant seed oil, rich in GLA and ALA, has been shown to modulate cell membrane lipid composition and eicosanoid production, finally reducing prostaglandin-E2 production [217]. Cermak et al. highlighted that in women with primary or secondary Sjögren's syndrome (a systemic autoimmune inflammatory disease of the exocrine glands, including the lacrimal gland, thus resulting in a serious dry eye syndrome [218]), the intake of LA, and other specific PUFAs was significantly lower with respect to gender matched controls [219]. In another clinical trial involving 20 patients with primary Sjögren's syndrome, an oral mixture of omega- 6 induced a significant increase in anti-inflammatory PGE-1 content in tears, improving the symptoms of ocular discomfort and the signs derived from corneal epithelial defects [220]. The drug cyclosporine, present in eye drops approved for the treatment of dry eye disease [221], prevents T-cell activation and production of inflammatory cytokines, therefore breaking the inflammatory cycle of autoimmune dry eye disease and increasing the production of tears and mucin-producing Goblet cells in the conjunctiva [222]. However, the use of cyclosporine is not free from side effects which depend on the dose used; therefore it is important to maximise its effects in order to use lower doses. To this purpose, the effects of topical cyclosporine on dry eye signs and symptoms has been evaluated either alone, or in association with a prescription-only medical food supplement containing omega- 3 and omega-6 PUFAs acids. It has been reported that a proper balance of omega- 3 and omega- 6 essential fatty acids could indeed improve the efficacy of cyclosporine on tear break up time and patients' symptoms [223]. PUFAs have also proven to be effective in dry eye syndrome further to autoimmune rosacea disease. In fact, in rosacea patients which develop dry eye, diet supplementation with omega-3 for 6 months ameliorated dry eye parameters such as tear breakup time and Schirmer score [224].

\section{Vitamins D and A}

A nutritional deficiency, often associated to dry eye, is the lack of vitamin D [177,178,180,182,183]. Patients with vitamin D deficiency have a higher risk to develop dry eye disease [225]. The correlation of Vitamin D levels and inadequate sunlight exposure with severity of dry eye syndrome was highlighted in a recent study on Korean adults, concluding that sufficient sunlight exposure or vitamin D supplementation may attenuate signs and symptoms of dry eye [183]. Furthermore, an interesting correlation has been shown between 
single nucleotide polymorphisms in the vitamin $\mathrm{D}$ receptor gene and the incidence of dry eye disease in the Chinese Han population [226]. Vitamin D deficiency is relatively frequent in patients with primary Sjögren syndrome and also in this case its serum levels correlate with the severity of dry eye parameters [182,227,228]. In a retrospective observational study, in which subjects were divided into 3 groups according to serum Vitamin D levels (sufficient, inadequate or deficient group), tear break-up time and tear secretion were lower in the vitamin D-deficient group compared to the sufficient group [229]. In a recent work Dikci et al. observed that vitamin D deficiency may cause conjunctival squamous metaplasia and loss of goblet cells on the ocular surface in the eyes of 36 patients with mild to severe dry eye [230]. Inflammatory reactions and oxidative damage are common findings in dry eye, and in fact a study run on 217 patients (397 eyes) either normal or with various severity of dry eye has shown a correlation between its severity and the amount of oxidative tissue damage and polymorphonuclear leucocytes infiltration [231]. Within this frame, Eksioglu et al. evaluated the antioxidant effects of active vitamin $\mathrm{D}$ against high-dose radioiodine therapy-associated oxidative damage of the lacrimal gland in Wistar albino rats. Radioiodine caused significant oxidative stress and inflammation in lacrimal glands and vitamin D could blunt these effects, thus showing anti-inflammatory, antioxidant and radio-protective effects [232]. As mentioned before, chronic inflammatory events further to immunologic activation have a pivotal role in dry eye pathogenesis, and vitamin $\mathrm{D}$ is known to have immunomodulatory properties [179]. Further research on experimental animal models has provided evidence about the antinflammatory and immunomodulatory roles of vitamin $\mathrm{D}$ on the ocular surface, particularly in the cornea $[233,234]$, and clinical data confirmed that a low serum vitamin $\mathrm{D}$ level is associated with different pathological states, such as autoimmune diseases, lymphoma, or neuropathy [218]. Reins et al. highlighted that vitamin $\mathrm{D}$ modulates the expression of inflammatory cytokines and protects corneal epithelial barrier function [180,235,236]. Antigen presenting Langerhans cells resident in the ocular surface epithelia have a role in aqueous tear-deficient dry eye pathogenesis [237], and topical administration of vitamin D can suppress ocular surface inflammation via inhibition of the increased Langerhans cells migration into mouse corneas [234]. The activation of inflammatory ROS-NLRP3-IL1 $\beta$ signaling axis induced by hyperosmotic stress has been recognized as a key priming stage of epithelial inflammation in dry eye pathogenesis [238,239]. Vitamin D has shown the ability to inhibit this signaling axis in human corneal epithelial cells under hyperosmotic stress via the activation of a competitive antioxidant signaling cascade dependent on the activation of $\mathrm{Nrf2}$, a transcription factor regulating the expression of genes coding for antioxidant proteins [240]. Shetty et al. investigated the correlation between levels of serum vitamin $\mathrm{D}$ and tear-inflammatory proteins. They found that decreased serum vitamin D was significantly associated with higher levels of inflammatory interleukin IL-17A/F, interferon- $\gamma$, monocyte chemotactic protein 1 , intercellular adhesion molecule 1, IL-4, IL-10, and decreased levels of antinflammatory IL-2 in tears of dry eye patients in comparison to healthy controls [241]. Altered tear fluid soluble factors with potential to modulate nociception exhibited a distinct association with the ocular surface discomfort status [242]. Vitamin D deficiency was found to be associated with neuralgia and chronic pain. In a case report it was observed that a vitamin D-deficient patient with corneal neuralgia had relief from burning sensation and pain by vitamin $\mathrm{D}$ supplementation, 1,000 IU/day, while topical therapies and lubricants were not effective [243]. It is thus probable that low vitamin D could contribute to the severity of ocular surface symptoms either by directly influencing nociceptive mechanisms or by affecting the presence of inflammatory cytokines $[235,236,241,242]$. Khamar et al., reported the dysregulation of tear fluid nociception-associated factors, corneal dendritic cell density, and vitamin $\mathrm{D}$ levels in dry eye patients. The use of lubricants (artificial tears or biological tear substitutes) is one of the strategies to manage dry eye symptoms [244,245], since tear film instability can lead to ocular surface damage [246]. Hwang et al., showed that Vitamin D enhanced the efficacy of topical carbomerbased lipid-containing artificial tears and Hyaluronic Acid (HA) in patients with dry eye and it may be a useful adjuvant therapy for patients with dry eye syndrome refractory to topical lubricants [247].

Vitamin A deficiency has also been suggested to be a contributory factor in the development of dry eye disease [248-250]. Vitamin A is essential for multiple functions in mammals including vision [251]; in fact it is a precursor in the formation of the rod photopigment rhodopsin [252]. An adequate consumption of vitamin A avoids night blindness, exophthalmia $[253,254]$ and its deficiency is the main cause for blindness among children in third world Countries [255]. Apoptotic death of corneal epithelial cells is part of the pathological process of dry eye [256,257]. Vitamin A has been found to be able to prevent this event in a mice model of dry eye induced by benzalkonium chloride by decreasing the ratio between the pro-apoptotic gene Bax and the anti-apoptotic gene Bcl-2 [258]. In a recent clinical study on dry eye patients, tear ferning grades and tear osmolarity values were improved after vitamin A supplementation at a daily dose of 1,500 mg for 3 days [259].

\section{Lactoferrin}

Lactoferrin deficiency in tears is a frequent finding in dry eye disease, especially in the elderlies [260]. Lactoferrin is a glycoprotein with several functions, including anti-inflammatory and antimicrobial, as well as promotion of cell growth, antiangiogenic and antitumoral [261]. Lactoferrin represents around 25\% of tear proteins, with an average concentration in healthy subjects of $1.42 \mathrm{mg} /$ $\mathrm{mL}$ [262]. Its concentration decreases with prolonged closure of the eyelids, as it happens during sleep [263]. Lactoferrin concentration is also decreasing with age [264], and the decrease of its concentration in tear fluid correlates with the severity of dry eye disease [265-268]. Shimmura et al. reported a protective effect of lactoferrin against oxidative cellular damage in cultured corneal epithelial cells [269]. Accordingly, Fujihara et al. showed that lactoferrin eye drops may suppress the loss of corneal epithelial integrity produced in rabbits' eyes by an ocular speculum blocking blinking [270]. Patients affected by Sjogren's syndrome with dry eye symptoms and receiving 270 $\mathrm{mg} /$ day oral lactoferrin supplementation, showed improvements of both symptoms and tear film stability. This improvement reverted on cessation of treatment [271]. Moreover, oral lactoferrin administration preserves lacrimal gland function in aged mice by attenuating oxidative damage and suppressing subsequent gland inflammation [272]. Small 
incisions during cataract surgery may induce post-surgical dry eye, in which case oral lactoferrin may improve such condition [273]. Higuchi et al. showed the efficacy of Selenium-containing lactoferrin eye drops in a tobacco smoke exposure rat dry eye model and a shortterm rabbit dry eye model of blinking block [274]. Rusciano et al. described the potential use of lactobionic acid, a functional mimetic of lactoferrin, in the management of age-related dry eye [260], and its efficacy is supported by the results of a recent study showing that lactobionic acid - with or without hyaluronic acid-favored wound healing both in vitro and in vivo, through an improvement of reepithelization and the reduction of inflammatory markers [275].

\section{Amino Acids}

Amino acids are the building blocks of proteins and are essential for the construction and the functioning of the entire organism [276,277]. Amino acids are naturally present in human tears and their imbalance or deficiency could contribute to the development of the pathologies affecting the ocular surface [278]. Two different studies have reported that the concentration of amino acids is different in human tears and in serum $[279,280]$ and that tear concentration changes in patients affected by ocular dryness [280,281]. As mentioned before, we know that chronic inflammatory events have a pivotal role in the pathogenesis of dry eye $[207,208]$, and several studies have indicated that amino acids are involved in antinflammatory processes [282-284]. Dietary supplementation of arginine can enhance wound healing, regulate endocrine activity and potentiate immunity [285]. Glutamine may improve immunocompetence, thus reducing the susceptibility to infections and favoring the recovery of the seriously ill, therefore minimizing their hospital stay [286-292]. Branched chain amino acids (BCAAs), including leucine, isoleucine, and valine, play critical roles in the regulation of energy homeostasis, nutrition metabolism, gut health, immunity and disease in humans and animals [293]. BCAAs have shown anti-inflammatory and anti-genotoxic activity in lipopolysaccharide (LPS) stimulated RAW 264.7 macrophages [294]. In a randomized, double-blind, placebo-controlled study, DunnLewis et al. evaluated the antinflammatory properties and the capacity of improving physical performance of a multi-nutrient supplement containing leucine, isoleucine, valine, taurine plus anti-inflammatory plant extracts, and B vitamins. They reported that the multi-nutrient supplement was effective in improving the inflammatory status in both men and women, ameliorating the markers of pain, joints' pain, strength, and power in men only, and both anxiety and balance (a risk factor for hip fracture) in women [295]. Refractive surgery may alter ocular surface homeostasis and Meibomian gland function, thus leading to the development of dry eye signs and symptoms [296-299]. Two different studies reported that oral administration of an amino acids mixture promotes the recovery and maintenance of corneal stroma health after refractive surgery [300,301]. In the first, Vinciguerra et al., demonstrated that oral supplementation of amino acids improved the healing rate of patients subjected to photorefractive keratectomy (PRK) and had shown re-epithelization defects, by favoring keratocyte growth and repopulation of the corneal stroma [300]. In the second study, Torres Munoz et al. reported that oral supplementation with a mixture of 13 different amino acids favored an active healing process and the remodelling of the stroma in patients operated of cataract surgery, by inducing growth and migration of stromal cells [301]. The identical oral supplement with 13 amino acids, used in the previous study, was also used by Roszkowska (Roszkowska, 2006, personal communication). The analyses of the corneal epithelium removed from patients during the procedure of PRK showed that amino acid treatment resulted in decreased EGF expression, suggesting a low proliferation rate of epithelial cells and keratocytes (hence, a decreased risk of scar formation); an increased expression of TGF $\beta$, correlating again with decreased keratocyte proliferation and increased motility of epithelial cells (hence, faster re-epithelization); and a significant increase in the expression of polyamines, suggesting regulated differentiation and proliferation. Meduri et al. gave to patients undergoing PRK a cysteine oral supplement at a daily dose of $200 \mathrm{mg}$, then reporting shorter times for re-epithelization in comparison with eyes of untreated controls [302]. Observations at the confocal microscopy of the cornea of dry eye patients treated with eye drops containing HA and amino acids showed less hyperreflecting cells in the epithelial layers (a sign of metabolic damage) in comparison to those receiving HA alone; nerve tortuosity in the subepithelial layer was also improving faster and better in the presence of topic amino acids [303]. The administration as eye drops of the amino acid taurine changed the tear proteome of contact lens wearers and dry eye patients shifting it towards the profile of healthy control subjects [304]. Taurine has then been included in a contact lens cleaning solution because of the regenerative effect on the tear film of contact lens wearers [305]. Taurine in combination with sodium hyaluronate has shown antioxidant and osmoprotective activity in in vitro and in vivo models of dry eye [306]. In albino rabbits, taurine effectively protected ocular surface tissues from chemical damage induced by hypochlorous acid, and arrested the progression of tissue damage (as measured by the level of lactate dehydrogenase activity) that had already been initiated by hypochlorous acid [307]. A mixture of taurine, alpha-ketoglutarate, pyruvate and pantothenate prevented corneal damage induced by 2-chloroethyl-ethyl sulfide [308]. Taurine could protect corneal stroma and epithelium from lactic acidosis caused by contact lens wearing [309], because of its acid buffering ability against lactic acidosis [310].

\section{DIABETIC RETINOPATHY}

Diabetic retinopathy (DR) is a multifactorial microvascular complication of diabetes mellitus caused by damage to the blood vessels of the retina, the light-sensitive tissue located at the back of the eye. DR has been included by the World Health Organization in the priority list of eye diseases which can be partly prevented, but not cured yet. In its early stages, DR may cause only mild vision problems but, over time, persistent high blood sugar levels can lead to the obstruction of the tiny blood vessels that nourish the retina, cutting off its blood supply. As a result, the eye reacts by triggering an abnormal growth of new retinal vessels, causing micro-hemorrhages and edemas in the macular region, thus leading to severe visual impairment and eventually blindness. These intra-retinal microvascular changes are used to classify DR into non-proliferative diabetic retinopathy (NPDR) and proliferative diabetic retinopathy (PDR). NPDR is characterized by a complex array of vasodegenerative lesions within the retinal microvascular bed, such as thickening of capillary basement 
membranes (BMs), loss of pericytes and vascular smooth muscle cells, capillary occlusion and microaneurysms [311]. PDR is caused by an abnormal growth of new blood vessels (retinal neovascularization) in response to inflammation and/or ischemic damage and hypoxia, eventually giving rise to vitreous hemorrhages and tractional retinal detachment. A direct consequence of inner blood-retinal barrier (iBRB) breakdown is the development of macular edema. Retinal neovascularization and macular edema are the result of increasing secretion of pro-inflammatory cytokines, and pro-angiogenic growth factors, among which predominates the vascular endothelial growth factor (VEGF) [312]. The retina is a highly metabolic active tissue, and high-glucose concentrations are particularly detrimental to its functioning. As reported by Sayin and collegues, chronic hyperglycemia is the main risk factor for DR because of its toxic effects on pericytes, to which vascular endothelial dysfunction may follow, also involving the retina [313]. A chronic hyperglycemic status will activate alternative energetic and metabolic pathways besides glycolysis, generating a toxic oxidative stress leading pericytes to apoptotic death, and causing vascular degeneration in the retina [314-316]. The physiopathology of DR could be represented by a pyramidal scheme in which the hyperglycemic state is at the bottom of the pyramid, immediately topped by oxidative stress, lipid peroxidation, apoptosis, mytochondrial alterations, leading to endothelial dysfunction and finally to retinal damage and neurodegeneration [317-319]. Under normal conditions, a certain amount of reactive oxygen species (ROS) can be tolerated, because they derive from the metabolic processes necessary to sustain cellular proliferation, differentiation and their physiological activities; however, if the production of free radicals overwhelms the capacity of the antioxidant defenses, the normal cellular metabolism will be disrupted by oxidative stress, degrading nucleic acids, proteins and enzymes, eventually leading to organ and tissue pathologies, such as DR [320]. Kowluru et al. [321] and Kaštelan et al. [322] have demonstrated that oxidative stress not only is involved in the physiopathology of DR, but also hinders its remission when glycemic values return within the normal interval. Typically, metabolic pathways altered in DR (polyol, hexosamine and protein kinase C pathways) lead to ROS imbalance, or result from oxidative stress, giving rise to advanced glycation end products (AGE). It is well known that visual impairment is already manifest in the early stages of DR, but currently no efficient treatment has been found to arrest its progression. Treatments have been developed for the late stages, and PDR can be treated or at least contained by pan-retinal laser photocoagulation, vitreoretinal surgery, or intravitreal injections of anti-inflammatory and anti-angiogenic drugs, even though retinal and visual function integrity cannot be preserved. Therefore, effective treatments for all stages of DR are needed to help in preventing or delaying the development and progression of this diabetes-induced visual dysfunction [323]. Most recently [324], it has been suggested to implement the use of nutraceuticals, which may act upstream the disease, reducing neuronal stress and favoring neuroprotection, in order to slow down its progression. Considering that antioxidants can act as free radical scavengers providing protection against oxidative stress, a good strategy could be to use nutrients with antioxidant and/ or anti-inflammatory activity and a good safety profile. In fact, in the last years the optimization of the glycemic and lipidemic control by a correct dietetic regimen has been shown to be of great relevance in controlling diabetes progression and its complications [325,326]. Thanks to their low toxicity in comparison to drugs, the use of foodderived bioactive molecules can be considered a good strategy to contrast the risk factors contributing to DR. In this paragraph, we will sum up the effects of nutritional strategies used as adjuvant therapies, on the different pathways involved in the physiopathology of DR
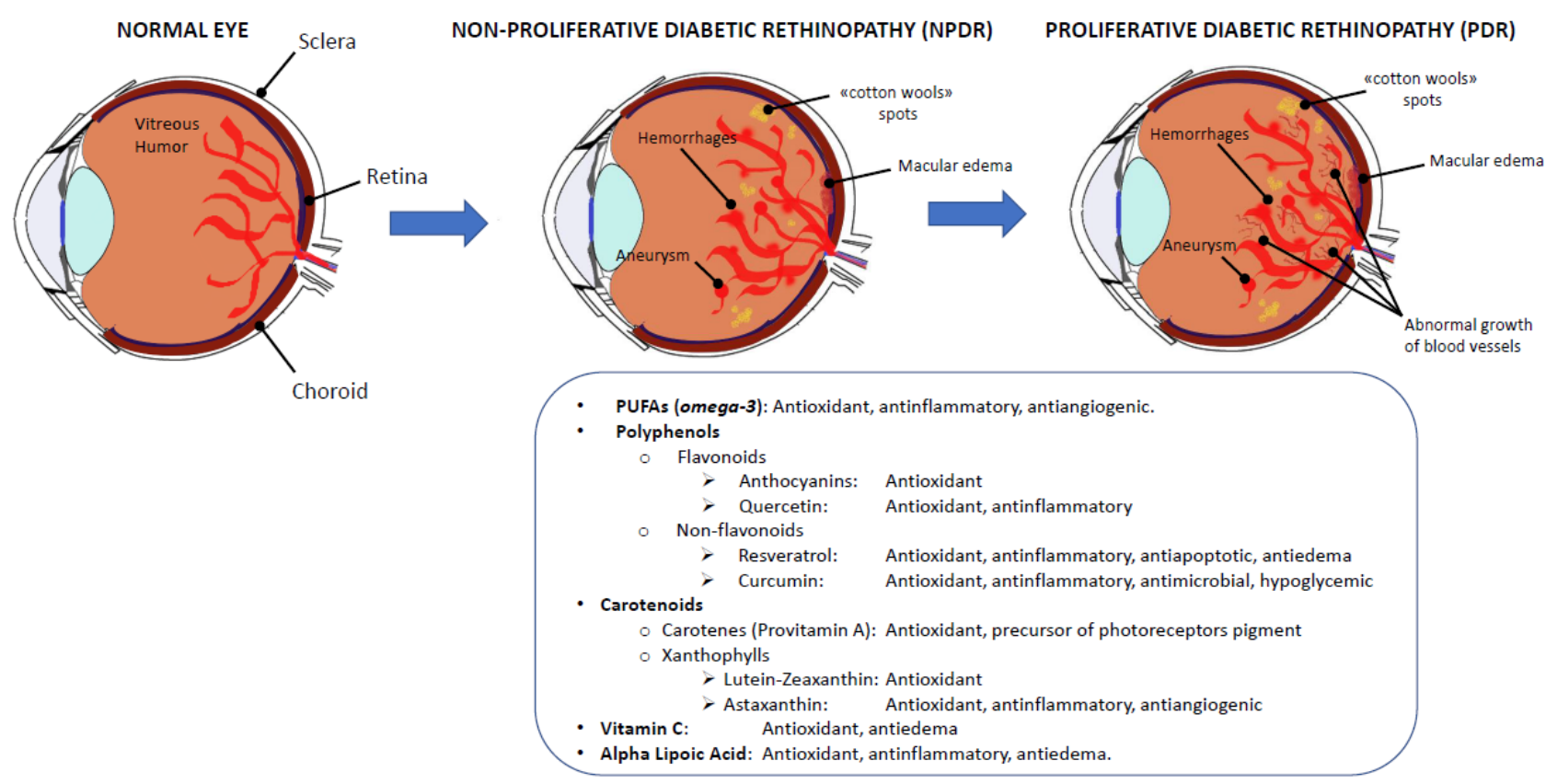

Figure 3: Diabetic retinopathy. Diabetic retinopathy is a frequent complication of diabetes, and mainly results from the oxidative stress and the inflammatory events triggered by the continuous hyperglycemic state of the organism and the retinal vasculature. Initially, local injuries are visible (NPDR), eventually leading to the proliferation of new vessels in the macular area (PDR) and the loss of sight (upper panel). The food supplements that have been shown some efficacy in slowing down the progression of DR have antioxidant, antinflammatory and vasoprotective activities (bottom panel). 
(Figure 3).

\section{Polyunsaturated Fatty Acids (PUFAs)}

A healthy diet widely known and appreciated is the Mediterranean diet, rich in vegetables, fish and extra virgin olive oil containing antioxidant and anti-inflammatory factors. Among these, we can find phenolic antioxidants; gamma- and delta-tocopherols and tocotrienols; long chain PUFAs: omega-6 and mostly omega-3, from which DHA and EPA are derived; several carotenoids of which lycopene may be the most active; isothiocyanates from cruciferous vegetables; sulfur compounds from allium vegetables; terpenoids. Interestingly, most of these health-promoting nutrients function, at least in part, by raising the nuclear factor Nrf2 (nuclear erythroid factor 2-related factor 2), responsible for the transcription of over 500 genes in the human genome, most of which have cytoprotective functions [327]. The role of PUFAs in the retina has been intensely studied for their involvement in regulating vascular function and angiogenesis. Tikhonenko et al. have demonstrated, by transcriptomic analysis in diabetic rats, that diabetes induced a downregulation of retinal enzymes known as elongases, necessary to metabolize PUFAs. This event resulted in a decreased content of retinal DHA, as well as decreased incorporation of very long-chain poly unsaturated fatty acids, particularly 32:6n3, into retinal phosphatidylcholine. This decrease in n3 PUFAs was coupled with the presence of an inflammatory status in diabetic retina, reflected by an increase in gene expression of the proinflammatory markers IL6, VEGF, and ICAM-1 [328]. Similar results were obtained by a lipidomic analysis showing that the omega-3 long-chain poly unsaturated fatty acids metabolites derived from the activity of cyclooxygenases and lipoxygenases, inhibit inflammation and angiogenesis [329]. Connor and colleagues showed that in mouse models of oxygen-induced retinopathy the dietary intake of omega-3and omega- 6 PUFAs decreased the avascular area of the retina and increased vessel regrowth after injury, thereby reducing the hypoxiainduced pathological neovascularization. Moreover, while the intake of omega-6 PUFAs increased the microglial production of the proinflammatory and pro-angiogenic cytokine TNF- $\alpha$, such increase was prevented by the intake of omega-3 PUFAs, which are the precursors of the mediators neuroprotectin-D1, resolvin-D1 and resolvin-E1, known to be potent inhibitors of neovascularization [330]. This antiangiogenic effect induced by omega-3 PUFAs on retinopathy in the mouse eye is comparable in magnitude to treatment with an inhibitor of VEGF [331]. Therefore, increased dietary intake of omega-3 PUFAs could be a useful addition to anti-VEGF therapy to control pathological retinal angiogenesis. Another important function of omega-3 PUFAs is correlated with the attenuation of apoptotic events induced by mytochondrial and endoplasmic reticulum oxidative stress by a reduction of caspase-3 activity in adipocytes via AMPK activation, and increased production of resolvins, a family of neuroprotector molecules derived from EPA and DHA [332]. Overall, omega-3 fatty acids act on different pathophysiological pathways of DR such as inflammation, oxidative stress and neoangiogenesis, showing a remarkable potential in the prevention of retinal disease progression.

\section{Polyphenols}

Polyphenols belong to a family of natural compounds characterized by one or more hydroxyl groups $(\mathrm{OH})$ linked to a benzene ring. These natural substances are present in a variety of foods including grapes, berries, dark chocolate, coffee and tea to mention a few, and are characterized by strong antioxidant and anti-inflammatory power, so that they are widely used in the prevention and/or treatment of different pathologies [316,324]. Several studies have shown that dietary polyphenols exert a protective effect against progression of age-related ocular abnormalities such as cataract, glaucoma, DR and macular degeneration [333]. Based on their structure, polyphenols are classified into non-flavonoid and flavonoid compounds. Flavonoids consist of two phenolic rings linked to a pyranosic ring and are highly represented in fruits, vegetables, roots, and wine.

Anthocyanins (anthos $=$ flower and kyanos $=$ blue) are a subgroup of flavonoids, water-soluble pigments very common in the plant kingdom and in many typical foods of the Mediterranean diet such as blueberries, aubergines, peaches, oranges, figs, cherries and olives. Consumption of foods rich in anthocyanins has been associated with a reduced risk of cardiovascular diseases. As reported by Fang and colleagues [334] anthocyanins can be absorbed as such through the gastrointestinal wall, where they undergo an extensive firstpass metabolism and the metabolites so formed enter the systemic circulation. In fact, anthocyanin metabolites were detected in the blood stream in much higher concentrations than their parent compounds. Several studies reported that dietary intake of anthocyanins may confer benefits in different brain functions, including vision. For example, in blueberry-fed pigs, which are a suitable model to mimic human digestive absorption, anthocyanins were detected in all examined tissues, including brain and eyes, thus indicating that anthocyanins can accumulate also in tissues beyond the blood-brain barrier [335]. Other studies have shown the role of anthocyanins as antioxidants in the retinal pigmented epithelium (RPE) where they can neutralize the ROS formed by the metabolic activity of photoreceptors thus playing a role in neuroprotection as also shown by their protective effect in a model system of rat retinal neurons damaged by N-methyl$\mathrm{N}$-nitrosourea [336]. Song and colleagues [337] addressed the effects of blueberry anthocyanins on retinas of diabetic rats subjected to oxidative stress and inflammation, demonstrating their antioxidant potency resulting in increased expression of HO-1 and nuclear localization of the transcription factor Nrf2 (which controls the expression of antioxidant response element-dependent genes) finally resulting in increased expression of GSH and glutathione peroxidase, and reduced levels of malondialdehyde (MDA) and ROS. Moreover, cyanidins and the orthodihydroxy group of anthocyanins can inhibit lipid peroxidation by chelation of metal ions [338].

Another flavonoid with antioxidant and anti-inflammatory properties in the retina is quercetin. It has been reported that in mouse retinal photoreceptor cells, quercetin inactivated the pro-inflammatory transcription factor NF- $\kappa B$ through inhibition of both mitogenactivated protein kinases (MAPK) and Akt, reducing in this way VEGF-induced inflammation [339]. Kumar et al. [340] demonstrated the retinal neuroprotective effects of quercetin. In streptozotocininduced diabetic rats, quercetin blunted inflammation and glyosis decreasing the retinal expression level of glial fibrillary acidic protein (GFAP) and NF- $\kappa B$ in specific retinal layers, such as the nerve fiber 
layer, the inner plexiform layer, and the inner nuclear layer. The effect of quercetin on NF- $\mathrm{kB}$ was also associated with decreased levels of TNFa and IL-1 $\beta$. Resveratrol (3,5,4'-trihydroxy-trans-stilbene) is a non-flavonoid polyphenol, and a phytoalexin found in red wine and grape skin. Many studies demonstrated its antioxidative and antiinflammatory properties, so that it has been often used to mitigate those eye diseases with a prevalence of oxidative stress, such as DR. In vitro studies have shown that resveratrol prevents ROS-induced apoptosis in retinal capillary endothelial cells stressed by high glucose, through the activation of the AMPK/Sirt1/PGC-1a pathway [341]. Other in vitro studies on the human pigmented epithelium ARPE-19 cell line put under chemically mimicked hypoxia by cobalt chloride have demonstrated that resveratrol could reduce oxidative stress and the production of pro-angiogenic and pro-fibrotic factors [342]. In the same model system, hower subjected to high glucose oxidative stress, resveratrol inhibited the stimulated secretion of inflammatory cytokines such as IL-6 and IL-8, and prevented the downregulation of gap junction associated connexin 43 while inducing the activation of TGF $\beta, P K C \beta$, and COX-2 [343]. In vivo studies by Chen and colleagues with streptozotocin (STZ)-induced diabetic rats, have revealed the effects of paraoxonase-1 (PON1) as an intermediary in the protective effects exerted by resveratrol. In fact, oral resveratrol treatment - via induction of PON1 in the retina - blunted the increased retinal vascular permeability, pro-apoptotic caspase-3 activity, retinal damage, as well as clearly showed an inhibitory effect on inflammatory markers, such as IL- $1 \beta$, IL-6, TNF $\alpha$, VEGF, IFN- $\gamma$ and monocyte chemoattractant protein-1. Therefore, these data suggest that PON1 induction by resveratrol in the retina may be a promising therapeutic strategy to prevent the progression of diabetes-related retinopathy [344]. Curcumin (1,7-bis(4-hydroxy-3-methoxyphenyl)1,6-heptadiene-3,5-dione) is another non-flavonoid polyphenol extracted from the root of Curcuma longa and exhibits a wide range of pharmacological properties, which include antioxidant, antiinflammatory, antimutagenic, antimicrobial and anticancer activities. For its anti-inflammatory and antioxidant properties, curcumin is exploited as oral supplementation therapy for retinal degenerative diseases, including DR [345]. The World Health Organization stated that an acceptable daily intake of curcumin can be up to $3 \mathrm{mg} / \mathrm{kg}$ as a food additive [346]. However, this "golden spice" despite a good efficacy has a limited bioavailability due to poor absorption and rapid metabolism and elimination. Clinical trials have shown that curcumin is safe in humans and well tolerated up to doses of $12 \mathrm{~g} / \mathrm{day}$ [347]. The antioxidant and anti-inflammatory activities of curcumin $(10 \mu \mathrm{M})$ have been tested on human retinal pigmented epithelial cells, human retinal endothelial cells and human retinal pericytes exposed to oxidative stress with high glucose. Results demonstrated a significant decrease of ROS concentration in retinal pigmented epithelial cells and of TNF- $\alpha$ release in retinal endothelial cells, while protecting retinal pericytes from high-glucose damage [348-349]. Human retinal endothelial cells exposed to high glucose and treated with curcumin $(10 \mu \mathrm{M})$ showed an increase of HO-1 expression [350], a stress response protein that is highly inducible under various conditions, such as oxidative or heat stress. This observation suggests that curcumin may have both a direct and indirect antioxidant activity, due to the activation of Nrf2. Once activated, Nrf2 translocates into the nucleus and promotes the transcription of genes that encode antioxidant enzymes including HO-1 [351,352]. In vivo studies have been done in rats with STZ-induced diabetes and treated with curcumin given by different routes. Intraperitoneal injections of curcumin $(80 \mathrm{mg} /$ $\mathrm{kg}$, once a day), prevented the retinal increase of malondialdehyde (MDA: a marker of oxidative stress) and the decrease of antioxidant GSH levels [353]. In the same model, Gupta et al. [354] have shown that oral curcumin $(1 \mathrm{gr} / \mathrm{Kg})$ showed hypoglycemic activity, decreased significantly the superoxide dismutase and catalase activities and prevented the increase of the proinflammatory cytokines TNF- $\alpha$ and VEGF in diabetic retinae. Moreover, they observed increased antioxidant levels of superoxide dismutase (SOD), catalase, and GSH and a lesser increase of retinal nitrotyrosine, a marker of oxidative protein damage, and of 8-hydroxy-20-deoxyguanosine, a marker of oxidative DNA damage [355].

\section{Carotenoids}

Carotenoids are naturally occurring pigments found in fruits and vegetables, but also in plants, algae, and photosynthetic bacteria. Carotenoids can be divided into two main classes: carotenes (precursors of vitamin A) and xanthophylls (non precursors of vitamin A). Carotenes are non-polar molecules, containing only carbon and hydrogen atoms, while xanthophylls are polar carotenoids, containing at least one oxygen atom [356]. Several studies demonstrated the beneficial power of carotenoids on human health and more specifically on eye health, exerting primarily antioxidant effects against AMD, age-related cataract (ARC), uveitis and DR [357]. Humans cannot synthesize carotenoids which must be supplemented by foods in order to be distributed to various tissues, especially to the retina. Lutein and zeaxanthin are non-provitamin A carotenoids from the xanthophyll family. These carotenoids are characterized by $\mathrm{OH}$ groups on each end. Their amphipathic character allows them to be inserted into the lipid bilayer of cell membranes and in the outer monolayer of lipoproteins. These xanthophylls have been found in the human retina, particularly in the macular region [358]. The highest concentration is found in the fovea, and in primates they are responsible for the characteristic central yellow coloration known as the macula lutea. The fovea contains approximately 13ng/ $\mathrm{mm}^{2}$ of carotenoids, compared with approximately $0.05 \mathrm{ng} / \mathrm{mm}^{2}$ in the peripheral retina [359]. The main mechanism by which lutein and zeaxanthin are involved in the prevention of retinal diseases appears to be due to their local antioxidant activity and their capacity to filter the blue light, responsible of photo-oxidative damage [360]. Elimination of lutein from the diet of experimental animals resulted in early degenerative signs in the retina, and patients with an acquired condition of macular pigment loss (Macular Telangiectasia) showed a serious visual handicap, highlighting the importance of macular pigment. Accordingly, a recent clinical study reported that thanks to lutein capacity of filtering short-wavelenght light, its administration to patients with NPDR led to some improvement in glare sensitivity [361]. Another study on diabetic rats treated with zeaxanthin has shown its ability to bring the retinal concentration levels of VEGF and intercellular adhesion molecule-1 (ICAM-1: related to the inflammatory state of the tissue) to values comparable to healthy controls. Moreover, zeaxanthin supplementation prevented diabetes- 
associated retinal damage by decreasing nitrotyrosine levels, DNA oxidative damage, lipid peroxidation and the decrease of retinal SOD [362]. Similarly, lutein administration to diabetic mice resulted to prevent retinal oxidative stress and restored normal retinal ROS levels [363]. $\mathrm{Hu}$ et al. addressed the potential benefits of supplementation with lutein and zeaxanthin in type 2 diabetic patients with diagnosed NPDR [364]. In this study, plasma concentration of these carotenoids was substantially lower in the diabetic group than in normal subjects at baseline. After 3 months treated patients presented higher plasma concentrations in comparison to untreated controls, correlating with reduction of the macular edema and improvement of visual acuity. Overall, these data indicate that lutein and zeaxanthin are main actors on the photo-oxidative stage, by quenching oxygen singlets, scavenging free radicals and protecting retinal cells from oxidative damage. Their dietary intake may be used to ameliorate or even to reverse vision loss in DR patients. Astaxanthin is a third member of the xanthophyll family, a ketocarotenoid generated by the oxidation of $\beta$-carotene, and is a common pigment in algae, fishes, and birds. One of the most important properties of astaxanthin is a potent antioxidant activity, almost 10 times higher than other known compounds such as polyphenols or $\beta$-carotene [365]. Because of this property, astaxanthin has been studied, mainly in animal and cell models, for its possible role in the treatment of chronic diseases involving oxidative stress, such as in diabetes and its complications. Yeh et al. [366] addressed the effect of orally administered astaxanthin on STZ-induced diabetic rats. Ocular tissues from astaxanthin and lutein treated rats showed a significant reduction of oxidative stress and inflammatory mediators depending on NF- $\mathrm{KB}$ transcription activity, and increased levels of antioxidant enzymes, thus preserving retinal architecture and function. Zhou and colleagues further demonstrated that astaxanthin can regulate the glycemic state and reduce insulin resistance, and can also exert an anti-inflammatory and anti-angiogenic effect by decreasing the expression of NF- $\kappa \beta$ and TNF- $\alpha$, thus inhibiting the expression of proinflammatory molecules such as ICAM-1, the monocyte chemoattractant protein-1 and VEGF [367]. In conclusion, several studies indicate that astaxanthin, zeaxanthin and lutein may blunt the generation of oxidation products in the retina, so that their oral uptake could be a good strategy to control the development of DR by reducing the oxidative damage to DNA, proteins, and lipids.

\section{Vitamin C}

Vitamin C is a water-soluble vitamin that exists in two main forms, ascorbic and dehydroascorbic acid. It is an important nutraceutical used as a support to therapy to treat oxidative-stress-induced diseases. Vitamin C scavenges ROS such as superoxide and peroxynitrite in plasma and cells (thus avoiding damage to proteins, lipids and DNA), prevents occludin dephosphorylation and the loosening of tight junctions. Several studies have reported that serum vitamin C levels were lower in diabetic patients in comparison to healthy subjects [368], and these levels were much lower in diabetic patients with DR [369]. The vitreous level of vitamin $\mathrm{C}$ is responsible for the regulation of oxygen tension and oxidative stress in the eye, which are implicated in retinal ischemia and the development of PDR [370]. Duarte et al. have demonstrated that in healthy individuals the concentration of vitamin $\mathrm{C}$ in vitreous humor is remarkably higher as compared to that in serum [371]. In patients with PDR, the vitreous level of vitamin $\mathrm{C}$ was decreased up to tenfold compared to healthy controls and was associated with the degree of macular ischemia, suggesting that vitreous vitamin $\mathrm{C}$ depletion may contribute to macular ischemia in PDR patients [370]. Ascorbic acid (AsA) has anti-inflammatory, immunostimulant, and antibacterial properties, and is used as adjuvant therapy in many inflammatory disorders [372]. In a doubleblind cross-over trial [373], 8 diabetic patients were treated with AsA tablets showing that the supplementation of $1000 \mathrm{mg}$ AsA/day for 2 weeks reduced the activity of the enzyme aldose reductase thus inhibiting the polyol pathway, which is activated in DR. Diabetic hyperglycemia triggers apoptosis of vascular pericytes thus impairing vascular regulation and weakening vessels, especially in brain and retina. May et al. demonstrated that vitamin $\mathrm{C}$ prevented high glucoseinduced perycytes apoptosis, that was largely due to the activation of the receptor for advanced glycation end products (RAGE) [374]. AsA may also have a role in angiogenesis. A recent study conducted on human umbilical vein endothelial cells (HUVECs) has shown that AsA prevented the increase of endothelial barrier permeability induced by VEGF. This effect may contribute to reduce the macular edema in DR [375].

\section{Alpha-Lipoic Acid}

Alpha-Lipoic Acid (1,2 dithiolane-3-pentanoic acid) (aLA), also known as thioctic acid, is a natural thiol antioxidant. After oral supplementation, it is quickly transported to intracellular compartments and reduced by enzymes to dihydrolipoic acid. This reduced form has many biochemical functions. It acts as biological antioxidant, metal chelator, and regenerates by reducing their oxidized forms other antioxidant agents such as vitamin C, E and GSH. It also functions as modulator of the signaling transduction of pathways involving insulin or NF-kB [376]. aLA plays an essential role in mitochondrial bioenergetic reactions, which makes it useful in managing diabetic vascular complications such as retinopathy and peripheral neuropathy. In an in vivo study [377], the mitochondrial functional integrity, biogenesis and DNA copy number were analyzed in the retina of STZ-diabetic rats. Animals under good glycemic control and fed with aLA have shown a lesser dysregulation of retinal mitochondrial biogenesis as measured by citrase synthase (a marker of mitochondria functional integrity) and the presence of fewer acellular capillaries (a marker of DR). In another experimental study [378], Wistar rats were treated with aLA (60 $\mathrm{mg} / \mathrm{kg}$ bodyweight) i.p. daily for 30 weeks. Results demonstrated that aLA treatment reduced oxidative stress, NF-kB activation and angiopoietin-2 expression, and reduced the amount of VEGF in the diabetic retina by $43 \%$. In a randomized, double-blind placebo-controlled study, 32 patients with preretinopathic diabetes were treated with aLA (400 mg/daily) in combination with other antioxidants (genistein and vitamins). Oxidative stress levels in plasma and changes in the full field ERG were evaluated. Results revealed that the oral treatment with antioxidants in preretinopathic diabetes subjects may have a protective effect on retinal cells, as detected by ERG analyses observed after 30 days of treatment [379]. In conclusion, several studies show that nutritional supplementation of natural molecules, as discussed above, protects neuronal and vascular cells from inflammatory damage and 
mitochondrial degeneration, thus slowing down DR progression and helping diabetic patients to spare their vision for longer times [380].

\section{AGE-RELATED MACULAR DEGENERATION}

$\mathrm{AMD}$ is a progressive degenerative disease of the retina principally affecting the macula, a highly specialized region of the central retina responsible for fine and colour vision. It is currently considered the leading cause of visual impairment and blindness among patients over 60 years [381]. AMD can occur in two distinct forms: the most frequent (roughly $90 \%$ of the cases) is the dry (atrophic, nonexudative) form, characterized by diffuse insoluble debris (known as drusen) causing the death of RPE cells and photoreceptors [381]; the wet (neovascular, exudative) form is less frequent (roughly $10 \%$ of the cases) but still responsible of the majority of blindness cases, and is characterized by the development of abnormal new vessels inside the macular region (choroidal neovascularisation) [382]. Oxidative stress and inflammation along with genetic risk factors are all involved in AMD pathogenesis [383]. An important and characteristic clinical hallmark of AMD is the presence of drusen - small yellow or whitish accumulations of extracellular debris (made of proteins and lipids) located between the basal lamina of the RPE and the inner collagenous layer of Bruch's membrane [382,384]. In particular, these protein/ lipid deposits are associated with an inefficient metabolism of RPE cells, which cannot get rid of catabolic products which then tend to accumulate in the extracellular spaces giving rise to drusen bodies [385]. Another early molecular event of AMD is the accumulation within RPE cells of lipofuscin, a remnant of the recycling of photoreceptor outer segments, that contributes to RPE degeneration [386]. Oxidative stress is a leading mechanism in the generation and progression of AMD, therefore antioxidant self-defense mechanisms are crucial for the mainteinance of retinal health. Two main targets of oxidative stress in RPE cells are the elements involved in autophagy and the transcription factor Nrf2. Dysregulation of both autophagy and the induction of antioxidant enzymes regulated by Nrf2 may trigger the cascade of events finally leading to lipofuscin and drusen generation, and start the inflammatory process causing AMD [387]. Inflammation processes thus induced occur through recruitment of macrophages and microglia, and complement activation [388]. Allelic variations of genes coding for complement factors, beside those participating in lipid metabolism or angiogenesis, constitute risk factors for AMD development [389]. Other risk factors include age, genetic predisposition, exposure to light, race, smoking habit, altered body/mass index, and diet [390-392]. Currently, the only therapy approved for the treatment of the dangerous wet form of AMD involves the inhibition of the pro-angiogenic factor VEGF in the retina. However, the search for more effective treatments of dry AMD is actively ongoing (Figure 4) [387].

\section{Food Supplements}

In recent years, epidemiological and clinical studies have suggested the importance of nutrients and food supplements to prevent or slow down the progression of AMD in the elderly. In particular, since free radicals and ROS are known to be the principal factors behind

\section{AGE RELATED MACULAR DEGENERATION}

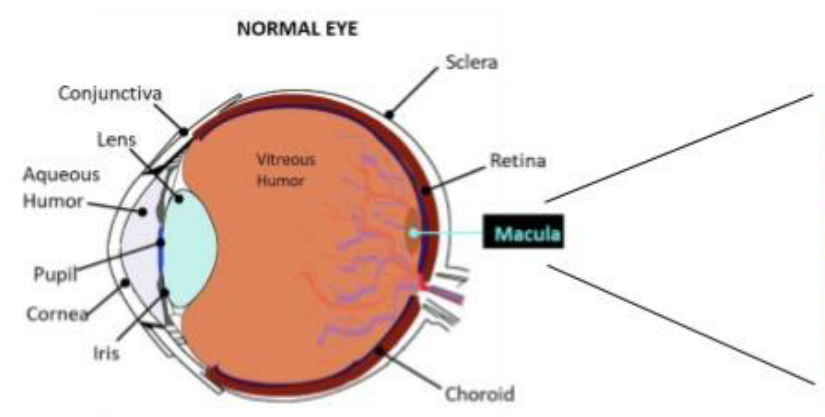

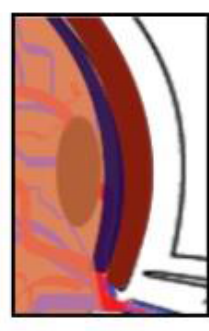

Normal Macula

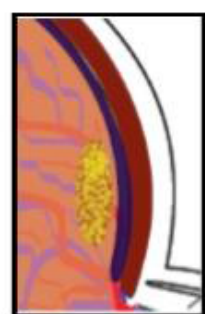

"Dry" Macular Degeneration

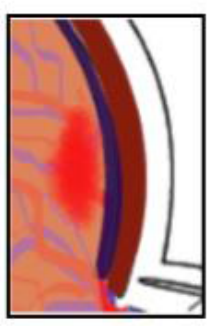

"Wet» Macular Degeneration

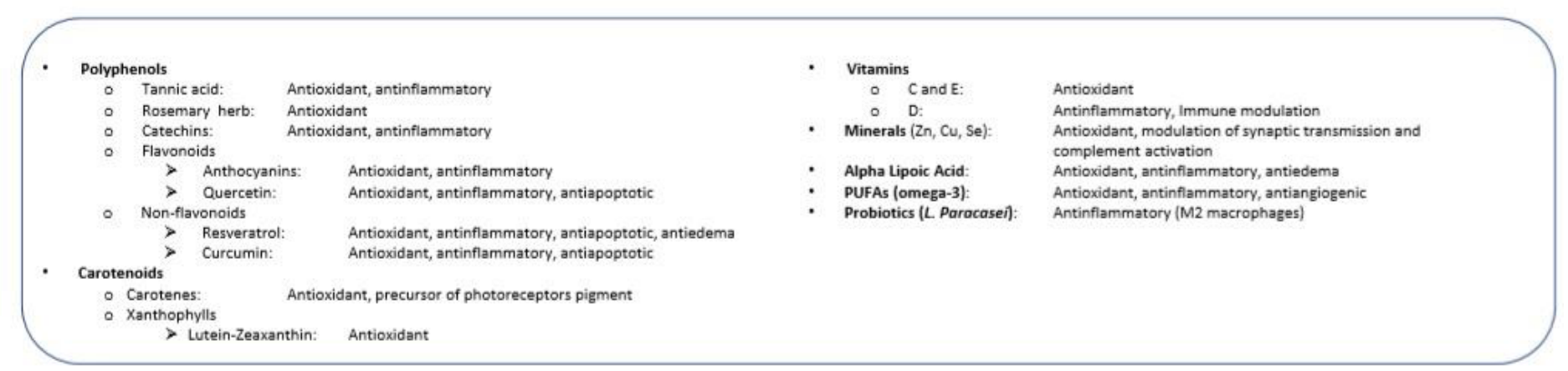

Figure 4: Age related macular degeneration. Oxidative stress and inflammation further to ageing, a wrong lifestyle and hyper reactivity of the natural immunity (mainly the complement system) may lead to the accumulation of catabolic debris (drusen) between the RPE and the Bruch's membrane (dry or atrophic MD), and eventually to the rupture of the Bruch's membrane and the invasion of new blood vessels into the macular area (wet or neovascular MD) (upper panel). Food supplements that may be useful to blunt these events have antioxidant, antinflammatory, antiapoptotic and antiangiogenic effects (bottom panel). 
this pathology, most of the nutrients studied have antioxidant and free radical scavenger characteristics [382,393]. They belong to several classes: polyphenols (anthocyanins, tannic acid, quercetin, curcumin, EGCG, resveratrol and herb rosemary), carotenoids (lutein, zeaxanthin, and $\beta$-carotene), vitamins ( $\mathrm{A}, \mathrm{C}, \mathrm{D}$ and $\mathrm{E}$ ) and minerals (zinc, selenium and copper). Other molecules with relevant antiaging and antioxidant properties used for AMD are aLA, omega- 3 fatty acids and Lactobacillus paracasei KW3110 [382,394-396]. The first important trial evaluating food supplements for AMD prevention has been the Age-Related Eye Disease Study (AREDS) started in 1992. Results have shown that a formulation with vitamin C $(500 \mathrm{mg})$, vitamin $\mathrm{E}$ (400 IU), $\beta$-carotene $(15 \mathrm{mg}$ ) and zinc (zinc oxide $80 \mathrm{mg}$ and cupric oxide $2 \mathrm{mg}$ ) showed a $25 \%$ risk reduction of the progression to advanced AMD over 5 years in patients with intermediate or advanced AMD [397]. A second trial, designated AREDS2, conducted between 2006 and 2012, was carried out to explore the added benefits of lutein, zeaxanthin and omega-3 fatty acids to the AREDS1 diet [398]. This study provided an opportunity to further refine the original AREDS formulation by eliminating $B$-carotene (because of increasing risk of lung cancer in smokers) and lowering the dose of zinc (because of the potential health risks of taking large quantities of zinc). AREDS2 found that lutein and zeaxanthin reduced the risk of developing advanced AMD by a further 10 per cent. For participants who had a poor dietary intake of lutein and zeaxanthin a further decrease of $20 \%$ of the risk of progression to advanced AMD was observed; omega- 3 fatty acids did not appear to further improve the efficacy of the AREDS1 diet, and the reduced amount of zinc conserved the same effects of the original higher amount $[398,399]$.

\section{Polyphenols}

Anthocyanins (a subgroup of flavonoids, with cyanidin and delphinidin among the most common) are red-purple pigments found in plants [400]. Berries, such as blueberry, blackcurrant, strawberry, and wolfberry (better known as 'goji berry'), are all rich in anthocyanins [401]. They have shown favorable effects on AMD for their antioxidant and anti-inflammatory properties, as demonstrated by both in vitro and in vivo models. Anthocyanins such as cyanidin 3-glucoside $(\mathrm{C} 3 \mathrm{G})$ promote regeneration and new synthesis of rhodopsin (the photosensible pigment of rod photoreceptor cells) and protect the retina from overexposure to visible and UV light [402-404]. A clinical study on 72 post-menopausal women showed that combining anthocyanin supplements with lutein and zeaxanthin did not influence their uptake in serum and macular pigment, so that an additive protection effect could be expected [405]. Tannic acid (a tannin derivative) contained in the polyphenolic extract of some plants, has been shown to protect human RPE cells from UVB damage, by inhibiting the activation of the transcription factor STAT3 and the downstream induction of the pro-inflammatory cytokine IL-6 and downregulating the expression of the complement factor $\mathrm{B}$, also involved in the inflammatory cascade leading to AMD [406]. Quercetin is an another natural polyphenol with known antioxidant and anti-apoptotic properties, the protective efficacy of which has been demonstrated both in vitro and in vivo models. RPE exposed to cytotoxic and inflammatory effects induced by 4 - hydroxynonenal [407] or by blue light [408] were prevented by quercetin. In a different model of peroxide-induced oxidative stress model in RPE cells [409] quercetin treatment influenced the transcription of genes involved in apoptosis regulation, including the anti-apoptotic Bcl-2 and the proapoptotic BAX and FADD, and the effectors of apoptosis Caspase-3 and Caspase-9. Intraperitoneal administration of quercetin blunted the photo-oxidative damage of rat retinas' photoreceptors exposed to intense light [410]. Curcumin, a polyphenol from Curcuma longa (turmeric plant) belonging to the ginger family, is also able to modulate apoptosis, inflammation and oxidative stress defense proteins [411]; these effects follow the upregulation of the anti-apoptotic protein Bcl2 , the downregulation of the pro-inflammatory transcription factor $\mathrm{NF}-\mathrm{kB}$, and the upregulation of the antioxidant proteins SOD, GR and HO-1, as shown in human retinal cell models exposed to oxidative damage [350,412]. An active phenolic component of green tea, EGCG, protected human ARPE19 cells from UVA-induced damage by decreasing both the production of hydrogen peroxide and the activation of the pro-inflammatory MAPK and COX-2 [413]; moreover, it has shown a protective effect in RPE cells against oxidative stress-induced damage by modulating the expression of the transcription factor $\mathrm{Nrf} 2$ [414]. Resveratrol (3,4,5-trihydroxystilbene), a polyphenolic antioxidant belonging to the stilbene family and commonly found in grape skin and seeds, has been shown to be protective against UVA-induced damage in ARPE19 cells [415] and to prevent the development of choroidal neovascularization by modulating protein kinase A (PKA) in macrophages [416]. A recent study has suggested that resveratrol could mitigate the adverse effects induced by repeated injections of bevacizumab (anti-VEGF antibody) in wet-AMD therapy [417]. One of the major limitations of anti-VEGF therapy is an excessive reduction of the available secreted VEGF, which is also important to maintain the homeostatic function of the RPE. In ARPE-19 cells, various combinations of resveratrol and bevacizumab prevented VEGF reduction observed after bevacizumab alone treatment [417]. A prospective, randomized clinical trial (NCT02625376) started on August 2015, the results of which have not been released yet, aimed to evaluate the safety and efficacy of resveratrol to reduce the progression of exudative AMD between two groups of patients, either receiving $250 \mathrm{mg}$ of resveratrol or placebo, after 24 months of follow-up. The common herb rosemary (Rosmarinus officinalis) contains a variety of polyphenolic compounds which, combined with zinc, decreased the amount of CEP-proteins (carboxyethyl-pyrrole modified proteins, found in drusen and considered a significant risk factor for the development of AMD), and improved photoreceptor cell survival in rat retinas exposed to photo-oxidative damage [418]. Chronic supplementation with rosemary antioxidants has been suggested to be a useful addition to the therapeutic benefits of AREDS supplements in slowing down the progression of AMD $[419,420]$.

\section{Carotenoids}

Lutein, zeaxanthin and meso-zeaxanthin are carotenoids present in high concentration in the macula where they form the macular pigment protecting the retina from the oxidative stress constantly induced by light [421]. They are not synthesized by mammalian cells but found in egg yolk and vegetables such as fruits, spices, lettuce, broccoli, and spinach [422]. In an oxidative stress model obtained in manganese superoxide dismutase knockout mice, zeaxanthin 
supplementation blunted the oxidative stress and preserved the structure of the RPE [423]. Human clinical studies demonstrated that lutein and zeaxanthin, as well as $\beta$-carotene supplementations have protective effects on AMD, improving visual performance measured as contrast sensitivity, glare tolerance, and photo-stress recovery $[396,424]$. Several other studies have shown that high blood levels of lutein and zeaxanthin correlate with a significant lower risk of AMD $[425,426]$.

\section{Vitamins}

Vitamins A, C and E appeared to reduce the risk of macular degeneration according to the AREDS studies I and II [397,398]. Positive outcomes concerning high dietary intakes of fruits and vegetables rich in pro vitamin $\mathrm{A}$ and vitamin $\mathrm{C}$ have been reported [394,427]. Vitamin C is known to be a potent antioxidant protecting proteins, lipids, carbohydrates and nucleic acids from free radicals and ROS damage [428]. Moreover, the AREDS Study Group has revealed that high vitamin $C$ intake is associated with a reduced likelihood of neo-vascular AMD [429]. Vitamin E, similarly to vitamin C, is a powerful antioxidant. Its deprivation leads to lipofuscin accumulation [430], retinal damage [431] and loss of photoreceptors [432]. High dietary intakes of vitamin $\mathrm{E}$ have been clinically correlated with a slower progression of AMD [433]. Vitamin D may exert beneficial effects on AMD prevention by modulating the immune system and inhibiting inflammation and angiogenesis. The role of vitamin D in the progression of AMD has been addressed recently, because the cognate receptor is expressed by mammalian RPE [434]. However, among the many clinical observations and studies run on the efficacy of vitamins A, C, E, not all the results could confirm their efficacy on the decourse of AMD [396]. As to vitamin D, its role in the prevention of AMD seems to be ascertained, though the amount to be given as food supplement is still in need of better clarification [435].

\section{Minerals}

Zinc, copper and selenium play important roles in the normal functioning of antioxidant enzymes and in retinal cell survival [436,437]. Supplementation of zinc and copper decreases the risk of AMD progression suggesting that these metals play an important role in the homeostasis of AMD and in retinal health [438]. In particular, zinc supplementation effectively blunts the risk of AMD and visual loss by its antioxidant properties, and by intervening in the regulation of the light-rhodopsin reaction, in the modulation of synaptic transmission and of complement activation [438]. Selenium is a well-known anti-oxidant agent, and may reduce the risk of AMD by blunting the oxidative damage of membrane lipids and by participating in the activity of GSH antioxidant defense [437]. Moreover, a diet deficient in vitamin $\mathrm{E}$ and selenium in laboratory animals resulted in a consistent decrease of total PUFAs in RPE and in retinal rod outer segments, which could be recovered by an adequate diet supplementation [439]. However, more clinical evidence has to be raised in order to better understand the role, the efficacy and the dietary doses of these minerals in the prevention and treatment of AMD.

\section{Alpha-Lipoic Acid}

aLA is a naturally occurring fatty acid found in some foods such as yeast, spinach, broccoli and potatoes [376]. It works as a cofactor of mitochondrial dehydrogenase and as a free radical scavenger, regenerating endogenous antioxidant systems like vitamins $\mathrm{C}$ and $\mathrm{E}$ and the enzyme SOD [440]. aLA dietary supplementation has been shown to improve vision-related quality of life in dry AMD patients most likely by improving the antioxidant defense [441]. aLA entered a phase 2 clinical trial in May of 2016 sponsored by the University of Pennsylvania (NCT02613572), with the aim of assessing safety and tolerability of the 800 and $1200 \mathrm{mg}$ daily doses in patients affected by geographic atrophy [417].

\section{Omega-3 Fatty Acids}

The deficiency of omega-3 fatty acids DHA and EPA in photoreceptor membrane lipids play an important role in the pathogenesis of AMD because their imbalance contribute to drusen formation in the RPE and sub-RPE layers [442]. Oral treatment with a complex mixture of fatty acids (commercially available as Macular$\mathrm{FAG}^{\circledR}$ ) has been used in a mouse model system of AMD induced by subretinal injection of polyethylene glycol (PEG-400). Results have shown a blunting of complement-mediated inflammation, a decrease of macrophage recruitment and modulation of the production of pro-inflammatory and angiogenic cytokines, finally resulting in a functional rescue of retinal electrophysiology [443].

\section{Lactobacillus Paracasei KW3110}

Anti-inflammatory agents appear to be optimal candidates for AMD prevention or slowing of its progression. Most recently, Morita et al. have demonstrated that Lactobaciullus paracasei KW3110 (a lactic acid bacterium) may activate M2 macrophages (macrophages associated with anti-inflammatory reactions), thus suppressing blue light-induced retinal inflammation both in vitro and in vivo. These results suggest that $L$. paracasei $K W 3110$ may have a preventive effect against degenerative retinal diseases, including AMD [395].

\section{MYOPIA}

Aristotle is considered to be the first person who described myopia. The term myopia derives from the Greek's verb $\mu$ visv, which means 'to close' and $\omega \psi$ which means 'eye', and together describe a typical action of myopic individuals who squeeze their eyes to improve farsight vision. This action reduces the opening of the iris diaphragm, thus increasing the focal depth. Scientifically, myopia (near-sightdness) is a spherical refractive error that occurs when rays of light running parallel to the optic axis focus the image anterior to the retinal plane [444]. This disorder is mostly due to an over-growth of the eyeball, which brings the retina behind the focal plan [445]. According to the recent definition by the IMI (International Myopia Institute), myopia can be divided into low myopia and high myopia, in which the spherical equivalent refractive error is $\leq-0.50$ diopters (D) and $\leq-6.00 \mathrm{D}$, respectively [445]. Myopia is among the most common ocular disorders causing visual loss. In 2010 a systematic analysis estimated that 1.9 billion of people in the world were myopic (about $27 \%$ of the world's population), among which 70 million had high myopia [446]. Holden et al. estimated that in 2050 there will be 
almost 5 billion myopic people (50\% of world's population) among which almost 1 billion with high myopia [447]. However, myopia is not equally distributed worldwide; $90 \%$ of the youngsters are myopic in East Asian countries, while in the United States and Europe their proportion remains around 50\% [448]. The prevalence of myopia also varies with age. In the Beaver Dam Eye Study, data suggested that the prevalence of myopics decreased from $42.9 \%$ among adults aged $43-54$ years to $14 \%$ in individuals older than 75 years [449]. To date, hundreds of genes and around twenty chromosomal loci have been identified to be associated with the occurrence of refractive error and myopia, although they cannot fully explain it [450-452]. A seminal study published in 1969 concerning Inuit people living in North Alaska, showed that only 2 out of 131 adults, grown up in an isolated group, were myopic. On the contrary, about $50 \%$ of the next generation individuals were shortsighted [453], demonstrating that genes alone cannot explain such increase in just one generation, because genetic changes require longer times. However, genes can determine the individual susceptibility to environmental factors, and familiarity is evident within families and within populations [454-456]. Environmental factors including socio-economic and the time spent in outdoor activities have also been correlated with myopia development. While the time spent indoor represents an environmental risk, the concomitant outdoor time may be an important protective factor [457-458]. High level of outdoor activity is positively correlated with lower odds of myopia in different epidemiological studies [459-461]. The idea that outdoor activities reduce the onset of myopia, introduces the concept that the amount of exposition to bright light has a pivotal
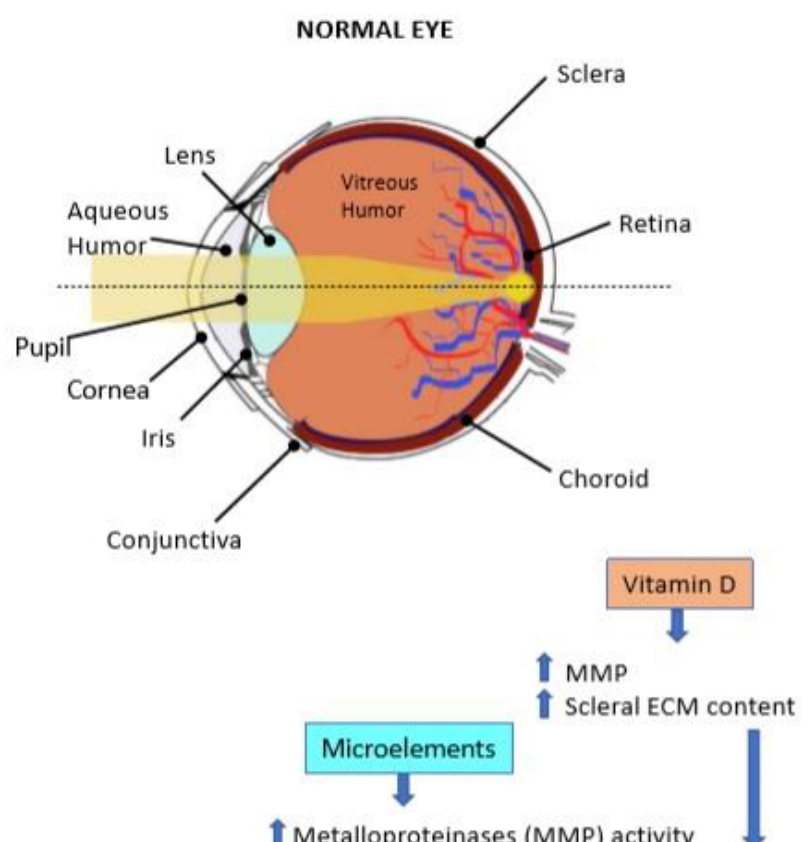

I Metalloproteinases (MMP) activity

1. Scleral ECM content

1 collagen biosynthesis processes

Ifibrillogenesis role in this prevention. In fact, light stimulates the release of dopamine and its accumulation in the retina, which starts a signaling cascade involving the retinal pigmented epithelium, finally slowing down the growth of the eye globe [462-465]. The molecular etiology of myopia is not clear yet. In a recent study, we observed that atropine, a molecule used to slow down myopia progression in children and teenagers, increased extra-cellular matrix production from scleral fibroblasts in vitro, thus contrasting the scleral thinning often observed during myopia progression; on the contrary, atropine effect on choroidal fibroblasts resulted in a decrease of ECM components production, suggesting an alternative mechanism, by which atropine might improve choroidal blood perfusion, known to be reduced in myopic eyes [466]. Further investigations are needed to better clarify the physio-pathological events leading to myopia. Current anti-myopic treatments include: use of eye-glasses or soft contact lenses, orthokeratology, topical administration of low dose atropine or pirenzepine, oral administration of 7-methylxanthine, corrective surgery. However, in many cases a "rebound effect" can be observed after interruption of treatment (Figure 5) [467-470].

\section{Nutrition and Food Supplements}

The use of food supplements to correct nutrition deficiencies is a strategy widely accepted and used to improve the general health and try to prevent many different pathologies, also including eye diseases. Eating brightly colored foods like green vegetables and fresh fruits, loaded with vitamins, is highly recommended also to intervene on eye growth. Moreover, the consumption of fish like salmon, tuna and
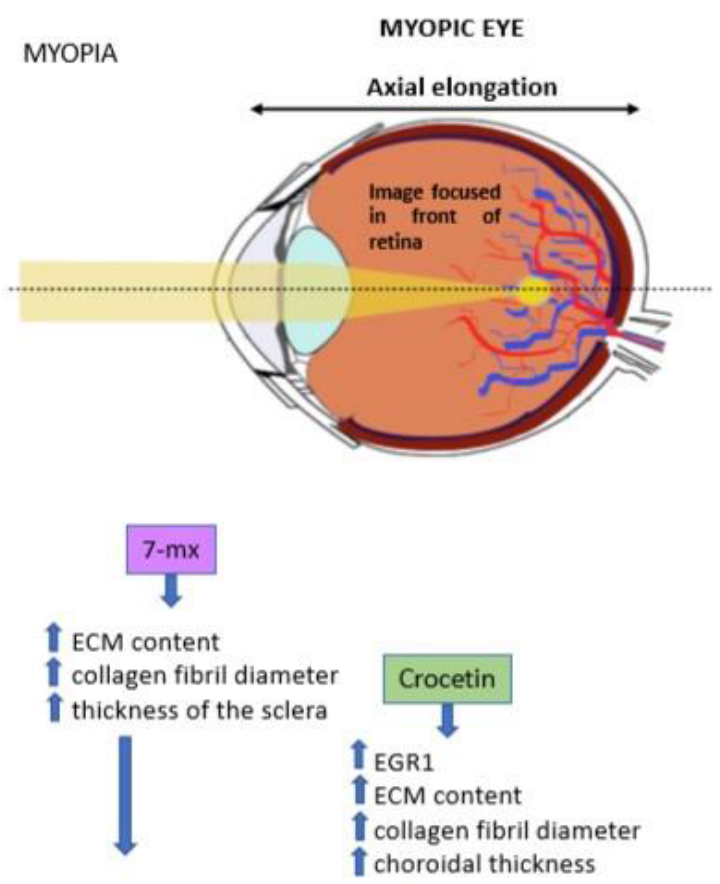

Normal condition (emmetropia)

Figure 5: Myopia. Myopia mostly results from the elongation of the eye globe, which brings the macular region of the retina out of focus, and puts a mechanical stress on this delicate tissue, increasing the risk of a retinal detachment and/or laceration (upper panel). Food supplements that might be useful are those reinforcing the matrix of the sclera, thus retarding its abnormal growth and elongation (bottom panel). 
mackerel is very important for a sufficient intake of omega- 3 fatty acids, needful to the brain and the eye to modulate neuronal cell membrane activity and their kinetics of transport systems [471]. In the study KNHANES VII (Korean National Health and Nutrition Examination Survey 2016-2017) the prevalence of high and low grade myopia among South Korean children 5-18 years of age and the associated risk factors were analyzed. In this study, a correlation was noted between high body mass index and high myopia [472]. In another study on Asian children a high dietary intake of cholesterol and fat was found to be associated with myopia progression [473]. Glycemic index can be regarded as a risk factor for myopia and refractive error is more frequent in young patients with newly diagnosed type I diabetes mellitus [474,475].

Microelements: Microelements are important during the entire life, since they are essential co-factors for many enzymes, and more specifically they have a critical role to support a normal growth in children. Fedor and coworkers [476] found an association between low serum concentration of zinc and selenium, and a high $\mathrm{Cu} / \mathrm{Zn}$ ratio in a cohort of 83 Polish myopic children aged 7-17 years, which might suggest that a dietary supplement of Zinc and Selenium could be indicated in myopic children. However, the finding was not confirmed by another study on American children [477], and more clinical data are necessary to consider microelements as a necessary supplement in the control of myopia progression in children.

Vitamin D: Although there is no direct evidence on the effect of vitamins on myopia progression, some studies have shown a correlation between vitamin $\mathrm{D}$ and myopia. The biosynthesis of vitamin $\mathrm{D}$ is promoted by sunlight exposure, and might be related to the time that individuals spend outdoor. Intake of folate and calcium also correlate with the amount of circulating vitamin D. In a study on 22 young American students ( 13 to 25 years old) the 14 myopes showed lower blood levels of vitamin D (average of $3.4 \mathrm{ng} / \mathrm{ml}$ ) compared with non-myopes when adjusted for age and dietary intakes, despite the fact that both groups spent similar amounts of time outdoor [478]. In a Western Australian Pregnancy Cohort (Raine) Study, Yzar and co-workers [479] analyzed 946 children during a follow-up of 20 years. Among these, $23.4 \%$ were myopic and had lower serum vitamin D3 concentrations compared to non-myopic individuals. Univariate analysis showed that lower serum vitamin D3 concentration was associated with higher risk of progressive myopia (with a cut-off value of $50 \mathrm{nmol} / \mathrm{L}$ the odds ratio for developing myopia with low vitamin D3 was 2.63). Two more studies investigated the correlation between low serum levels of vitamin D3 and myopia. A first study analyzed 2,666 European children aged 6 years [480], and the second study enrolled more than 15,000 Korean young adults (aged 20 years or more) [481]. Both studies found an association between low serum levels of vitamin D3 and presence of myopia, independently from the time spent outdoor.

7-Methylxanthine: 7-Methylxanthine (7-MX) is an intermediate metabolite in the synthesis of caffeine in plants, and a product of the metabolism of caffeine in humans [482]. Unpublished evidence by K. Trier had shown an effect of caffeine on the production of ECM components in the sclera of treated rabbits. Further evidence by the same author has shown that 7-MX - a non-selective adenosine receptor antagonist - may have a role in the retardation of myopia progression. 7-MX effects resemble those of atropine (a muscarinic receptor antagonist), both increasing ECM production and collagen fibril diameter, thus increasing thickness of the sclera $[483,484]$. A thicker sclera should be less prone to axial elongation, which is the main cause of myopia development. In a recent study, infant macaques with myopia induced by the use of corrective lenses were treated with $100 \mathrm{mg} / \mathrm{kg}$ of oral 7-MX twice daily, demonstrating the ability of 7-MX to retard myopia progression in primate puppets [483]. 7-MX is a common human dietary ingredient for coffee drinkers, which has shown no significant side effects during long term treatment. In a clinical study, it has been shown to limit eye elongation and myopia progression in childhood myopia [485].

Crocetin: Another promising natural compound is crocetin, a carotenoid compound consisting of a C-20 carbon chain contained in saffron and used in traditional herbal medicine [486]. This powerful compound is able to delay the growth of cancer cells by inhibiting the synthesis of nucleic acids and the activation of defense anti-oxidative systems, interfering with growth factor signaling pathways and finally inducing cancer cells apoptosis [487]. In a murine model of lens-induced myopia, a dietary crocetin supplement delayed myopia progression. Compared to controls $(n=14)$, crocetin administration resulted in a significant smaller change of refractive errors and axial elongation [488]. In a randomized clinical trial, 69 myopic children aged 6 to 12 years received either a placebo or oral crocetin for 24 weeks. The spherical equivalent refractive error progressed during the 6 months of the study by $-0.41 \pm 0.05$ Diopters in placebo controls, and by $-0.33 \pm 0.05$ Diopters in crocetin treated $(\mathrm{p}<0.05)$; the axial length increased by $0.21 \pm 0.02 \mathrm{~mm}$ in placebo controls, and by $0.18 \pm 0.02$ $\mathrm{mm}$ in crocetin treated $(\mathrm{p}<0.05)$, thus showing the potential effects of crocetin in slowing down myopia progression [489].

\section{CATARACT}

Cataract is the opacification of the normally transparent lens of the eye, which may occur centrally (nuclear and posterior subcapsular) thus impairing vision, or in periphery (cortical cataract) [490]. Oxidative stress in the lens, occurring as consequence of normal aging, or accelerated by genetic and environmental causes, plays an important role in the onset and progression of cataract [491,492]. Currently, the only treatment for cataract is surgical removal of the cloudy lens, which typically is then replaced with an intraocular lens (IOL) during cataract surgery (Figure 6).

\section{Food Supplements}

Despite the evidence indicating oxidative damage to lens epithelial cells as a likely common cause for cataractogenesis, the efficacy of nutritional supplements and antioxidants in the management of agerelated cataracts is still under debate. Several studies reported that nutritional supplements showed a long-term inhibitory effect on the development of sight threatening cataract. A randomized clinical trial enrolling 14,000 U.S. male physicians older than 50 years with a 


\section{CATARACT}

NORMAL EYE

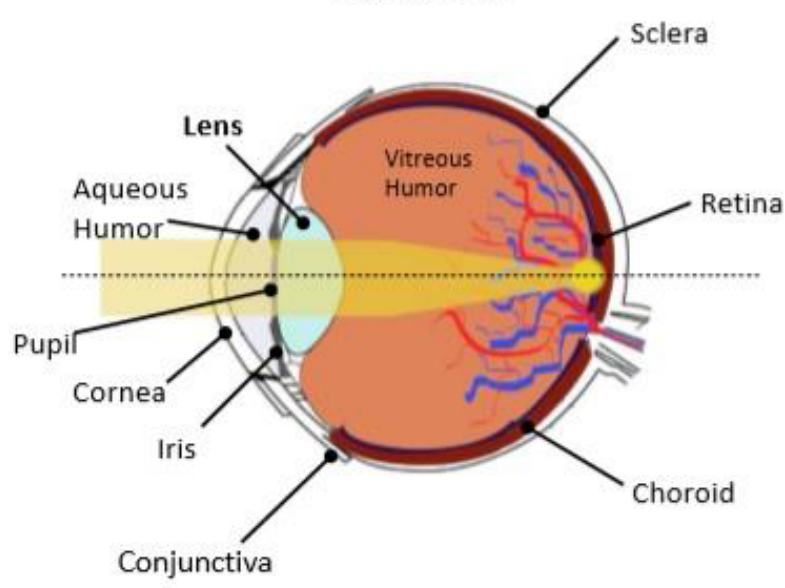

EYE WITH CATARACT

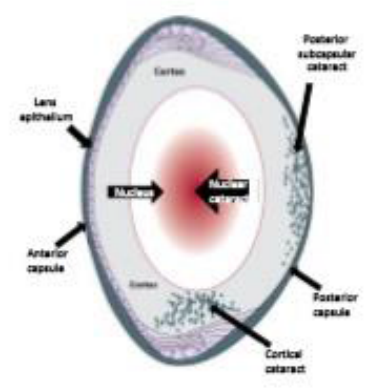

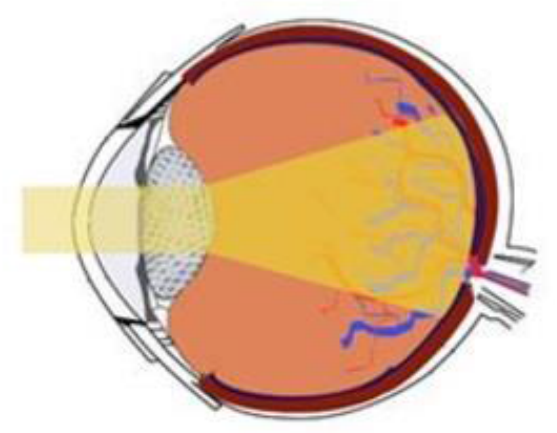

\begin{tabular}{lll}
\hline - Vitamin C: & Antioxidant \\
\hline & Lutein-Zeaxanthin: & Antioxidant \\
\hline
\end{tabular}

Figure 6: Cataract. Oxidative damage is the main and only recognized factor for lens opacification (upper panel). Antioxidants like vitamin C, lutein and zeaxanthin are the only food supplements that have shown some efficacy in retarding the insurgence of cataract (bottom panel).

follow-up of 11 years indicated that long-term daily multivitamin use had a slight, though significant effect in decreasing the risk of cataract [493]. A nutrition survey including more than 30,000 women older than 49 years followed for over 7 years detected a 13\% lesser risk of developing cataract among those indicating a higher dietary intake of antioxidants. The main contributors to dietary total antioxidant capacity in the study population were fruit and vegetables (44.3\%), whole grains (17.0\%) and coffee (15.1\%) [494]. Another large study of adult women in the United States correlated the eating of foods rich in a variety of vitamins and minerals with the delay of cataracts development [495]. A 10-year study of more than 2,400 older adults in Australia found that participants with the highest quintile of total intake (diet + supplements) of vitamin C had a reduced risk of incident nuclear cataract. An above-median intake of combined antioxidants (vitamins $\mathrm{C}$ and $\mathrm{E}$, beta-carotene, and zinc) was associated with a reduced risk of incident nuclear cataract. Antioxidant intake was not associated with incident cortical or posterior sub-capsular cataract [496]. A large study of female health professionals in the United States enrolled 1802 women aged 50 to 79 years with intakes of lutein and zeaxanthin above the $78^{\text {th }}$ (high) and below the $28^{\text {th }}$ (low) percentiles. Four to seven years later, it was found that diets rich in lutein and zeaxanthin are moderately associated with a decreased prevalence of nuclear cataract in older women [497]. However, a Cochrane metanalysis including 9 clinical trials involving more than 117,000 patients concluded that dietary supplements of beta-carotene, vitamin E, and vitamin $C$ had no clear beneficial effects on the inhibition of ARC development [498]. It has to be considered though that clinical studies on cataract development and progression require several years of observation, during which time the compliance of patients to treatment indications can be less tight, and that the endpoint parameters of such studies can be highly subjective. Most recently, a randomized, prospective, double-blind, placebo controlled human clinical trial has been launched to test the efficacy of a 6 months treatment with a nutritional supplement in inhibiting nuclear cataract progression on 20 patients subjected to Pars Plana Vitrectomy surgery. The nutritional supplement contained 11 compounds with reported cataract inhibitory properties: Riboflavin, L-GSH, C-Phycocyanin (as Spirulina Algae Extract), LA, Pyruvate (as Calcium Pyruvate), aLA, Quercetin, Turmeric, Silybin (as Milk Thistle Extract), Lutein, Zeaxanthin, and Astaxanthin [499]. In this study, cataract formation and progression were monitored by the serial Pentacam Nuclear Staging measurements (Oculus, Arlington, Wash.), supposed to be an objective, quantitative, and reproducible measurement of nuclear cataract density. Results showed a marginal borderline effect of the nutritional supplement, which however might suggest some efficacy, given the short observation time and the paucity of enrolled patients [499]. All nutrients associated with cataract prevention in clinical studies can be found in eye vitamins and vision supplements. Many experts believe these substances should be acquired from a healthy diet rather than from nutritional supplements. However, very often it happens that common dietary habits may lack key nutrients because not containing enough fruits and vegetables. In such occurrence, it could be wise to consider taking one or more daily nutritional supplements to assure the organism the intake of all the nutrients needed for optimum eye health. Antioxidant vitamins and phytochemicals that are supposed to reduce the risk of cataracts include vitamins $\mathrm{A}, \mathrm{C}$ 
and E, lutein and zeaxanthin; consumption of fish high in omega-3 fatty acids has also been linked to a potential reduction of the risk of cataracts or their progression [500]. Here follows a sample of recent research suggesting the role of such nutrients in the prevention of cataracts.

\section{Antioxidants and Vitamins}

Seminal preclinical studies performed in the 80's of the past century on cataract induced in mice by hyperbaric oxygen exposure [501] or by photo-oxidative stress in isolated rat lenses [502] have highlighted the potential protective activity of antioxidants, also including vitamin $\mathrm{C}$, against cataract. The level of AsA is known to be low or absent in cataractous patients, with a concomitant increase of di-hydro-AsA (the oxidized form of ascorbic acid) [503]. However, the concentration of vitamin $\mathrm{C}$ in the aqueous humor and lens of human subjects could be increased after supplementation of 2 gr per day for 2 to 4 weeks prior to lens removal [504]. Along the same line, the Second National Health and Nutrition Examination Survey reported an inverse association between serum AsA and self-reported cataract [505], confirmed by the findings of the Nutrition and Vision Project, in which the inverse association between cortical and posterior subcapsular cataract with the use of long-term vitamin C supplement was evidenced [506]. These results are also consistent with those from the Beaver Dam Eye study where the 5-year risk to develop nuclear or cortical cataract was $40 \%$ and $60 \%$ lower among individuals who reported the abitual use of multivitamins or any other supplement containing vitamin C [507]. Daily oral use for 3 years of a mixture of antioxidant micronutrients including vitamin $\mathrm{C}$ produced a small deceleration in the progression of ARC [508]. In a population-based cross-sectional analytic study, which included 5638 people (aged $\geq 60$ years), a strong inverse association between vitamin $C$ and cataract was described [509]. Finally, a recent prospective cohort study, has shown that vitamin $\mathrm{C}$ protected against nuclear cataract progression as evaluated approximately 10 years after the baseline [510].

\section{Lutein and Zeaxanthin}

Lutein and zeaxanthin are the main carotenoids found in the eye and look like promising nutrients in the fight against cataracts. Recent preclinical and clinical works have addressed the risk of developing cataracts in relation to dietary assumption of these nutrients.

Diabetic cataract is a frequent eye complication in diabetes. Dietary lutein effects on the prevention of diabetic cataract have been addressed in a rat model of diabetes induced by streptozotocin [511]. An oral lutein supplement $(0.5 \mathrm{mg} / \mathrm{kg})$ did not significantly affect blood glycemic values or body weights in diabetic rats. Most (81\%) of diabetic rats' eyes developed lens opacity and $43 \%$ developed mature cataract. Diabetic rats treated with lutein, developed lens opacity in $38 \%$ of the eyes and no mature cataracts were observed. Diabetic rats' lenses showed a parallel increase of MDA and a decrease of GSH levels. Lutein treatment blunted MDA levels, though not raising $\mathrm{GSH}$, hence indicating that lutein effects on the prevention of diabetic cataract may work through the inhibition of lipid peroxidation, finally suggesting that a lutein dietary supplement, combined with glycemic control, might work in the prevention of diabetic cataract [511]. The Nurses' Health Study enrolled over 77,000 US female nurses aged 45$71 \mathrm{y}$, and observed for 12 years. Results showed that those subjects with a dietary intake of high amounts of lutein+zeaxanthin (more than the average amount of $6 \mathrm{mg} /$ day registered in the study) had a reduced need for cataract surgery [511]. The POLA (Pathologies Oculaires Liées à l'Age) study evaluated the associations of plasma lutein and zeaxanthin and other carotenoids with the risk of agerelated maculopathy and cataract in 899 residents in the south of France and aged $>60$ years. Results were strongly suggestive of a protective role of the xanthophylls, in particular zeaxanthin, for the development and progression of age-related maculopathy and nuclear cataract [512]. The Melbourne Visual Impairment Project recruited 2322 permanent residents aged $>40$ years, with a follow-up of 2 years. This study confirmed the inverse association between high dietary zeaxanthin intake and prevalence of nuclear cataract [513]. On the contrary, the AREDS2 study concluded that daily supplementation with lutein/zeaxanthin had no detectable effects on rates of cataract surgery or vision [514]. However, these results are biased by the fact that the enrolled population was relatively well nourished and given at baseline a multivitamin supplement which could already have a protective effect on cataract progression, thus masking the effects of lutein and zeaxanthin [515].

\section{Conclusion}

Most often pathologies result from the loss of homeostasis of the whole organism, and may involve one or more organs at a time. Pache and Flammer defined POAG as "a sick eye in a sick body" [516], and indeed this definition might be extended to more ophthalmic pathologies, which can be derived or aggravated by imbalances of the homeostatic equilibrium of the body. Food supplements aim at re-establishing such equilibrium, both at the organism level, and sometimes specifically at the organ level, in case an organ is in major need of some specific nutrients or defense molecules that can be delivered by the food supplement. In fact, medical treatments are specifically aimed at the diseased organ, and their effect might be potentiated by food supplements cooperating with the drug(s) both at the specific site, and more generally at the organism level. Several decades of preclinical and clinical research have substantiated this hypothesis, telling us that nutrition is the most important element in our lifestyle influencing our health and disease status. Food supplements can thus be seen as nutritional aids to prevent disease, but also to cooperate with the treatment of diseases, of the eyes, but of other organs as well. 


\section{Abbreviations}

\begin{tabular}{l|l} 
7-MX & 7-methylxanthine \\
ASA & Ascorbic acid \\
AH & Aqueous humour \\
ALA & Alpha-linolenic acid \\
aLA & alpha-Lipoic Acid (tioctic acid) \\
AMD & Age-related macular degeneration \\
ARC & Age-related cataract \\
AREDS & Age-Related Eye Disease Study \\
ARPE-19 & Adult Retinal Pigment Epithelial cell line-19 \\
ATP & Adenosine triphosphate \\
BBB & Blood brain barrier \\
BDNF & Brain derived neurotrophic factor \\
BRB & Blood retinal barrier \\
C3G & Cyanidin 3-Glycosides
\end{tabular}

\begin{tabular}{l|l} 
CAMP & Cyclic adenosine monophosphate \\
COQ10 & Coenzyme Q10 \\
COX-2 & Cyclooxygenase 2 \\
DHA & Docosahexaenoic acid \\
DR & Diabetic retinopathy \\
ECM & Extracellular matrix \\
EGCG & Epigallo-catechin-gallate \\
EPA & Eicosapentaenoic acid \\
ERG & Electroretinogram \\
GAG & Glycosaminoglycans \\
GLA & Gamma-linolenic acid \\
GR & Glutathione reductase \\
GSH & Glutathione \\
HA & Hyaluronic acid
\end{tabular}

\section{References}

1. World report on vision (2019) World Health Organization: Geneva; ISBN 978-924-151657-0.

2. Dry Eye Syndrome: Epidemiology Forecast to 2026. GlobalData Report Store.

3. VISION 2020: THE CATARACT CHALLENGE. Community Eye Health 2000, 13, $17-19$.

4. Flaxman SR, Bourne RRA, Resnikoff S, Ackland P, Braithwaite, T, et al. (2017) Global causes of blindness and distance vision impairment 1990-2020: a systematic review and meta-analysis. Lancet Glob Health 5.

5. National Eye Institute, National Eye Institute Available online.

6. Liu YC, Wilkins M, Kim T, Malyugin B, Mehta JS (2017) Cataracts. Lancet 390: 600-612.

7. Singh RP, Lewis H (2006) Innovations in Eye Surgery. Clinics in Geriatric Medicine 22: 659-675.

8. Hooper P (2010) Next generation eye surgery and drug delivery. Can. J. Ophthalmol 45. [crossref]

9. Lawrenson JG, Downie LE (2019) Nutrition and Eye Health. Nutrients 11. [crossref]

10. Bunce GE (1994) Nutrition and eye disease of the elderly. The Journal of Nutritional Biochemistry 5: 66-77.

11. Coleman AL, Brigatti L (2001) The glaucomas. Minerva Med 92: 365-379. [crossref]

12. Mroczkowska S, Benavente-Perez A, Negi A, Sung V, Patel SR, et al. (2013) Primary Open-Angle Glaucoma vs Normal-Tension Glaucoma: The Vascular Perspective. JAMA Ophthalmol 131: 36-43. [crossref]

13. Yücel Y, Gupta N (2008) Glaucoma of the brain: a disease model for the study of transsynaptic neural degeneration. In: Nucci C, Cerulli L, Osborne NN, Bagetta G (eds.). Progress in Brain Research; Glaucoma: An Open Window to Neurodegeneration and Neuroprotection. Elsevier 173: 465-478.

14. Lawlor M, Danesh-Meyer H, Levin LA, Davagnanam I., Vita ED, et al. (2018) Glaucoma and the brain: Trans-synaptic degeneration, structural change, and implications for neuroprotection. Survey of Ophthalmology 63: 296-306. [crossref]

15. Salinas-Navarro M, Alarcón-Martínez L, Valiente-Soriano FJ, Jiménez-López M, Mayor-Torroglosa S, et al. (2010) Ocular hypertension impairs optic nerve axonal transport leading to progressive retinal ganglion cell degeneration. Experimental Eye Research 90: 168-183. [crossref]

16. Pasquale LR (2016) Vascular and autonomic dysregulation in primary open-angle glaucoma. Curr Opin Ophthalmol 27: 94-101. [crossref]

17. Fan N, Wang P, Tang, L, Liu X (2015) Ocular Blood Flow and Normal Tension Glaucoma. Biomed Res Int. [crossref]

18. Russo R, Varano GP, Adornetto A, Nucci C, Corasaniti MT, et al. (2016) Retinal ganglion cell death in glaucoma: Exploring the role of neuroinflammation. European Journal of Pharmacology 787: 134-142. [crossref]

\begin{tabular}{l|l} 
Nrf2 & Nuclear erythroid factor 2-releted factor \\
NTG & Normal tension glaucoma \\
OH & Hydroxyl groups \\
OHT & Ocular hypertension \\
ON & Optic nerve \\
ONH & Optic nerve head \\
PCB & Phytocannabinoid \\
PDR & Proliferative diabetic retinopathy \\
PEG & Polyethyleae glycol \\
PERG & Pattern electroretinogram \\
PKA & Protein kinase A \\
PKC & Protein kinase C \\
POAG & Primary open angle giaucoma \\
PRK & Photorefractive keratectomy \\
PUFA & Polyunsaturated fatty acids \\
RGC & Retinal ganglion cells \\
ROS & Reactive oxygen species \\
RPE & Retinal pigment epithelium
\end{tabular}

\begin{tabular}{l|l} 
HIF & Hypoxia inducible factor \\
HO-1 & Heme oxygenase-1 \\
HUVEC & Human umbilical vein endothelial cell \\
iBRB & Inner blood-retinal barrier \\
ICAM-1 & Intercellular adhesion molecule 1 \\
IOP & Intraocular pressure \\
LA & Linoleic acid \\
LPS & Lipopolysaccharide \\
MAPK & Mitogen-activated protein kinases \\
MDA & Malondialdehyde \\
MGD & Meibomian gland dysfunction \\
MPTP & Mitochondrial permeability transition \\
More \\
MTMT & Maximum tolerated medical therapy \\
NMDA & N-methyl-D-aspartate \\
NPDR & Non-proliferative diabetic retinopathy
\end{tabular}

19. Seki M, Lipton SA (2008) Targeting excitotoxic/free radical signaling pathways for therapeutic intervention in glaucoma. Progress in Brain Research, 173: 495-510.

20. Chrysostomou V, Rezania F, Trounce I.A, Crowston JG (2013) Oxidative stress and mitochondrial dysfunction in glaucoma. Current Opinion in Pharmacology 13: 12-15. [crossref]

21. Osborne NN (2010) Mitochondria: Their role in ganglion cell death and survival in primary open angle glaucoma. Experimental Eye Research 90: 750-757. [crossref]

22. Drugs for common eye disorders. (c2019) Med Lett Drugs Ther 61: 187-194.

23. Weinreb RN, Aung T, Medeiros FA (2014) The pathophysiology and treatment of glaucoma: a review. JAMA 311: 1901-1911. [crossref]

24. Tatham AJ, Weinreb RN, Medeiros FA (2014) Strategies for improving early detection of glaucoma: the combined structure-function index. Clin Ophthalmol 8: 611-621. [crossref]

25. Rusciano D, Pezzino S, Mutolo MG, Giannotti R, Librando A, et al. (2017) Neuroprotection in Glaucoma: Old and New Promising Treatments. Adv Pharmaco Sci. [crossref]

26. Oh DJ, Chen JL, Vajaranant TS, Dikopf MS (2018) Brimonidine tartrate for the treatment of glaucoma. Expert Opinion on Pharmacotherapy 20: 115-122. [crossref]

27. Vetrugno $M$ (2001) Acute and chronic effects of brimonidine $0.2 \%$ on intraocular pressure and pulsatile ocular blood flow in patients with primary open-angle glaucoma: an open-label, uncontrolled, prospective study. Clinical Therapeutics 23: 1519-1528. [crossref]

28. Tatton WG, Chalmers-Redman RM, Tatton NA (2001) Apoptosis and anti-apoptosis signalling in glaucomatous retinopathy. Eur J Ophthalmol 11. [crossref]

29. Dong CJ, Guo Y, Wheeler L, Hare WA (2007) a2 Adrenergic Receptor-Mediated Modulation of Cytosolic Ca++Signals at the Inner Plexiform Layer of the Rat Retina. Investigative Opthalmology \& Visual Science 48.

30. Dong, CJ, GuoY, Agey P, Wheeler L, Hare WA (2008) a2 Adrenergic Modulation of NMDA Receptor Function as a Major Mechanism of RGC Protection in Experimental Glaucoma and Retinal Excitotoxicity. Investigative Opthalmology \& Visual Science 49.

31. Gao H, Qiao X, Cantor LB, WuDunn D (2002) Up-regulation of Brain-Derived Neurotrophic Factor Expression by Brimonidine in Rat Retinal Ganglion Cells. Arch Ophthalmol 120: 797-803. [crossref]

32. Wheeler L, WoldeMussie E, Lai R (2003) Role of Alpha-2 Agonists in Neuroprotection Survey of Ophthalmology 48. [crossref]

33. Krupin T, Liebmann JM, Greenfield DS, Ritch R, Gardiner mS (2011) A Randomized Trial of Brimonidine Versus Timolol in Preserving Visual Function: Results From the Low-pressure Glaucoma Treatment Study. American Journal of Ophthalmology 151: 671-681. [crossref]

34. Potenza MA, Marasciulo FL, Tarquinio M, Tiravanti E, Colantuono G, et al. (2007) EGCG, a green tea polyphenol, improves endothelial function and insulin sensitivity, reduces blood pressure, and protects against myocardial I/R injury in SHR. American Journal of Physiology-Endocrinology and Metabolism 292. [crossref] 
35. Kim E, Han S, Hwang K, Kim D, Kim EM, et al. (2019) Antioxidant and Cytoprotective Effects of (-)-Epigallocatechin-3-(3区-O-methyl) Gallate. Int J Mol Sci 20. [crossref]

36. Yokotani K, Umegaki K (2017) Evaluation of plasma antioxidant activity in rats given excess EGCg with reference to endogenous antioxidants concentrations and assay methods. Free Radical Research 51: 193-199. [crossref]

37. Peng PH, Chiou LF, Chao HM, Lin S, Chen CF, et al. (2010) Effects of epigallocatechin3 -gallate on rat retinal ganglion cells after optic nerve axotomy. Experimental Eye Research 90: 528-534.

38. Singh NA, Mandal AKA, Khan ZA (2016) Potential neuroprotective properties of epigallocatechin-3-gallate (EGCG). Nutr J 15. [crossref]

39. Zhang B, Osborne NN (2006) Oxidative-induced retinal degeneration is attenuated by epigallocatechin gallate. Brain Research 1124: 176-187. [crossref]

40. Zhang B, Rusciano D, Osborne NN (2008) Orally administered epigallocatechin gallate attenuates retinal neuronal death in vivo and light-induced apoptosis in vitro. Brain Research 1198: 141-152. [crossref]

41. Osborne NN (2008) Pathogenesis of ganglion "cell death" in glaucoma and neuroprotection: focus on ganglion cell axonal mitochondria. Progress in Brain Research 173: 339-352. [crossref]

42. Falsini B, Marangoni D, Salgarello T, Stifano G, Montrone L, et al. (2009) Effect of epigallocatechin-gallate on inner retinal function in ocular hypertension and glaucoma: A short-term study by pattern electroretinogram. Graefe's Archive for Clinical and Experimental Ophthalmology 247: 1223-1233. [crossref]

43. Roberti G, Tanga L, Michelessi M, Quaranta L, Parisi V, et al. (2015) Cytidine 5'-Diphosphocholine (Citicoline) in Glaucoma: Rationale of Its Use, Current Evidence and Future Perspectives. Int J Mol Sci 16: 28401-28417. [crossref]

44. Manaka S, Sano K, Fuchinoue T, Sekino H (1974) Mechanism of action of CDPcholine in parkinsonism. Experientia 30: 179-180.

45. Chitu I, Tudosescu R, Leasu-Branet C, Voinea LM (2017) Citicoline - a neuroprotector with proven effects on glaucomatous disease. Romanian Journal of Ophthalmology 61: 152-158. [crossref]

46. Hatcher JF, Dempsey RJ (2002) Citicoline: neuroprotective mechanisms in cerebral ischemia. Journal of Neurochemistry 80: 12-23. [crossref]

47. Schuettauf F, Rejdak R, Thaler S, Bolz S, Lehaci C, et al. (2006) Citicoline and lithium rescue retinal ganglion cells following partial optic nerve crush in the rat. Experimental Eye Research 83: 1128-1134. [crossref]

48. Oshitari T, Yoshida-Hata N, Yamamoto S (2010) Effect of neurotrophic factors on neuronal apoptosis and neurite regeneration in cultured rat retinas exposed to high glucose. Brain Research 1346: 43-51. [crossref]

49. Parisi V, Manni G, Colacino G, Bucci MG (1999) Cytidine-5'-diphosphocholine (citicoline) improves retinal and cortical responses in patients with glaucoma11The authors have no proprietary interest in the development or marketing of this or a competing drug. Ophthalmology 106: 1126-1134. [crossref]

50. Parisi V (2005) Electrophysiological Assessment of Glaucomatous Visual Dysfunction During Treatment with Cytidine-5'-diphosphocholine (citicoline): A Study of 8 years of Follow-up. Documenta Ophthalmologica 110: 91-102. [crossref]

51. Parisi V, Coppola G, Centofanti M, Oddone F, Maria Angrisani A, et al. (2008) Evidence of the neuroprotective role of citicoline in glaucoma patients. Progress in Brain Research 173: 541-554. [crossref]

52. Parisi V, Centofanti M, Ziccardi L, Tanga L, Michelessi M, et al. (2015) Treatment with citicoline eye drops enhances retinal function and neural conduction along the visual pathways in open angle glaucoma. Graefe's Archive for Clinical and Experimental Ophthalmology 253: 1327-1340. [Crossref]

53. Ernster L, Dallner G (1995) Biochemical, physiological and medical aspects of ubiquinone function. Biochimica et Biophysica Acta (BBA) - Molecular Basis of Disease, 1271: 195-204. [crossref]

54. Lee D, Shim MS, Kim KY, Noh YH, Kim H (2014). Coenzyme Q10 inhibits glutamate excitotoxicity and oxidative stress-mediated mitochondrial alteration in a mouse model of glaucoma. Invest Ophthalmol Vis Sci 55: 993-1005. [crossref]

55. Papucci L, Schiavone, N, Witort E, Donnini M, Lapucci A, et al. (2003) Coenzyme Q10Prevents Apoptosis by Inhibiting Mitochondrial Depolarization Independently of Its Free Radical Scavenging Property. Journal of Biological Chemistry 278: 2822028228. [crossref]
56. Ekicier Acar S, Sarıcaoğlu MS, Colak A, Aktas Z, Sepici Dinçel A (2019) Neuroprotective effects of topical coenzyme Q10 + vitamin E in mechanic optic nerve injury model. European Journal of Ophthalmology 30.

57. Quaranta L, Riva I, Biagioli E, Rulli E, Poli D, et al. (2019) Evaluating the Effects of an Ophthalmic Solution of Coenzyme Q10 and Vitamin E in Open-Angle Glaucoma Patients: A Study Protocol. Advances in Therapy 36: 2506-2514. [crossref]

58. Karimi E, Oskoueian E, Hendra R, Jaafar HZE (2010) Evaluation of Crocus sativus L. stigma phenolic and flavonoid compounds and its antioxidant activity. Molecules 15: 6244-6256. [crossref]

59. Hashemi M, Hosseinzadeh H (2019) A comprehensive review on biological activities and toxicology of crocetin. Food and Chemical Toxicology 130: 44-60. [crossref]

60. Karkoula E, Lemonakis N, Kokras N, Dalla C, Gikas E, et al. (2018) Trans-crocin 4 is not hydrolyzed to crocetin following i.p. administration in mice, while it shows penetration through the blood brain barrier. Fitoterapia 129: 62-72. [crossref]

61. Zhang X, Fan Z, Jin T (2017) Crocin protects against cerebral- ischemia-induced damage in aged rats through maintaining the integrity of blood-brain barrier. Restorative Neurology and Neuroscience 35: 65-75. [crossref]

62. Fernández-Albarral JA, de Hoz R, Ramírez AI, López-Cuenca I., Salobrar-García E, et al. (2020) Beneficial effects of saffron (Crocus sativus L.) in ocular pathologies, particularly neurodegenerative retinal diseases. Neural Regen Res 15: 1408-1416. [crossref]

63. Heitmar R, Brown J, Kyrou I. (2019) Saffron (Crocus sativus L.) in Ocular Diseases: A Narrative Review of the Existing Evidence from Clinical Studies. Nutrients 11. [crossref]

64. Ishizuka F, Shimazawa M, Umigai N, Ogishima H, Nakamura S, et al. (2013) Crocetin, a carotenoid derivative, inhibits retinal ischemic damage in mice. European Journal of Pharmacology 703: 1-10. [crossref]

65. Qi Y, Chen L, Zhang L, Liu WB, Chen XY, et al. (2013) Crocin prevents retinal ischaemia/reperfusion injury-induced apoptosis in retinal ganglion cells through the PI3K/AKT signalling pathway. Experimental Eye Research 107: 44-51. [crossref]

66. Chen L, Qi Y, Yang X (2015) Neuroprotective Effects of Crocin against Oxidative Stress Induced by Ischemia/Reperfusion Injury in Rat Retina. Ophthalmic Research 54: 157-168. [crossref]

67. Ohno Y, Nakanishi T, Umigai N, Tsuruma K, Shimazawa M, et al. (2012) Oral administration of crocetin prevents inner retinal damage induced by N-methyl-daspartate in mice. European Journal of Pharmacology 690: 84-89. [crossref]

68. Fernández-Albarral JA, Ramírez AI, de Hoz R, López-Villarín N, Salobrar-García E, et al. (2019) Neuroprotective and Anti-Inflammatory Effects of a Hydrophilic Saffron Extract in a Model of Glaucoma. Int J Mol Sci 20.

69. Jabbarpoor Bonyadi MH, Yazdani S, Saadat (2014) The ocular hypotensive effect of saffron extract in primary open angle glaucoma: a pilot study. BMC Complement Altern Med 14: 399-399. [crossref]

70. Hecht I, Achiron A, Bartov E, Maharshak I, Mendel L, et al. (2019) Effects of dietary and lifestyle recommendations on patients with glaucoma: A randomized controlled pilot trial. European Journal of Integrative Medicine 25: 60-66. [crossref]

71. Schmidt M, Betti G, Hensel A (2007) Saffron in phytotherapy: Pharmacology and clinical uses. Wiener Medizinische Wochenschrift 157: 315-319. [crossref]

72. Modaghegh, M.-H.; Shahabian, M.; Esmaeili, H.-A.; Rajbai, O.; Hosseinzadeh, H. Safety evaluation of saffron (Crocus sativus) tablets in healthy volunteers. Phytomedicine 2008, 15, 1032-1037, http://doi.org/10.1016/j.phymed.2008.06.003.

73. Langcake, P.; Pryce, R.J. A new class of phytoalexins from grapevines. Experientia 1977, 33, 151-152, http://doi.org/10.1007/bf02124034.

74. Wu, J.M.; Hsieh, T. Resveratrol: a cardioprotective substance. Annals of the New York Academy of Sciences 2011, 1215, 16-21, http://doi.org/10.1111/j.1749 6632.2010.05854.x

75. Richard, T.; Pawlus, A.D.; Iglésias, M.-L.; Pedrot, E.; Waffo-Teguo, P.; Mérillon, J.-M.; Monti, J.-P. Neuroprotective properties of resveratrol and derivatives. Annals of the New York Academy of Sciences 2011, 1215, 103-108, http://doi.org/10.1111/j.17496632.2010.05865.x.

76. Alarcón de la Lastra, C.; Villegas, I. Resveratrol as an anti-inflammatory and antiaging agent: Mechanisms and clinical implications. Molecular Nutrition \& Food Research 2005, 49, 405-430, http://doi.org/10.1002/mnfr.200500022. 
77. Lopez, M.S.; Dempsey, R.J.; Vemuganti, R. Resveratrol neuroprotection in stroke and traumatic CNS injury. Neurochem Int 2015, 89, 75-82, http://doi.org/10.1016/j. neuint.2015.08.009.

78. Sun, A.Y.; Wang, Q.; Simonyi, A.; Sun, G.Y. Resveratrol as a therapeutic agent for neurodegenerative diseases. Mol Neurobiol 2010, 41, 375-383, http://doi. org/10.1007/s12035-010-8111-y.

79. Raval, A.; Lin, H.; Dave, K.; DeFazio, R.; Morte, D.; Kim, E.; Perez-Pinzon, M. Resveratrol and Ischemic Preconditioning in the Brain. Current Medicinal Chemistry 2008, 15, 1545-1551, http://doi.org/10.2174/092986708784638861.

80. Morin, C.; Zini, R.; Albengres, E.; Bertelli, A. a. E.; Bertelli, A.; Tillement, J.P. Evidence for resveratrol-induced preservation of brain mitochondria functions after hypoxia-reoxygenation. Drugs Exp Clin Res 2003, 29, 227-233.

81. Bhullar, K.S.; Hubbard, B.P. Lifespan and healthspan extension by resveratrol. Biochimica et Biophysica Acta (BBA) - Molecular Basis of Disease 2015, 1852, 12091218, http://doi.org/10.1016/j.bbadis.2015.01.012

82. Park, S.-J.; Ahmad, F.; Philp, A.; Baar, K.; Williams, T.; Luo, H.; Ke, H.; Rehmann, H.; Taussig, R.; Brown, A.L.; et al. Resveratrol ameliorates aging-related metabolic phenotypes by inhibiting cAMP phosphodiesterases. Cell 2012, 148, 421-433, http:// doi.org/10.1016/j.cell.2012.01.017.

83. Wang, Y. Molecular Links between Caloric Restriction and Sir2/SIRT1 Activation. Diabetes Metab J 2014, 38, 321-329, http://doi.org/10.4093/dmj.2014.38.5.321.

84. Luna, C.; Li, G.; Liton, P.B.; Qiu, J.; Epstein, D.L.; Challa, P.; Gonzalez, P. Resveratrol prevents the expression of glaucoma markers induced by chronic oxidative stress in trabecular meshwork cells. Food Chem Toxicol 2009, 47, 198-204, http://doi. $\operatorname{org} / 10.1016 /$ j.fct.2008.10.029.

85. Pirhan, D.; Yüksel, N.; Emre, E.; Cengiz, A.; Kürşat Yıldız, D. Riluzole- and Resveratrol-Induced Delay of Retinal Ganglion Cell Death in an Experimental Model of Glaucoma. Current Eye Research 2015, 41, 59-69, http://doi.org/10.3109/027136 83.2015.1004719

86. Lindsey, J.D.; Duong-Polk, K.X.; Hammond, D.; Leung, C.K.; Weinreb, R.N. Protection of injured retinal ganglion cell dendrites and unfolded protein response resolution after long-term dietary resveratrol. Neurobiology of Aging 2015, 36, 19691981, http://doi.org/10.1016/j.neurobiolaging.2014.12.021.

87. Liu, X.-Q.; Wu, B.-J.; Pan, W.H.T.; Zhang, X.-M.; Liu, J.-H.; Chen, M.-M.; Chao, F.P.; Chao, H.-M. Resveratrol mitigates rat retinal ischemic injury: the roles of matrix metalloproteinase- 9 , inducible nitric oxide, and heme oxygenase-1. J Ocul Pharmacol Ther 2013, 29, 33-40, http://doi.org/10.1089/jop.2012.0141.

88. Zhang, X.; Feng, Y.; Wang, Y.; Wang, J.; Xiang, D.; Niu, W.; Yuan, F. Resveratrol ameliorates disorders of mitochondrial biogenesis and dynamics in a rat chronic ocular hypertension model. Life Sciences 2018, 207, 234-245, http://doi.org/10.1016/j. lfs.2018.06.010.

89. Khan, R.S.; Fonseca-Kelly, Z.; Callinan, C.; Zuo, L.; Sachdeva, M.M.; Shindler K.S. SIRT1 activating compounds reduce oxidative stress and prevent cell death in neuronal cells. Front Cell Neurosci 2012, 6, 63-63, http://doi.org/10.3389/ fncel.2012.00063.

90. Means, J.C.; Lopez, A.A.; Koulen, P. Resveratrol Protects Optic Nerve Head Astrocytes from Oxidative Stress-Induced Cell Death by Preventing Caspase-3 Activation, Tau Dephosphorylation at Ser422 and Formation of Misfolded Protein Aggregates. Cellular and Molecular Neurobiology 2020, http://doi.org/10.1007/ s10571-019-00781-6.

91. Clark, A.F.; Wordinger, R.J. The role of steroids in outflow resistance. Experimental Eye Research 2009, 88, 752-759, http://doi.org/10.1016/j.exer.2008.10.004.

92. Razali, N.; Agarwal, R.; Agarwal, P.; Kumar, S.; Tripathy, M.; Vasudevan, S.; Crowston, J.G.; Ismail, N.M. Role of adenosine receptors in resveratrol-induced intraocular pressure lowering in rats with steroid-induced ocular hypertension. Clinical \& Experimental Ophthalmology 2014, 43, 54-66, http://doi.org/10.1111/ceo.12375.

93. Ramírez-Garza, S.L.; Laveriano-Santos, E.P.; Marhuenda-Muñoz, M.; Storniolo, C.E.; Tresserra-Rimbau, A.; Vallverdú-Queralt, A.; Lamuela-Raventós, R.M. Health Effects of Resveratrol: Results from Human Intervention Trials. Nutrients 2018, 10, 1892, http://doi.org/10.3390/nu10121892.

94. Pandi-Perumal, S.R.; Srinivasan, V.; Maestroni, G.J.M.; Cardinali, D.P.; Poeggeler, B.; Hardeland, R. Melatonin. FEBS Journal 2006, 273, 2813-2838, http://doi.org/10.1111/ j.1742-4658.2006.05322.x
95. Czeisler, C.A. Stability, Precision, and Near-24-Hour Period of the Human Circadian Pacemaker. Science 1999, 284, 2177-2181, http://doi.org/10.1126/ science.284.5423.2177.

96. Ng, K.Y.; Leong, M.K.; Liang, H.; Paxinos, G. Melatonin receptors: distribution in mammalian brain and their respective putative functions. Brain Structure and Function 2017, 222, 2921-2939, http://doi.org/10.1007/s00429-017-1439-6.

97. Tosini, G.; Menaker, M. The clock in the mouse retina: melatonin synthesis and photoreceptor degeneration. Brain Research 1998, 789, 221-228, http://doi. org/10.1016/s0006-8993(97)01446-7.

98. Martin, X.D; Malina, H.Z; Brennan, M.C; Hendrickson, Ph.H.; Lichter, P.R. The Ciliary Body - The Third Organ Found to Synthesize Indoleamines in Humans. European Journal of Ophthalmology 1992, 2, 67-72, http://doi. org/10.1177/112067219200200203

99. Mhatre, M.C.; van Jaarsveld, A.S.; Reiter, R.J. Melatonin in the lacrimal gland: First demonstration and experimental manipulation. Biochemical and Biophysical Research Communications 1988, 153, 1186-1192, http://doi.org/10.1016/s0006$291 x(88) 81353-6$.

100. Peyrot, F.; Ducrocq, C. Potential role of tryptophan derivatives in stress responses characterized by the generation of reactive oxygen and nitrogen species. Journal of Pineal Research 2008, 45, 235-246, http://doi.org/10.1111/j.1600-079x.2008.00580.x.

101. Hardeland, R.; Tan, D.-X.; Reiter, R.J. Kynuramines, metabolites of melatonin and other indoles: the resurrection of an almost forgotten class of biogenic amines. Journal of Pineal Research 2009, 47, 109-126, http://doi.org/10.1111/j.1600079x.2009.00701.x

102. Siu, A.W.; Maldonado, M.; Sanchez-Hidalgo, M.; Tan, D.-X.; Reiter, R.J. Protective effects of melatonin in experimental free radical-related ocular diseases. Journal of Pineal Research 2006, 40, 101-109, http://doi.org/10.1111/j.1600-079x.2005.00304.x.

103. Park, S.-W.; Lee, H.-S.; Sung, M.-S.; Kim, S.-J. The effect of melatonin on retinal ganglion cell survival in ischemic retina. Chonnam Med J 2012, 48, 116-122, http:// doi.org/10.4068/cmj.2012.48.2.116

104. Belforte, N.A.; Moreno, M.C.; de Zavalía, N.; Sande, P.H.; Chianelli, M.S.; Keller Sarmiento, M.I.; Rosenstein, R.E. Melatonin: a novel neuroprotectant for the treatment of glaucoma. Journal of Pineal Research 2010, 48, 353-364, http://doi. org/10.1111/j.1600-079x.2010.00762.x.

105. del Valle Bessone, C.; Fajreldines, H.D.; de Barboza, G.E.D.; Tolosa de Talamoni, N.G.; Allemandi, D.A.; Carpentieri, A.R.; Quinteros, D.A. Protective role of melatonin on retinal ganglionar cell: In vitro an in vivo evidences. Life Sciences 2019, 218, 233-240, http://doi.org/10.1016/j.lfs.2018.12.053.

106. Arranz-Romera, A.; Davis, B.M.; Bravo-Osuna, I.; Esteban-Pérez, S.; MolinaMartínez, I.T.; Shamsher, E.; Ravindran, N.; Guo, L.; Cordeiro, M.F.; Herrero-Vanrell, R. Simultaneous co-delivery of neuroprotective drugs from multi-loaded PLGA microspheres for the treatment of glaucoma. Journal of Controlled Release 2019, 297, 26-38, http://doi.org/10.1016/j.jconrel.2019.01.012.

107. Gressens, P.; Schwendimann, L.; Husson, I.; Sarkozy, G.; Mocaer, E.; Vamecq, J.; Spedding, M. Agomelatine, a melatonin receptor agonist with 5-HT2C receptor antagonist properties, protects the developing murine white matter against excitotoxicity. European Journal of Pharmacology 2008, 588, 58-63, http://doi. org/10.1016/j.ejphar.2008.04.016.

108. Rowland, J.M.; Potter, D.E.; Reiter, R.J. Circadian rhythm in intraocular pressure: A rabbit model. Current Eye Research 1981, 1, 169-173, http://doi. org/10.3109/02713688109001822.

109. Samples, J.R.; Krause, G.; Lewy, A.J. Effect of melatonin on intraocular pressure Current Eye Research 1988, 7, 649-653, http://doi.org/10.3109/02713688809033192.

110. Serle, J.B.; Wang, R.-F.; Peterson, W.M.; Plourde, R.; Yerxa, B.R. Effect of 5-MCANAT, a Putative Melatonin MT3 Receptor Agonist, on Intraocular Pressure in Glaucomatous Monkey Eyes. Journal of Glaucoma 2004, 13, 385-388, http://doi. org/10.1097/01.ijg.0000133150.44686.0b

111. Pintor, J.; Martin, L.; Pelaez, T.; Hoyle, C.H.V.; Peral, A. Involvement of melatonin MT3 receptors in the regulation of intraocular pressure in rabbits. European Journal of Pharmacology 2001, 416, 251-254, http://doi.org/10.1016/s0014-2999(01)00864-0.

112. Dal Monte, M.; Cammalleri, M.; Pezzino, S.; Corsaro, R.; Pescosolido, N.; Bagnoli, P.; Rusciano, D. Hypotensive Effect of Nanomicellar Formulation of Melatonin and Agomelatine in a Rat Model: Significance for Glaucoma Therapy. Diagnostics 2020, 10, 138, http://doi.org/10.3390/diagnostics10030138. 
113. Pescosolido, N.; Gatto, V.; Stefanucci, A.; Rusciano, D. Oral treatment with the melatonin agonist agomelatine lowers the intraocular pressure of glaucoma patients. Ophthalmic and Physiological Optics 2015, 35, 201-205, http://doi.org/10.1111/ opo.12189.

114. Chen, J.; Matias, I.; Dinh, T.; Lu, T.; Venezia, S.; Nieves, A.; Woodward, D.F.; Di Marzo, V. Finding of endocannabinoids in human eye tissues: Implications for glaucoma. Biochemical and Biophysical Research Communications 2005, 330, 10621067, http://doi.org/10.1016/j.bbrc.2005.03.095

115. Matias, I.; Wang, J.W.; Moriello, A.S.; Nieves, A.; Woodward, D.F.; Di Marzo, V. Changes in endocannabinoid and palmitoylethanolamide levels in eye tissues of patients with diabetic retinopathy and age-related macular degeneration. Prostaglandins, Leukotrienes and Essential Fatty Acids 2006, 75, 413-418, http://doi. org/10.1016/j.plefa.2006.08.002.

116. Kuepper, R.; Morrison, P.D.; van Os, J.; Murray, R.M.; Kenis, G.; Henquet, C. Does dopamine mediate the psychosis-inducing effects of cannabis? A review and integration of findings across disciplines. Schizophrenia Research 2010, 121, 107117, http://doi.org/10.1016/j.schres.2010.05.031.

117. Tomida, I.; Pertwee, R.G.; Azuara-Blanco, A. Cannabinoids and glaucoma. Br J Ophthalmol 2004, 88, 708-713, http://doi.org/10.1136/bjo.2003.032250.

118. Tomida, I.; Azuara-Blanco, A.; House, H.; Flint, M.; Pertwee, R.G.; Robson, P.J. Effect of Sublingual Application of Cannabinoids on Intraocular Pressure: A Pilot Study. Journal of Glaucoma 2006, 15, 349-353, http://doi.org/10.1097/01. ijg.0000212260.04488.60.

119. Rapino, C.; Tortolani, D.; Scipioni, L.; Maccarrone, M. Neuroprotection by (endo)Cannabinoids in Glaucoma and Retinal Neurodegenerative Diseases. Curr Neuropharmacol 2018, 16, 959-970, http://doi.org/10.2174/157015 9X15666170724104305.

120. Njie, Y.F.; Kumar, A.; Qiao, Z.; Zhong, L.; Song, Z.-H. Noladin Ether Acts on Trabecular Meshwork Cannabinoid (CB1) Receptors to Enhance Aqueous Humor Outflow Facility. Investigative Opthalmology \& Visual Science 2006, 47, 1999, http:// doi.org/10.1167/iovs.05-0729.

121. Chien, F.Y. Effect of WIN 55212-2, a Cannabinoid Receptor Agonist, on Aqueous Humor Dynamics in Monkeys. Archives of Ophthalmology 2003, 121, 87, http://doi. org/10.1001/archopht.121.1.87

122. Panahi, Y.; Manayi, A.; Nikan, M.; Vazirian, M. The arguments for and against cannabinoids application in glaucomatous retinopathy. Biomedicine \& Pharmacotherapy 2017, 86, 620-627, http://doi.org/10.1016/j.biopha.2016.11.106.

123. Purnell, W.D.; Gregg, J.M. Delta(9)-tetrahydrocannabinol,, euphoria and intraocular pressure in man. Ann Ophthalmol 1975, 7, 921-923.

124. Taskar, P.S.; Patil, A.; Lakhani, P.; Ashour, E.; Gul, W.; ElSohly, M.A.; Murphy, B.; Majumdar, S. $\Delta(9)$-Tetrahydrocannabinol Derivative-Loaded Nanoformulation Lowers Intraocular Pressure in Normotensive Rabbits. Transl Vis Sci Technol 2019, 8, 15-15, http://doi.org/10.1167/tvst.8.5.15.

125. Pescosolido, N.; Stefanucci, A.; Librando, A.; Pezzino, S.; Rusciano, D. Evaluation of cannabinoid eye drops on five patients with intractable hypertensive open angle glaucoma. The Ophthalmologist: Clinical and Therapeutic Journal 2018, 2, 1-3.

126. Wagh, V.; Patil, P.; Surana, S.; Wagh, K. Forskolin: Upcoming antiglaucoma molecule. Journal of Postgraduate Medicine 2012, 58, 199, http://doi.org/10.4103/00223859.101396.

127. Caprioli, J.; Sears, M. FORSKOLIN LOWERS INTRAOCULAR PRESSURE IN RABBITS, MONKEYS, AND MAN. The Lancet 1983, 321, 958-960, http://doi. org/10.1016/s0140-6736(83)92084-6.

128. Caprioli, J.; Sears, M.; Bausher, L.; Gregory, D.; Mead, A. Forskolin lowers intraocular pressure by reducing aqueous inflow. Invest. Ophthalmol. Vis. Sci. 1984, 25, 268-277.

129. Lee, P.Y.; Podos, S.M.; Mittag, T.; Severin, C. Effect of topically applied forskolin on aqueous humor dynamics in cynomolgus monkey. Invest. Ophthalmol. Vis. Sci. 1984, 25, 1206-1209.

130. Shen, X.; Koga, T.; Park, B.-C.; SundarRaj, N.; Yue, B.Y.J.T. Rho GTPase and cAMP/ protein kinase A signaling mediates myocilin-induced alterations in cultured human trabecular meshwork cells. J Biol Chem 2008, 283, 603-612, http://doi.org/10.1074/ jbc.M708250200

131. Ganeshpurkar, A.; Saluja, A.K. The Pharmacological Potential of Rutin. Saudi Pharm J 2017, 25, 149-164, http://doi.org/10.1016/j.jsps.2016.04.025.
132. Vetrugno, M.; Uva, M.G.; Russo, V.; Iester, M.; Ciancaglini, M.; Brusini, P.; Centofanti, M.; Rossetti, L.M. Oral Administration of Forskolin and Rutin Contributes to Intraocular Pressure Control in Primary Open Angle Glaucoma Patients Under Maximum Tolerated Medical Therapy. Journal of Ocular Pharmacology and Therapeutics 2012, 28, 536-541, http://doi.org/10.1089/jop.2012.0021.

133. Pescosolido, N.; Librando, A. Oral administration of an association of forskolin, rutin and vitamins $\mathrm{B} 1$ and $\mathrm{B} 2$ potentiates the hypotonising effects of pharmacological treatments in POAG patients. Clin Ter 2010, 161, e81-85.

134. Jurič, D.M.; Lončar, D.; Čarman-Kržan, M. Noradrenergic stimulation of BDNF synthesis in astrocytes: Mediation via $\alpha 1-$ and $\beta 1 / \beta 2$-adrenergic receptors. Neurochemistry International 2008, 52, 297-306, http://doi.org/10.1016/j. neuint.2007.06.035.

135. Nakahashi, T.; Fujimura, H.; Altar, C.A.; Li, J.; Kambayashi, J.; Tandon, N.N.; Sun, B. Vascular endothelial cells synthesize and secrete brain-derived neurotrophic factor. FEBS Letters 2000, 470, 113-117, http://doi.org/10.1016/s0014-5793(00)01302-8.

136. Meyer-Franke, A.; Wilkinson, G.A.; Kruttgen, A.; Hu, M.; Munro, E.; Hanson, M.G.; Reichardt, L.F.; Barres, B.A. Depolarization and cAMP Elevation Rapidly Recruit TrkB to the Plasma Membrane of CNS Neurons. Neuron 1998, 21, 681-693, http:// doi.org/10.1016/s0896-6273(00)80586-3

137. Pescosolido, N.; Scarsella, G.; Rusciano, D. Oral administration of forskolin decreases retinal damage after experimental induction of ocular hypertension in the rat. In; 2015; pp. 31-50.

138. Sisto, D.; Lavermicocca, N.; Errico, D.; Rusciano, D. Oral Administration of Forskolin and Rutin Contributes to Reduce Intraocular Pressure and Improve PERG (Pattern Electroretinogram) Amplitude in Glaucomatous Patients. JSM Biotechnology \& Biomedical Engineering.

139. Tsolaki, M. Future strategies of management of Alzheimer's Disease. The role of homotaurine. Hell J Nucl Med 2019, 22 Suppl, 82-94.

140. Ricciardi, L.; De Nigris, F.; Specchia, A.; Fasano, A. Homotaurine in Parkinson's disease. Neurological Sciences 2015, 36, 1581-1587, http://doi.org/10.1007/s10072015-2201-6.

141. Berezhnoy, D.S.; Stvolinsky, S.L.; Lopachev, A.V.; Devyatov, A.A.; Lopacheva, O.M.; Kulikova, O.I.; Abaimov, D.A.; Fedorova, T.N. Carnosine as an effective neuroprotector in brain pathology and potential neuromodulator in normal conditions. Amino Acids 2018, 51, 139-150, http://doi.org/10.1007/s00726-0182667-7.

142. Schön, M.; Mousa, A.; Berk, M.; Chia, W.L.; Ukropec, J.; Majid, A.; Ukropcová B.; de Courten, B. The Potential of Carnosine in Brain-Related Disorders: A Comprehensive Review of Current Evidence. Nutrients 2019, 11, 1196, http://doi. org/10.3390/nu11061196

143. Russo, R.; Adornetto, A.; Cavaliere, F.; Varano, G.P.; Rusciano, D.; Morrone, L.A.; Corasaniti, M.T.; Bagetta, G.; Nucci, C. Intravitreal injection of forskolin, homotaurine, and L-carnosine affords neuroprotection to retinal ganglion cells following retinal ischemic injury. Mol. Vis. 2015, 21, 718-729.

144. Mutolo, M.G.; Albanese, G.; Rusciano, D.; Pescosolido, N. Oral Administration of Forskolin, Homotaurine, Carnosine, and Folic Acid in Patients with Primary Open Angle Glaucoma: Changes in Intraocular Pressure, Pattern Electroretinogram Amplitude, and Foveal Sensitivity. Journal of Ocular Pharmacology and Therapeutics 2016, 32, 178-183, http://doi.org/10.1089/jop.2015.0121.

145. Nieman, K.M.; Sanoshy, K.D.; Bresciani, L.; Schild, A.L.; Kelley, K.M.; Lawless, A.L.; Ceddia, M.A.; C. Maki, K.; Del Rio, D.; Herrlinger, K.A. Tolerance, bioavailability, and potential cognitive health implications of a distinct aqueous spearmint extract. Functional Foods in Health and Disease 2015, 5, 165, http://doi.org/10.31989/ffhd. v5i5.181.

146. Locri, F.; Cammalleri, M.; Dal Monte, M.; Rusciano, D.; Bagnoli, P. Protective Efficacy of a Dietary Supplement Based on Forskolin, Homotaurine, Spearmint Extract, and Group B Vitamins in a Mouse Model of Optic Nerve Injury. Nutrients 2019, 11, 2931, http://doi.org/10.3390/nu11122931.

147. Cammalleri, M.; Dal Monte, M.; Amato, R.; Bagnoli, P.; Rusciano, D. A dietary combination of forskolin with homotaurine, spearmint and B vitamins protects injured retinal ganglion cells in a rodent model of hypertensive glaucoma. Nutrients 2020

148. Ramdas, W.D.; Schouten, J.S.A.G.; Webers, C.A.B. The Effect of Vitamins on Glaucoma: A Systematic Review and Meta-Analysis. Nutrients 2018, 10, http://doi. org/10.3390/nu10030359. 
149. Coleman, A.L. Glaucoma. Lancet 1999, 354, 1803-1810, http://doi.org/10.1016/ S0140-6736(99)04240-3.

150. Ramdas, W.D.; Wolfs, R.C.W.; Kiefte-de Jong, J.C.; Hofman, A.; de Jong, P.T.V.M.; Vingerling, J.R.; Jansonius, N.M. Nutrient intake and risk of open-angle glaucoma: the Rotterdam Study. Eur J Epidemiol 2012, 27, 385-393, http://doi.org/10.1007/ s10654-012-9672-z.

151. Asregadoo, E.R. Blood levels of thiamine and ascorbic acid in chronic open-angle glaucoma. Ann Ophthalmol 1979, 11, 1095-1100.

152. Cumurcu, T.; Sahin, S.; Aydin, E. Serum homocysteine, vitamin B 12 and folic acid levels in different types of glaucoma. BMC Ophthalmol 2006, 6, 6, http://doi. org/10.1186/1471-2415-6-6.

153. Franken, D.G.; Blom, H.J.; Boers, G.H.; Tangerman, A.; Thomas, C.M.; Trijbels, FJ. Thiamine (vitamin B1) supplementation does not reduce fasting blood homocysteine concentration in most homozygotes for homocystinuria. Biochim. Biophys. Acta 1996, 1317, 101-104, http://doi.org/10.1016/s0925-4439(96)00033-6.

154. Navneet, S.; Zhao, J.; Wang, J.; Mysona, B.; Barwick, S.; Ammal Kaidery, N.; Saul, A.; Kaddour-Djebbar, I.; Bollag, W.B.; Thomas, B.; et al. Hyperhomocysteinemiainduced death of retinal ganglion cells: The role of Müller glial cells and Nrf2. Redox Biol 2019, 24, http://doi.org/10.1016/j.redox.2019.101199.

155. Roedl, J.B.; Bleich, S.; Reulbach, U.; von Ahsen, N.; Schlötzer-Schrehardt, U.; Rejdak, R.; Naumann, G.O.H.; Kruse, F.E.; Kornhuber, J.; Jünemann, A.G.M. Homocysteine levels in aqueous humor and plasma of patients with primary open-angle glaucoma. J Neural Transm (Vienna) 2007, 114, 445-450, http://doi.org/10.1007/s00702-0060556-9.

156. Xu, F.; Zhang, L.; Li, M. Plasma homocysteine, serum folic acid, serum vitamin B12, serum vitamin B6, MTHFR and risk of pseudoexfoliation glaucoma: a meta-analysis. Graefes Arch. Clin. Exp. Ophthalmol. 2012, 250, 1067-1074, http://doi.org/10.1007/ s00417-011-1877-4.

157. Roedl, J.B.; Bleich, S.; Reulbach, U.; Rejdak, R.; Naumann, G.O.H.; Kruse, F.E.; Schlötzer-Schrehardt, U.; Kornhuber, J.; Jünemann, A.G.M. Vitamin deficiency and hyperhomocysteinemia in pseudoexfoliation glaucoma. J Neural Transm (Vienna) 2007, 114, 571-575, http://doi.org/10.1007/s00702-006-0598-z.

158. Kang, J.H.; Loomis, S.J.; Wiggs, J.L.; Willett, W.C.; Pasquale, L.R. A prospective study of folate, vitamin B6 and vitamin B12 in relation to exfoliation glaucoma or exfoliation glaucoma suspect. JAMA Ophthalmol 2014, 132, 549-559, http://doi. org/10.1001/jamaophthalmol.2014.100.

159. Moores, J. Vitamin C: a wound healing perspective. Br J Community Nurs 2013 , Suppl, S6, S8-11, http://doi.org/10.12968/bjcn.2013.18.sup12.s6.

160. Knepper, P.A.; Goossens, W; Hvizd, E, Palmberg, P.F. Glycosaminoglycans of the human trabecular meshwork in primary open-angle glaucoma. Invest Ophthalmol Vis Sci 1996, Jun;37(7):1360-7.

161. Schachtschabel, D.O.; Binninger, E. Stimulatory effects of ascorbic acid on hyaluronic acid synthesis of in vitro cultured normal and glaucomatous trabecular meshwork cells of the human eye. Z Gerontol 1993, 26, 243-246.

162. Wang, S.Y.; Singh, K.; Lin, S.C. Glaucoma and vitamins A, C, and E supplement intake and serum levels in a population-based sample of the United States. Eye 2013, 27, 487-494, http://doi.org/10.1038/eye.2013.10

163. Giaconi, J.A.; Yu, F.; Stone, K.L.; Pedula, K.L.; Ensrud, K.E.; Cauley, J.A.; Hochberg, M.C.; Coleman, A.L.; Study of Osteoporotic Fractures Research Group The association of consumption of fruits/vegetables with decreased risk of glaucoma among older African-American women in the study of osteoporotic fractures. Am. J. Ophthalmol. 2012, 154, 635-644, http://doi.org/10.1016/j.ajo.2012.03.048.

164. Yuki, K.; Murat, D.; Kimura, I.; Ohtake, Y.; Tsubota, K. Reduced-serum vitamin C and increased uric acid levels in normal-tension glaucoma. Graefes Arch. Clin. Exp. Ophthalmol. 2010, 248, 243-248, http://doi.org/10.1007/s00417-009-1183-6.

165. Xu, P.; Lin, Y.; Porter, K.; Liton, P.B. Ascorbic acid modulation of iron homeostasis and lysosomal function in trabecular meshwork cells. J Ocul Pharmacol Ther 2014, 30, 246-253, http://doi.org/10.1089/jop.2013.0183.

166. Traber, M.G.; Atkinson, J. Vitamin E, Antioxidant and Nothing More. Free Radic Biol Med 2007, 43, 4-15, http://doi.org/10.1016/j.freeradbiomed.2007.03.024.

167. López-Riquelme, N.; Villalba, C.; Tormo, C.; Belmonte, A.; Fernandez, C.; Torralba, G.; Hernández, F. Endothelin-1 levels and biomarkers of oxidative stress in glaucoma patients. Int Ophthalmol 2015, 35, 527-532, http://doi.org/10.1007/s10792-014-9979-8.
168. Goyal, A.; Srivastava, A.; Sihota, R.; Kaur, J. Evaluation of oxidative stress markers in aqueous humor of primary open angle glaucoma and primary angle closure glaucoma patients. Curr. Eye Res. 2014, 39, 823-829, http://doi.org/10.3109/02713 683.2011 .556299 .

169. Hossein-nezhad, A.; Holick, M.F. Vitamin D for health: a global perspective. Mayo Clin. Proc. 2013, 88, 720-755, http://doi.org/10.1016/j.mayocp.2013.05.011.

170. Dalan, R.; Liew, H.; Tan, W.K.A.; Chew, D.E.K.; Leow, M.K.-S. Vitamin D and the endothelium: basic, translational and clinical research updates. IJC Metabolic \& Endocrine 2014, 4, 4-17, http://doi.org/10.1016/j.ijcme.2014.06.003.

171. Goncalves, A.; Milea, D.; Gohier, P.; Jallet, G.; Leruez, S.; Baskaran, M.; Aung, T.; Annweiler, C. Serum vitamin D status is associated with the presence but not the severity of primary open angle glaucoma. Maturitas 2015, 81, 470-474, http://doi. org/10.1016/j.maturitas.2015.05.008.

172. Kim, H.T.; Kim, J.M.; Kim, J.H.; Lee, M.Y.; Won, Y.S.; Lee, J.Y.; Park, K.H. The Relationship between Vitamin D and Glaucoma: A Kangbuk Samsung Health Study. Korean J Ophthalmol 2016, 30, 426-433, http://doi.org/10.3341/kjo.2016.30.6.426.

173. Burgess, L.G.; Uppal, K.; Walker, D.I.; Roberson, R.M.; Tran, V.; Parks, M.B.; Wade, E.A.; May, A.T.; Umfress, A.C.; Jarrell, K.L.; et al. Metabolome-Wide Association Study of Primary Open Angle Glaucoma. Invest. Ophthalmol. Vis. Sci. 2015, 56, 5020-5028, http://doi.org/10.1167/iovs.15-16702.

174. Lv, Y.; Yao, Q.; Ma, W.; Liu, H.; Ji, J.; Li, X. Associations of vitamin D deficiency and vitamin D receptor (Cdx-2, Fok I, Bsm I and Taq I) polymorphisms with the risk of primary open-angle glaucoma. BMC Ophthalmol 2016, 16, http://doi.org/10.1186/ s12886-016-0289-y.

175. Vuković Arar, Ž.; Knežević Praveček, M.; Miškić, B.; Vatavuk, Z.; Vuković Rodriguez, J.; Sekelj, S. Association Between Serum Vitamin D Level and Glaucoma in Women. Acta Clin Croat 2016, 55, 203-208, http://doi.org/10.20471/acc.2016.55.02.04.

176. Craig, J.P.; Nichols, K.K.; Akpek, E.K.; Caffery, B.; Dua, H.S.; Joo, C.-K.; Liu, Z.; Nelson, J.D.; Nichols, J.J.; Tsubota, K.; et al. TFOS DEWS II Definition and Classification Report. The Ocular Surface 2017, 15, 276-283, http://doi.org/10.1016/j. jtos.2017.05.008

177. Rand, A.L.; Asbell, P.A. Nutritional supplements for dry eye syndrome. Curr Opin Ophthalmol 2011, 22, 279-282, http://doi.org/10.1097/ICU.0b013e3283477d23.

178. Askari, G.; Rafie, N.; Miraghajani, M.; Heidari, Z.; Arab, A. Association between vitamin $D$ and dry eye disease: A systematic review and meta-analysis of observational studies. Cont Lens Anterior Eye 2020, http://doi.org/10.1016/j.clae.2020.03.001.

179. Prietl, B.; Treiber, G.; Pieber, T.R.; Amrein, K. Vitamin D and Immune Function. Nutrients 2013, 5, 2502-2521, http://doi.org/10.3390/nu5072502.

180. Reins, R.Y.; McDermott, A.M. Vitamin D: Implications for ocular disease and therapeutic potential. Exp. Eye Res. 2015, 134, 101-110, http://doi.org/10.1016/j. exer.2015.02.019.

181. Sheppard, J.D.J.; Singh, R.; McClellan, A.J.; Weikert, M.P.; Scoper, S.V.; Joly, T.J.; Whitley, W.O.; Kakkar, E.; Pflugfelder, S.C. Long-term Supplementation With n-6 and n-3 PUFAs Improves Moderate-to-Severe Keratoconjunctivitis Sicca: A Randomized Double-Blind Clinical Trial. Cornea 2013, 32, 1297-1304, http://doi. org/10.1097/ICO.0b013e318299549c

182. Yildirim, P.; Garip, Y.; Karci, A.A.; Guler, T. Dry eye in vitamin D deficiency: more than an incidental association. Int J Rheum Dis 2016, 19, 49-54, http://doi. org/10.1111/1756-185X.12727.

183. Yoon, S.Y.; Bae, S.H.; Shin, Y.J.; Park, S.G.; Hwang, S.-H.; Hyon, J.Y.; Wee, W.R. Low Serum 25-Hydroxyvitamin D Levels Are Associated with Dry Eye Syndrome. PLoS ONE 2016, 11, e0147847, http://doi.org/10.1371/journal.pone.0147847.

184. Al Mahmood, A.M.; Al-Swailem, S.A. Essential fatty acids in the treatment of dry eye syndrome: A myth or reality? Saudi J Ophthalmol 2014, 28, 195-197, http://doi. org/10.1016/j.sjopt.2014.06.004.

185. Roncone, M.; Bartlett, H.; Eperjesi, F. Essential fatty acids for dry eye: A review. Contact Lens and Anterior Eye 2010, 33, 49-54, http://doi.org/10.1016/j. clae.2009.11.002

186. Swanson, D.; Block, R.; Mousa, S.A. Omega-3 Fatty Acids EPA and DHA: Health Benefits Throughout Life. Adv Nutr 2012, 3, 1-7, http://doi.org/10.3945/ an.111.000893

187. Saini, R.K.; Keum, Y.-S. Omega- 3 and omega- 6 polyunsaturated fatty acids: Dietary sources, metabolism, and significance - A review. Life Sci. 2018, 203, 255-267, http:// doi.org/10.1016/j.lfs.2018.04.049. 
188. Miljanović, B.; Trivedi, K.A.; Dana, R.M.; Gilbard, J.P.; Buring, J.E.; Schaumberg, D.A. The relationship between dietary n-3 and n-6 fatty acids and clinically diagnosed dry eye syndrome in women. Am J Clin Nutr 2005, 82, 887-893.

189. Zhu, W.; Wu, Y.; Li, G.; Wang, J.; Li, X. Efficacy of polyunsaturated fatty acids for dry eye syndrome: a meta-analysis of randomized controlled trials. Nutr. Rev. 2014, 72, 662-671, http://doi.org/10.1111/nure.12145.

190. Liu, A.; Ji, J. Omega-3 Essential Fatty Acids Therapy for Dry Eye Syndrome: A MetaAnalysis of Randomized Controlled Studies. Med Sci Monit 2014, 20, 1583-1589, http://doi.org/10.12659/MSM.891364

191. Chan, T.C.Y.; Chow, S.S.W.; Wan, K.H.N.; Yuen, H.K.L. Update on the association between dry eye disease and meibomian gland dysfunction. Hong Kong Med J 2019, 25, 38-47, http://doi.org/10.12809/hkmj187331.

192. Chhadva, P.; Goldhardt, R.; Galor, A. Meibomian Gland Disease: The Role of Gland Dysfunction in Dry Eye Disease. Ophthalmology 2017, 124, S20-S26, http://doi. org/10.1016/j.ophtha.2017.05.031.

193. Driver, P.J.; Lemp, M.A. Meibomian gland dysfunction. Surv Ophthalmol 1996, 40, 343-367, http://doi.org/10.1016/s0039-6257(96)80064-6.

194. Schnebelen, C.; Viau, S.; Grégoire, S.; Joffre, C.; Creuzot-Garcher, C.P.; Bron, A.M.; Bretillon, L.; Acar, N. Nutrition for the eye: different susceptibility of the retina and the lacrimal gland to dietary omega- 6 and omega- 3 polyunsaturated fatty acid incorporation. Ophthalmic Res. 2009, 41, 216-224, http://doi.org/10.1159/000217726.

195. Schnebelen, C.; Fourgeux, C.; Pasquis, B.; Creuzot-Garcher, C.P.; Bron, A.M.; Bretillon, L.; Acar, N. Dietary polyunsaturated fatty acids reduce retinal stress induced by an elevation of intraocular pressure in rats. Nutr Res 2011, 31, 286-295, http://doi.org/10.1016/j.nutres.2011.03.011.

196. Viau, S.; Maire, M.-A.; Pasquis, B.; Grégoire, S.; Acar, N.; Bron, A.M.; Bretillon, L.; Creuzot-Garcher, C.P.; Joffre, C. Efficacy of a 2-month dietary supplementation with polyunsaturated fatty acids in dry eye induced by scopolamine in a rat model. Graefes Arch. Clin. Exp. Ophthalmol. 2009, 247, 1039-1050, http://doi.org/10.1007/s00417009-1080-z.

197. Wojtowicz, J.; Butovich, I.; Uchiyama, E.; Aronowicz, J.; Agee, S.; McCulley, J. Pilot, Prospective, Randomized, Double-masked, Placebo-controlled Clinical Trial of an Omega-3 Supplement for Dry Eye. Cornea 2011, 30, 308-314, http://doi.org/10.1097/ ICO.0b013e3181f22e03.

198. Ziemanski, J.F.; Wolters, L.R.; Jones-Jordan, L.; Nichols, J.J.; Nichols, K.K. Relation Between Dietary Essential Fatty Acid Intake and Dry Eye Disease and Meibomian Gland Dysfunction in Postmenopausal Women. Am. J. Ophthalmol. 2018, 189, 2940, http://doi.org/10.1016/j.ajo.2018.01.004.

199. Potvin, R.; Makari, S.; Rapuano, C.J. Tear film osmolarity and dry eye disease: a review of the literature. Clin Ophthalmol 2015, 9, 2039-2047, http://doi.org/10.2147/ OPTH.S95242.

200. Larmo, P.S.; Järvinen, R.L.; Setälä, N.L.; Yang, B.; Viitanen, M.H.; Engblom, J.R.K.; Tahvonen, R.L.; Kallio, H.P. Oral sea buckthorn oil attenuates tear film osmolarity and symptoms in individuals with dry eye. J. Nutr. 2010, 140, 1462-1468, http://doi. org/10.3945/jn.109.118901.

201. Deinema, L.A.; Vingrys, A.J;; Wong, C.Y.; Jackson, D.C.; Chinnery, H.R.; Downie, L.E. A Randomized, Double-Masked, Placebo-Controlled Clinical Trial of Two Forms of Omega-3 Supplements for Treating Dry Eye Disease. Ophthalmology 2017, 124, 43-52, http://doi.org/10.1016/j.ophtha.2016.09.023.

202. Kokke, K.H.; Morris, J.A.; Lawrenson, J.G. Oral omega- 6 essential fatty acid treatment in contact lens associated dry eye. Cont Lens Anterior Eye 2008, 31, 141-146; quiz 170, http://doi.org/10.1016/j.clae.2007.12.001.

203. Oleñik, A. Effectiveness and tolerability of dietary supplementation with a combination of omega-3 polyunsaturated fatty acids and antioxidants in the treatment of dry eye symptoms: results of a prospective study. Clin Ophthalmol 2014, 8, 169-176, http://doi.org/10.2147/OPTH.S54658.

204. Bhargava, R.; Kumar, P.; Kumar, M.; Mehra, N.; Mishra, A. A randomized controlled trial of omega-3 fatty acids in dry eye syndrome. Int J Ophthalmol 2013, 6, 811-816, http://doi.org/10.3980/j.issn.2222-3959.2013.06.13.

205. Kangari, H.; Eftekhari, M.H.; Sardari, S.; Hashemi, H.; Salamzadeh, J.; GhassemiBroumand, M.; Khabazkhoob, M. Short-term consumption of oral omega-3 and dry eye syndrome. Ophthalmology 2013, 120, 2191-2196, http://doi.org/10.1016/j. ophtha.2013.04.006.
206. Bhargava, R.; Kumar, P.; Phogat, H.; Kaur, A.; Kumar, M. Oral omega-3 fatty acids treatment in computer vision syndrome related dry eye. Cont Lens Anterior Eye 2015, 38, 206-210, http://doi.org/10.1016/j.clae.2015.01.007.

207. Baudouin, C.; Irkeç, M.; Messmer, E.M.; Benítez-del-Castillo, J.M.; Bonini, S. Figueiredo, F.C.; Geerling, G.; Labetoulle, M.; Lemp, M.; Rolando, M.; et al. Clinical impact of inflammation in dry eye disease: proceedings of the ODISSEY group meeting. Acta Ophthalmol 2018, 96, 111-119, http://doi.org/10.1111/aos.13436.

208. Hessen, M.; Akpek, E.K. Dry Eye: an Inflammatory Ocular Disease. J Ophthalmic Vis Res 2014, 9, 240-250.

209. Calder, P.C. Polyunsaturated fatty acids, inflammation, and immunity. Lipids 2001 36, 1007-1024, http://doi.org/10.1007/s11745-001-0812-7.

210. Rashid, S.; Jin, Y.; Ecoiffier, T.; Barabino, S.; Schaumberg, D.A.; Dana, M.R. Topical omega-3 and omega-6 fatty acids for treatment of dry eye. Arch. Ophthalmol. 2008 126, 219-225, http://doi.org/10.1001/archophthalmol.2007.61.

211. Barabino, S.; Rolando, M.; Camicione, P.; Ravera, G.; Zanardi, S.; Giuffrida, S.; Calabria, G. Systemic linoleic and gamma-linolenic acid therapy in dry eye syndrome with an inflammatory component. Cornea 2003, 22, 97-101, http://doi. org/10.1097/00003226-200303000-00002.

212. Pinazo-Durán, M.D.; Galbis-Estrada, C.; Pons-Vázquez, S.; Cantú-Dibildox, J.; Marco-Ramírez, C.; Benítez-del-Castillo, J. Effects of a nutraceutical formulation based on the combination of antioxidants and \&omega;-3 essential fatty acids in the expression of inflammation and immune response mediators in tears from patients with dry eye disorders Available online: https://www.dovepress.com/effects-of-anutraceutical-formulation-based-on-the-combination-of-ant-peer-reviewed-articleCIA (accessed on Apr 8, 2020).

213. Brignole-Baudouin, F.; Baudouin, C.; Aragona, P.; Rolando, M.; Labetoulle, M.; Pisella, P.J.; Barabino, S.; Siou-Mermet, R.; Creuzot-Garcher, C. A multicentre, doublemasked, randomized, controlled trial assessing the effect of oral supplementation of omega- 3 and omega- 6 fatty acids on a conjunctival inflammatory marker in dry eye patients. Acta Ophthalmologica 2011, 89, e591-e597, http://doi.org/10.1111/j.17553768.2011.02196.x.

214. Ricciotti, E.; FitzGerald, G.A. Prostaglandins and Inflammation. Arterioscler Thromb Vasc Biol 2011, 31, 986-1000, http://doi.org/10.1161/ATVBAHA.110.207449.

215. Lekhanont, K.; Sathianvichitr, K.; Pisitpayat, P.; Anothaisintawee, T.; Soontrapa, K.; Udomsubpayakul, U. Association between the levels of prostaglandin E2 in tears and severity of dry eye. Int J Ophthalmol 2019, 12, 1127-1133, http://doi.org/10.18240/ ijo.2019.07.12.

216. Shim, J.; Park, C.; Lee, H.S.; Park, M.S.; Lim, H.T.; Chauhan, S.; Dana, R.; Lee, H.; Lee, H.K. Change in prostaglandin expression levels and synthesizing activities in dry eye disease. Ophthalmology 2012, 119, 2211-2219, http://doi.org/10.1016/j. ophtha.2012.05.038.

217. Wu, D.; Meydani, M.; Leka, L.S.; Nightingale, Z.; Handelman, G.J.; Blumberg, J.B.; Meydani, S.N. Effect of dietary supplementation with black currant seed oil on the immune response of healthy elderly subjects. Am. J. Clin. Nutr. 1999, 70, 536-543, http://doi.org/10.1093/ajen/70.4.536.

218. Tincani, A.; Andreoli, L.; Cavazzana, I.; Doria, A.; Favero, M.; Fenini, M.-G.; Franceschini, F.; Lojacono, A.; Nascimbeni, G.; Santoro, A.; et al. Novel aspects of Sjögren's syndrome in 2012. BMC Medicine 2013, 11, 93, http://doi.org/10.1186/17417015-11-93.

219. Cermak, J.M.; Papas, A.S.; Sullivan, R.M.; Dana, M.R.; Sullivan, D.A. Nutrient intake in women with primary and secondary Sjögren's syndrome. Eur J Clin Nutr 2003, 57, 328-334, http://doi.org/10.1038/sj.ejcn.1601543.

220. Aragona, P.; Bucolo, C.; Spinella, R.; Giuffrida, S.; Ferreri, G. Systemic omega-6 essential fatty acid treatment and pge1 tear content in Sjögren's syndrome patients. Invest. Ophthalmol. Vis. Sci. 2005, 46, 4474-4479, http://doi.org/10.1167/iovs.041394

221. de Paiva, C.S.; Pflugfelder, S.C.; Ng, S.M.; Akpek, E.K. Topical cyclosporine A therapy for dry eye syndrome. Cochrane Database Syst Rev 2019, 9, CD010051, http://doi. org/10.1002/14651858.CD010051.pub2.

222. Oliveira, R.C. de; Wilson, S.E. $<\mathrm{p}>$ Practical guidance for the use of cyclosporine ophthalmic solutions in the management of dry eye disease $</ \mathrm{p}>$ Available online https://www.dovepress.com/practical-guidance-for-the-use-of-cyclosporineophthalmic-solutions-in-peer-reviewed-fulltext-article-OPTH (accessed on Apr 15, 2020). 
223. Jackson, M.A.; Burrell, K.; Gaddie, I.B.; Richardson, S.D. Efficacy of a new prescription-only medical food supplement in alleviating signs and symptoms of dry eye, with or without concomitant cyclosporine A Available online: https://www. dovepress.com/efficacy-of-a-new-prescription-only-medical-food-supplement-inallevia-peer-reviewed-article-OPTH (accessed on Apr 8, 2020).

224. Bhargava, R.; Chandra, M.; Bansal, U.; Singh, D.; Ranjan, S.; Sharma, S. A Randomized Controlled Trial of Omega 3 Fatty Acids in Rosacea Patients with Dry Eye Symptoms. Curr. Eye Res. 2016, 41, 1274-1280, http://doi.org/10.3109/02713683.2015.1122810.

225. Demirci, G.; Karaman Erdur, S.; Ozsutcu, M.; Eliacik, M.; Olmuscelik, O.; Aydin, R.; Kocabora, M.S. Dry Eye Assessment in Patients With Vitamin D Deficiency. Eye Contact Lens 2018, 44 Suppl 1, S62-S65, http://doi.org/10.1097/ ICL.0000000000000325.

226. Meng, B.; LI, S.-M.; Yang, Y.; Yang, Z.-R.; Sun, F.; Kang, M.-T.; Sun, Y.-Y.; Ran, A.-R.; Wang, J.-N.; Yan, R.; et al. The association of TGFB1 genetic polymorphisms with high myopia: a systematic review and meta-analysis. Int J Clin Exp Med 2015, 8, 20355-20367.

227. Kurtul, B.E.; Özer, P.A.; Aydinli, M.S. The association of vitamin D deficiency with tear break-up time and Schirmer testing in non-Sjögren dry eye. Eye (Lond) 2015, 29, 1081-1084, http://doi.org/10.1038/eye.2015.96.

228. Lee, J.H.; Kim, S.J.; Byun, Y.-S.; Lee, J.; Park, S.-H.; Chung, S.-H. The Association of Serum Vitamin D Level With the Severity of Dry Eye Parameters in Primary Sjögren Syndrome. Cornea 2019, http://doi.org/10.1097/ICO.0000000000002234.

229. Jin, K.W.; Ro, J.W.; Shin, Y.J.; Hyon, J.Y.; Wee, W.R.; Park, S.G. Correlation of vitamin D levels with tear film stability and secretion in patients with dry eye syndrome. Acta Ophthalmol 2017, 95, e230-e235, http://doi.org/10.1111/aos.13241.

230. Dikci, S.; Akatll, A.N.; Yıldırım, T. Conjunctival impression cytology and tearfilm changes in cases with vitamin D deficiency. Int Ophthalmol 2020, http://doi. org/10.1007/s10792-020-01336-1

231. Augustin, A.J.; Spitznas, M.; Kaviani, N.; Meller, D.; Koch, F.H.; Grus, F.; Göbbels, M.J. Oxidative reactions in the tear fluid of patients suffering from dry eyes. Graefes Arch. Clin. Exp. Ophthalmol. 1995, 233, 694-698, http://doi.org/10.1007/bf00164671.

232. Eksioglu, U.; Atilgan, H.I.; Yakin, M.; Yazihan, N.; Altiparmak, U.E.; Yumusak, N.; Korkmaz, M.; Demir, A.; Ornek, F.; Aribal Ayral, P.; et al. Antioxidant effects of vitamin $\mathrm{D}$ on lacrimal glands against high dose radioiodine-associated damage in an animal model. Cutan Ocul Toxicol 2019, 38, 18-24, http://doi.org/10.1080/1556 9527.2018.1498507

233. Dang, S.-T.; Lu, X.-H.; Zhou, J.; Bai, L. [Effects of 1alpha, 25-dihydroxyvitamin D3 on the acute immune rejection and corneal neovascularization in high-risk penetrating keratoplasty in rats]. Di Yi Jun Yi Da Xue Xue Bao 2004, 24, 892-896, 903.

234. Suzuki, T.; Sano, Y.; Kinoshita, S. Effects of 1a,25-Dihydroxyvitamin D3 on Langerhans Cell Migration and Corneal Neovascularization in Mice. Invest. Ophthalmol. Vis. Sci. 2000, 41, 154-158.

235. Reins, R.Y.; Mesmar, F.; Williams, C.; McDermott, A.M. Vitamin D Induces Global Gene Transcription in Human Corneal Epithelial Cells: Implications for Corneal Inflammation. Invest Ophthalmol Vis Sci 2016, 57, 2689-2698, http://doi. org/10.1167/iovs.16-19237.

236. Reins, R.Y.; Baidouri, H.; McDermott, A.M. Vitamin D Activation and Function in Human Corneal Epithelial Cells During TLR-Induced Inflammation. Invest Ophthalmol Vis Sci 2015, 56, 7715-7727, http://doi.org/10.1167/iovs.15-17768.

237. Lin, H.; Li, W.; Dong, N.; Chen, W.; Liu, J.; Chen, L.; Yuan, H.; Geng, Z.; Liu, Z. Changes in Corneal Epithelial Layer Inflammatory Cells in Aqueous Tear-Deficient Dry Eye. Invest. Ophthalmol. Vis. Sci. 2010, 51, 122-128, http://doi.org/10.1167/ iovs.09-3629.

238. Niu, L.; Zhang, S.; Wu, J.; Chen, L.; Wang, Y. Upregulation of NLRP3 Inflammasome in the Tears and Ocular Surface of Dry Eye Patients. PLoS One 2015, 10, http://doi. org/10.1371/journal.pone.0126277.

239. Zheng, Q.; Tan, Q.; Ren, Y.; Reinach, P.S.; Li, L.; Ge, C.; Qu, J.; Chen, W. Hyperosmotic Stress-Induced TRPM2 Channel Activation Stimulates NLRP3 Inflammasome Activity in Primary Human Corneal Epithelial Cells. Invest. Ophthalmol. Vis. Sci. 2018, 59, 3259-3268, http://doi.org/10.1167/iovs.18-23965.

240. Dai, Y.; Zhang, J.; Xiang, J.; Li, Y.; Wu, D.; Xu, J. Calcitriol inhibits ROS-NLRP3IL-1 $\beta$ signaling axis via activation of Nrf2-antioxidant signaling in hyperosmotic stress stimulated human corneal epithelial cells. Redox Biol 2018, 21, http://doi. org/10.1016/j.redox.2018.101093.
241. Shetty, R.; Sethu, S.; Chevour, P.; Deshpande, K.; Pahuja, N.; Nagaraja, H.; Pindipapanahalli, N.; Ghosh, A. Lower Vitamin D Level and Distinct Tear Cytokine Profile Were Observed in Patients with Mild Dry Eye Signs but Exaggerated Symptoms. Transl Vis Sci Technol 2016, 5, http://doi.org/10.1167/tvst.5.6.16.

242. Khamar, P.; Nair, A.P.; Shetty, R.; Vaidya, T.; Subramani, M.; Ponnalagu, M.; Dhamodaran, K.; D'souza, S.; Ghosh, A.; Pahuja, N.; et al. Dysregulated Tear Fluid Nociception-Associated Factors, Corneal Dendritic Cell Density, and Vitamin D Levels in Evaporative Dry Eye. Invest. Ophthalmol. Vis. Sci. 2019, 60, 2532-2542, http://doi.org/10.1167/iovs.19-26914.

243. Singman, E.L.; Poon, D.; Jun, A.S. Putative Corneal Neuralgia Responding to Vitamin D Supplementation. Case Rep Ophthalmol 2013, 4, 105-108, http://doi. org $/ 10.1159 / 000354965$

244. Ngo, W.; Srinivasan, S.; Houtman, D.; Jones, L. The relief of dry eye signs and symptoms using a combination of lubricants, lid hygiene and ocular nutraceuticals. J Optom 2017, 10, 26-33, http://doi.org/10.1016/j.optom.2016.05.001.

245. Rolando, M.; Autori, S.; Badino, F.; Barabino, S. Protecting the ocular surface and improving the quality of life of dry eye patients: a study of the efficacy of an HP-guar containing ocular lubricant in a population of dry eye patients. J Ocul Pharmacol Ther 2009, 25, 271-278, http://doi.org/10.1089/jop.2008.0026.

246. Pflugfelder, S.C.; de Paiva, C.S. The pathophysiology of dry eye disease: What we know and future directions for research. Ophthalmology 2017, 124, S4-S13, http:// doi.org/10.1016/j.ophtha.2017.07.010

247. Hwang, J.S.; Lee, Y.P.; Shin, Y.J. Vitamin D Enhances the Efficacy of Topical Artificial Tears in Patients With Dry Eye Disease. Cornea 2019, 38, 304-310, http://doi. org/10.1097/ICO.0000000000001822.

248. Faustino, J.F.; Ribeiro-Silva, A.; Dalto, R.F.; Souza, M.M. de; Furtado, J.M.F.; Rocha, G. de M.; Alves, M.; Rocha, E.M.; Faustino, J.F.; Ribeiro-Silva, A.; et al. Vitamin A and the eye: an old tale for modern times. Arquivos Brasileiros de Oftalmologia 2016, 79, 56-61, http://doi.org/10.5935/0004-2749.20160018.

249. Gilbert, C. The eye signs of vitamin A deficiency. Community Eye Health 2013, 26, 66-67.

250. Lanska, D.J. Vitamin A-Deficiency Eye Disease Among Soldiers in the U.S. Civil War: Spectrum of Clinical Disease. Mil Med 2015, 180, 774-779, http://doi.org/10.7205/ MILMED-D-14-00642.

251. Tanumihardjo, S.A. Vitamin A: biomarkers of nutrition for development. Am. J. Clin. Nutr. 2011, 94, 658S-65S, http://doi.org/10.3945/ajcn.110.005777.

252. Wässle, H.; Boycott, B.B. Functional architecture of the mammalian retina. Physiol. Rev. 1991, 71, 447-480, http://doi.org/10.1152/physrev.1991.71.2.447.

253. Reddy, V. HYPOVITAMINOSIS A. In Encyclopedia of Food Sciences and Nutrition (Second Edition); Caballero, B., Ed.; Academic Press: Oxford, 2003; pp. 3212-3219 ISBN 978-0-12-227055-0.

254. Underwood, B.A. Hypovitaminosis A and its control. Bull World Health Organ 1978, $56,525-541$

255. Smith, J.; Steinemann, T.L. Vitamin A Deficiency and the Eye. International Ophthalmology Clinics 2000, 40, 83-91.

256. Dua, H.S.; Gomes, J.A.; Singh, A. Corneal epithelial wound healing. Br J Ophthalmol 1994, 78, 401-408.

257. Li, B.; Sheng, M.; Li, J.; Yan, G.; Lin, A.; Li, M.; Wang, W.; Chen, Y. Tear proteomic analysis of Sjögren syndrome patients with dry eye syndrome by two-dimensionalnano-liquid chromatography coupled with tandem mass spectrometry. Sci Rep 2014, 4, http://doi.org/10.1038/srep05772.

258. Zhang, W.; Li, W.; Zhang, C.; Zhu, C.; Yi, X.; Zhou, Y.; Lv, Y. Effects of Vitamin A on Expressions of Apoptosis Genes Bax and Bcl-2 in Epithelial Cells of Corneal Tissues Induced by Benzalkonium Chloride in Mice with Dry Eye. Med. Sci. Monit. 2019, 25, 4583-4589, http://doi.org/10.12659/MSM.913478

259. Alanazi, S.A.; El-Hiti, G.A.; Al-Baloud, A.A.; Alfarhan, M.I.; Al-Shahrani, A.; Albakri, A.A.; Alqahtani, S.; Masmali, A.M. Effects of short-term oral vitamin A supplementation on the ocular tear film in patients with dry eye. Clin Ophthalmol 2019, 13, 599-604, http://doi.org/10.2147/OPTH.S198349.

260. Rusciano, D.; Pezzino, S.; Olivieri, M.; Cristaldi, M.; Gagliano, C.; Lupo, G.; Anfuso, C.D. Age-Related Dry Eye Lactoferrin and Lactobionic Acid. Ophthalmic Res. 2018, 60, 94-99, http://doi.org/10.1159/000489093. 
261. Giansanti, F.; Panella, G.; Leboffe, L.; Antonini, G. Lactoferrin from Milk: Nutraceutical and Pharmacological Properties. Pharmaceuticals (Basel) 2016, 9, http://doi.org/10.3390/ph9040061.

262. Janssen, P.T.; van Bijsterveld, O.P. A simple test for lacrimal gland function: a tear lactoferrin assay by radial immunodiffusion. Graefe's Arch Clin Exp Ophthalmol 1983, 220, 171-174, http://doi.org/10.1007/BF02186663.

263. Willcox, M.D.; Morris, C.A.; Thakur, A.; Sack, R.A.; Wickson, J.; Boey, W. Complement and complement regulatory proteins in human tears. Invest. Ophthalmol. Vis. Sci. 1997, 38, 1-8.

264. McGill, J.I.; Liakos, G.M.; Goulding, N.; Seal, D.V. Normal tear protein profiles and age-related changes. Br J Ophthalmol 1984, 68, 316-320.

265. Danjo, Y.; Lee, M.; Horimoto, K.; Hamano, T. Ocular surface damage and tear lactoferrin in dry eye syndrome. Acta Ophthalmol (Copenh) 1994, 72, 433-437, http://doi.org/10.1111/j.1755-3768.1994.tb02791.x.

266. Mt, K.; Pc, F.; Tl, C.; A, C.; Yh, L.; Yt, H.; Cy, T. Tear Proteomics Approach to Monitoring Sjögren Syndrome or Dry Eye Disease. Int J Mol Sci 2019, 20, http://doi. org/10.3390/ijms20081932.

267. Sonobe, H.; Ogawa, Y.; Yamada, K.; Shimizu, E.; Uchino, Y.; Kamoi, M.; Saijo, Y.; Yamane, M.; Citterio, D.; Suzuki, K.; et al. A novel and innovative paper-based analytical device for assessing tear lactoferrin of dry eye patients. Ocul Surf 2019, 17, 160-166, http://doi.org/10.1016/j.jtos.2018.11.001

268. Yanwei, L.; Wei, Z.; Yu, Z. The relationship between dry eye and lactoferrin levels in tears. Asian Biomedicine 2012, 6, 81-85, http://doi.org/10.5372/1905-7415.0601.130.

269. Shimmura, S.; Shimoyama, M.; Hojo, M.; Urayama, K.; Tsubota, K. Reoxygenation injury in a cultured corneal epithelial cell line protected by the uptake of lactoferrin. INVEST.OPHTHAL.VISUAL SCI 1998, 39, 1346-1351.

270. Fujihara, T.; Nagano, T.; Nakamura, M.; Shirasawa, E. Lactoferrin suppresses loss of corneal epithelial integrity in a rabbit short-term dry eye model. J Ocul Pharmacol Ther 1998, 14, 99-107, http://doi.org/10.1089/jop.1998.14.99.

271. Dogru, M.; Matsumoto, Y.; Yamamoto, Y.; Goto, E.; Saiki, M.; Shimazaki, J.; Takebayashi, T.; Tsubota, K. Lactoferrin in Sjögren's syndrome. Ophthalmology 2007, 114, 2366-2367, http://doi.org/10.1016/j.ophtha.2007.06.027.

272. Kawashima, M.; Kawakita, T.; Inaba, T.; Okada, N.; Ito, M.; Shimmura, S.; Watanabe, M.; Shinmura, K.; Tsubota, K. Dietary Lactoferrin Alleviates Age-Related Lacrimal Gland Dysfunction in Mice. PLOS ONE 2012, 7, e33148, http://doi.org/10.1371/ journal.pone.0033148.

273. Devendra, J.; Singh, S. Effect of Oral Lactoferrin on Cataract Surgery Induced Dry Eye: A Randomised Controlled Trial. J Clin Diagn Res 2015, 9, NC06-NC09, http:// doi.org/10.7860/JCDR/2015/15797.6670

274. Higuchi, A.; Inoue, H.; Kaneko, Y.; Oonishi, E.; Tsubota, K. Selenium-binding lactoferrin is taken into corneal epithelial cells by a receptor and prevents corneal damage in dry eye model animals. Sci Rep 2016, 6, 36903, http://doi.org/10.1038/ srep36903.

275. Olivieri, M.; Cristaldi, M.; Pezzino, S.; Lupo, G.; Anfuso, C.; Gagliano, C.; Genovese, C.; Rusciano, D. Experimental Evidence of the Healing Properties of Lactobionic Acid for Ocular Surface Disease. Cornea 2018, 37, 1058-1063, http://doi.org/10.1097/ ICO.0000000000001594.

276. Bröer, S.; Bröer, A. Amino acid homeostasis and signalling in mammalian cells and organisms. Biochem J 2017, 474, 1935-1963, http://doi.org/10.1042/BCJ20160822.

277. Wu, G. Amino acids: metabolism, functions, and nutrition. Amino Acids 2009, 37, 1-17, http://doi.org/10.1007/s00726-009-0269-0.

278. Rusciano, D.; Roszkowska, A.M.; Gagliano, C.; Pezzino, S. Free amino acids: an innovative treatment for ocular surface disease. Eur. J. Pharmacol. 2016, 787, 9-19, http://doi.org/10.1016/j.ejphar.2016.04.029.

279. ChenZhuo, L.; Murube, J.; Latorre, A.; del Río, R.M. Different concentrations of amino acids in tears of normal and human dry eyes. Adv. Exp. Med. Biol. 2002, 506, 617-621.

280. Nakatsukasa, M.; Sotozono, C.; Shimbo, K.; Ono, N.; Miyano, H.; Okano, A.; Hamuro, J.; Kinoshita, S. Amino Acid profiles in human tear fluids analyzed by high-performance liquid chromatography and electrospray ionization tandem mass spectrometry. Am. J. Ophthalmol. 2011, 151, 799-808.e1, http://doi.org/10.1016/j. ajo.2010.11.003.
281. ChenZhuo, L.; Murube, J.; Latorre, A.; del Río, R.M. Different concentrations of amino acids in tears of normal and human dry eyes. Adv. Exp. Med. Biol. 2002, 506, 617-621, http://doi.org/10.1007/978-1-4615-0717-8_87.

282. Calder, P.C. Branched-Chain Amino Acids and Immunity. J Nutr 2006, 136 , 288S-293S, http://doi.org/10.1093/jn/136.1.288S.

283. Cruzat, V.F.; Krause, M.; Newsholme, P. Amino acid supplementation and impact on immune function in the context of exercise. J Int Soc Sports Nutr 2014, 11, http://doi. org/10.1186/s12970-014-0061-8

284. McGaha, T.L.; Huang, L.; Lemos, H.; Metz, R.; Mautino, M.; Prendergast, G.C.; Mellor A.L. Amino acid catabolism: a pivotal regulator of innate and adaptive immunity. Immunol Rev 2012, 249, 135-157, http://doi.org/10.1111/j.1600-065X.2012.01149.x.

285. Efron, D.; Barbul, A. Role of arginine in immunonutrition. J. Gastroenterol. 2000, 35 Suppl 12, 20-23.

286. Jones, C.; Palmer, T.E.; Griffiths, R.D. Randomized clinical outcome study of critically ill patients given glutamine-supplemented enteral nutrition. Nutrition 1999, 15, 108115

287. Lacey, J.M.; Wilmore, D.W. Is glutamine a conditionally essential amino acid? Nutr. Rev. 1990, 48, 297-309.

288. Houdijk, A.P.; Rijnsburger, E.R.; Jansen, J.; Wesdorp, R.I.; Weiss, J.K.; McCamish, M.A.; Teerlink, T.; Meuwissen, S.G.; Haarman, H.J.; Thijs, L.G.; et al. Randomised trial of glutamine-enriched enteral nutrition on infectious morbidity in patients with multiple trauma. Lancet 1998, 352, 772-776, http://doi.org/10.1016/S01406736(98)02007-8.

289. Bollhalder, L.; Pfeil, A.M.; Tomonaga, Y.; Schwenkglenks, M. A systematic literature review and meta-analysis of randomized clinical trials of parenteral glutamine supplementation. Clin Nutr 2013, 32, 213-223, http://doi.org/10.1016/j. clnu.2012.11.003.

290. Atkinson, M.; Worthley, L.I.G. Nutrition in the critically ill patient: part I. Essential physiology and pathophysiology. Crit Care Resusc 2003, 5, 109-120.

291. Platell, C.; Kong, S.E.; McCauley, R.; Hall, J.C. Branched-chain amino acids. J. Gastroenterol. Hepatol. 2000, 15, 706-717.

292. De Bandt, J.-P.; Cynober, L. Therapeutic use of branched-chain amino acids in burn, trauma, and sepsis. J. Nutr. 2006, 136, 308S-13S

293. Nie, C.; He, T.; Zhang, W.; Zhang, G.; Ma, X. Branched Chain Amino Acids: Beyond Nutrition Metabolism. Int J Mol Sci 2018, 19, http://doi.org/10.3390/ijms19040954.

294. Lee, J.H.; Park, E.; Jin, H.J.; Lee, Y.; Choi, S.J.; Lee, G.W.; Chang, P.-S.; Paik, H.-D. Anti-inflammatory and anti-genotoxic activity of branched chain amino acids (BCAA) in lipopolysaccharide (LPS) stimulated RAW 264.7 macrophages. Food Sci. Biotechnol. 2017, 26, 1371-1377, http://doi.org/10.1007/s10068-017-0165-4.

295. Dunn-Lewis, C.; Kraemer, W.J.; Kupchak, B.R.; Kelly, N.A.; Creighton, B.A.; Luk, H.Y.; Ballard, K.D.; Comstock, B.A.; Szivak, T.K.; Hooper, D.R.; et al. A multi-nutrient supplement reduced markers of inflammation and improved physical performance in active individuals of middle to older age: a randomized, double-blind, placebocontrolled study. Nutr J 2011, 10, 90, http://doi.org/10.1186/1475-2891-10-90.

296. Kohlhaas, M. Corneal sensation after cataract and refractive surgery. J Cataract Refract Surg 1998, 24, 1399-1409.

297. Cho, Y.K.; Kim, M.S. Dry eye after cataract surgery and associated intraoperative risk factors. Korean J Ophthalmol 2009, 23, 65-73, http://doi.org/10.3341/ kjo.2009.23.2.65.

298. Han, K.E.; Yoon, S.C.; Ahn, J.M.; Nam, S.M.; Stulting, R.D.; Kim, E.K.; Seo, K.Y Evaluation of dry eye and meibomian gland dysfunction after cataract surgery. Am. J. Ophthalmol. 2014, 157, 1144-1150.e1, http://doi.org/10.1016/j.ajo.2014.02.036.

299. Li, X.-M.; Hu, L.; Hu, J.; Wang, W. Investigation of dry eye disease and analysis of the pathogenic factors in patients after cataract surgery. Cornea 2007, 26, S16-20, http:// doi.org/10.1097/ICO.0b013e31812f67ca.

300. Vinciguerra, P.; Camesasca, F.I.; Ponzin, D. Use of amino acids in refractive surgery. J Refract Surg 2002, 18, S374-377.

301. Torres Munoz, I.; Grizzi, F.; Russo, C.; Camesasca, F.I.; Dioguardi, N.; Vinciguerra, P. The role of amino acids in corneal stromal healing: a method for evaluating cellular density and extracellular matrix distribution. J Refract Surg 2003, 19, S227-230. 
302. Meduri, A.; Grenga, P.L.; Scorolli, L.; Ceruti, P.; Ferreri, G. Role of cysteine in corneal wound healing after photorefractive keratectomy. Ophthalmic Res. 2009, 41, 76-82, http://doi.org/10.1159/000187623.

303. Aragona, P.; Rania, L.; Roszkowska, A.M.; Spinella, R.; Postorino, E.; Puzzolo, D.; Micali, A. Effects of amino acids enriched tears substitutes on the cornea of patients with dysfunctional tear syndrome. Acta Ophthalmol 2013, 91, e437-444, http://doi. org/10.1111/aos.12134

304. Funke, S.; Azimi, D.; Wolters, D.; Grus, F.H.; Pfeiffer, N. Longitudinal analysis of taurine induced effects on the tear proteome of contact lens wearers and dry eye patients using a RP-RP-Capillary-HPLC-MALDI TOF/TOF MS approach. J Proteomics 2012, 75, 3177-3190, http://doi.org/10.1016/j.jprot.2012.03.018.

305. Grus, F.H.; Kramann, C.; Bozkurt, N.; Wiegel, N.; Bruns, K.; Lackner, N.; Pfeiffer, $\mathrm{N}$. Effects of multipurpose contact lens solutions on the protein composition of the tear film. Cont Lens Anterior Eye 2005, 28, 103-112, http://doi.org/10.1016/j. clae.2005.06.004

306. Bucolo, C.; Fidilio, A.; Platania, C.B.M.; Geraci, F.; Lazzara, F.; Drago, F. Antioxidant and Osmoprotecting Activity of Taurine in Dry Eye Models. J Ocul Pharmacol Ther 2018, 34, 188-194, http://doi.org/10.1089/jop.2017.0008.

307. Koyama, I.; Nakamori, K.; Nagahama, T.; Ogasawara, M.; Nemoto, M. The reactivity of taurine with hypochlorous acid and its application for eye drops. Adv. Exp. Med. Biol. 1996, 403, 9-18.

308. Varma, S.D.; Devamanoharan, P.S.; Ali, A.H.; Brozetti, J.; Petrali, J.; Lehnert, E. Weir, A. Half mustard (CEES) induced damage to rabbit cornea: attenuating effect of taurine-pyruvate-alpha-ketoglutarate-pantothenate mixture. J Ocul Pharmacol Ther $1998,14,423-428$

309. Bonanno, J.A.; Polse, K.A. Corneal acidosis during contact lens wear: effects of hypoxia and CO2. Invest. Ophthalmol. Vis. Sci. 1987, 28, 1514-1520.

310. Nakada, T.; Hida, K.; Kwee, I.L. pH-lactate dissociation during anoxic insult: taurine effect. Neuroreport 1991, 2, 325-328.

311. Gardiner, T.A.; Archer, D.B.; Curtis, T.M.; Stitt, A.W. Arteriolar Involvement in the Microvascular Lesions of Diabetic Retinopathy: Implications for Pathogenesis. Microcirculation 2007, 14, 25-38, http://doi.org/10.1080/10739680601072123.

312. Feenstra, D.J.; Drawnel, F.M.; Jayagopal, A. Imaging of Hypoxia in Retinal Vascular Disease. Early Events in Diabetic Retinopathy and Intervention Strategies 2018, http://doi.org/10.5772/intechopen.72252.

313. Sayin, N.; Kara, N.; Pekel, G. Ocular complications of diabetes mellitus. World J Diabetes 2015, 6, 92-108, http://doi.org/10.4239/wjd.v6.i1.92.

314. Whitehead, M.; Wickremasinghe, S.; Osborne, A.; Van Wijngaarden, P.; Martin, K.R. Diabetic retinopathy: a complex pathophysiology requiring novel therapeutic strategies. Expert Opin Biol Ther 2018, 18, 1257-1270, http://doi.org/10.1080/1471 2598.2018.1545836.

315. Semeraro, F.; Morescalchi, F.; Cancarini, A.; Russo, A.; Rezzola, S.; Costagliola, C. Diabetic retinopathy, a vascular and inflammatory disease: Therapeutic implications. Diabetes \& Metabolism 2019, 45, 517-527, http://doi.org/10.1016/j. diabet.2019.04.002

316. Robles-Rivera, R.R.; Castellanos-González, J.A.; Olvera-Montaño, C.; Flores-Martin, R.A.; López-Contreras, A.K.; Arevalo-Simental, D.E.; Cardona-Muñoz, E.G.; Roman-Pintos, L.M.; Rodríguez-Carrizalez, A.D. Adjuvant Therapies in Diabetic Retinopathy as an Early Approach to Delay Its Progression: The Importance of Oxidative Stress and Inflammation. Oxid Med Cell Longev 2020, 2020, 30964703096470, http://doi.org/10.1155/2020/3096470.

317. Oguntibeju, O.O. Type 2 diabetes mellitus, oxidative stress and inflammation: examining the links. Int J Physiol Pathophysiol Pharmacol 2019, 11, 45-63.

318. Kowluru, R.A.; Kowluru, A.; Mishra, M.; Kumar, B. Oxidative stress and epigenetic modifications in the pathogenesis of diabetic retinopathy. Prog Retin Eye Res 2015, 48, 40-61, http://doi.org/10.1016/j.preteyeres.2015.05.001.

319. Schlotterer, A.; Kolibabka, M.; Lin, J.; Acunman, K.; Dietrich, N.; Sticht, C.; Fleming, T.; Nawroth, P.; Hammes, H.-P. Methylglyoxal induces retinopathy-type lesions in the absence of hyperglycemia: studies in a rat model. FASEB J. 2019, 33, 4141-4153, http://doi.org/10.1096/f.201801146RR.

320. Zhong, Q.; Mishra, M.; Kowluru, R.A. Transcription factor Nrf2-mediated antioxidant defense system in the development of diabetic retinopathy. Invest Ophthalmol Vis Sci 2013, 54, 3941-3948, http://doi.org/10.1167/iovs.13-11598.
321. Kowluru, R.A.; Chan, P.-S. Oxidative stress and diabetic retinopathy. Exp Diabetes Res 2007, 2007, 43603-43603, http://doi.org/10.1155/2007/43603.

322. Kaštelan, S.; Tomić, M.; Gverović Antunica, A.; Salopek Rabatić, J.; Ljubić, S Inflammation and pharmacological treatment in diabetic retinopathy. Mediators Inflamm 2013, 2013, 213130-213130, http://doi.org/10.1155/2013/213130.

323. Curtis, T.M.; Gardiner, T.A.; Stitt, A.W. Microvascular lesions of diabetic retinopathy: clues towards understanding pathogenesis? Eye 2009, 23, 1496-1508, http://doi. org/10.1038/eye.2009.108.

324. Rossino, M.G.; Casini, G. Nutraceuticals for the Treatment of Diabetic Retinopathy. Nutrients 2019, 11, 771, http://doi.org/10.3390/nu11040771.

325. Wong, M.Y.Z.; Man, R.E.K.; Fenwick, E.K.; Gupta, P.; Li, L.-J.; van Dam, R.M.; Chong, M.F.; Lamoureux, E.L. Dietary intake and diabetic retinopathy: A systematic review. PLoS One 2018, 13, e0186582-e0186582, http://doi.org/10.1371/journal. pone. 0186582 .

326. Orwell, G. Introduction: Standards of Medical Care in Diabetes-2018. Dia Care 2018, 41, S1-S2, http://doi.org/10.2337/dc18-Sint01.

327. Pall, M.L.; Levine, S. Nrf2, a master regulator of detoxification and also antioxidant, anti-inflammatory and other cytoprotective mechanisms, is raised by health promoting factors. Sheng Li Xue Bao 2015, 67, 1-18.

328. Tikhonenko, M.; Lydic, T.A.; Wang, Y.; Chen, W.; Opreanu, M.; Sochacki, A.; McSorley, K.M.; Renis, R.L.; Kern, T.; Jump, D.B.; et al. Remodeling of retinal Fatty acids in an animal model of diabetes: a decrease in long-chain polyunsaturated fatty acids is associated with a decrease in fatty acid elongases Elovl2 and Elovl4. Diabetes 2010, 59, 219-227, http://doi.org/10.2337/db09-0728.

329. Gong, Y.; Fu, Z.; Liegl, R.; Chen, J.; Hellström, A.; Smith, L.E. $\omega$-3 and $\omega-6$ long-chain PUFAs and their enzymatic metabolites in neovascular eye diseases. Am J Clin Nutr 2017, 106, 16-26, http://doi.org/10.3945/ajcn.117.153825.

330. Connor, K.M.; SanGiovanni, J.P.; Lofqvist, C.; Aderman, C.M.; Chen, J.; Higuchi, A.; Hong, S.; Pravda, E.A.; Majchrzak, S.; Carper, D.; et al. Increased dietary intake of omega-3-polyunsaturated fatty acids reduces pathological retinal angiogenesis. Nat Med 2007, 13, 868-873, http://doi.org/10.1038/nm1591.

331. Aiello, L.P.; Pierce, E.A.; Foley, E.D.; Takagi, H.; Chen, H.; Riddle, L.; Ferrara, N.; King, G.L.; Smith, L.E. Suppression of retinal neovascularization in vivo by inhibition of vascular endothelial growth factor (VEGF) using soluble VEGF-receptor chimeric proteins. Proc Natl Acad Sci U S A 1995, 92, 10457-10461, http://doi.org/10.1073/ pnas.92.23.10457.

332. Lepretti, M.; Martucciello, S.; Burgos Aceves, M.A.; Putti, R.; Lionetti, L. Omega-3 Fatty Acids and Insulin Resistance: Focus on the Regulation of Mitochondria and Endoplasmic Reticulum Stress. Nutrients 2018, 10, 350, http://doi.org/10.3390/ nu10030350.

333. Bungau, S.; Abdel-Daim, M.M.; Tit, D.M.; Ghanem, E.; Sato, S.; Maruyama-Inoue, M.; Yamane, S.; Kadonosono, K. Health Benefits of Polyphenols and Carotenoids in Age-Related Eye Diseases. Oxid Med Cell Longev 2019, 2019, 9783429-9783429, http://doi.org/10.1155/2019/9783429.

334. Fang, J. Bioavailability of anthocyanins. Drug Metabolism Reviews 2014, 46, 508-520, http://doi.org/10.3109/03602532.2014.978080.

335. Kalt, W.; Blumberg, J.B.; McDonald, J.E.; Vinqvist-Tymchuk, M.R.; Fillmore, S.A.E.; Graf, B.A.; O'Leary, J.M.; Milbury, P.E. Identification of Anthocyanins in the Liver, Eye, and Brain of Blueberry-Fed Pigs. Journal of Agricultural and Food Chemistry 2008, 56, 705-712, http://doi.org/10.1021/jf071998l.

336. Paik, S.-S.; Jeong, E.; Jung, S.W.; Ha, T.J.; Kang, S.; Sim, S.; Jeon, J.H.; Chun, M.H.; Kim, I.-B. Anthocyanins from the seed coat of black soybean reduce retinal degeneration induced by N-methyl-N-nitrosourea. Experimental Eye Research 2012, 97, 55-62, http://doi.org/10.1016/j.exer.2012.02.010.

337. Song, Y.; Huang, L.; Yu, J. Effects of blueberry anthocyanins on retinal oxidative stress and inflammation in diabetes through Nrf2/HO-1 signaling. Journal of Neuroimmunology 2016, 301, 1-6, http://doi.org/10.1016/j.jneuroim.2016.11.001.

338. Wang, H.; Nair, M.G.; Strasburg, G.M.; Chang, Y.-C.; Booren, A.M.; Gray, J.I.; DeWitt, D.L. Antioxidant and Antiinflammatory Activities of Anthocyanins and Their Aglycon, Cyanidin, from Tart Cherries. Journal of Natural Products 1999, 62, 294-296, http://doi.org/10.1021/np980501m. 
339. Lee, M.; Yun, S.; Lee, H.; Yang, J. Quercetin Mitigates Inflammatory Responses Induced by Vascular Endothelial Growth Factor in Mouse Retinal Photoreceptor Cells through Suppression of Nuclear Factor Kappa B. Int J Mol Sci 2017, 18, 2497, http://doi.org/10.3390/ijms18112497.

340. Kumar, B.; Gupta, S.K.; Nag, T.C.; Srivastava, S.; Saxena, R.; Jha, K.A.; Srinivasan, B.P. Retinal neuroprotective effects of quercetin in streptozotocin-induced diabetic rats. Experimental Eye Research 2014, 125, 193-202, http://doi.org/10.1016/j. exer.2014.06.009.

341. Li, J.; Yu, S.; Ying, J.; Shi, T.; Wang, P. Resveratrol Prevents ROS-Induced Apoptosis in High Glucose-Treated Retinal Capillary Endothelial Cells via the Activation of AMPK/Sirt1/PGC-1a Pathway. Oxid Med Cell Longev 2017, 2017, 7584691-7584691, http://doi.org/10.1155/2017/7584691.

342. Chang, Y.-C.; Lin, C.-W.; Hsieh, M.-C.; Wu, H.-J.; Wu, W.-S.; Wu, W.-C.; Kao, Y.-H. High mobility group B1 up-regulates angiogenic and fibrogenic factors in human retinal pigment epithelial ARPE-19 cells. Cellular Signalling 2017, 40, 248-257, http://doi.org/10.1016/j.cellsig.2017.09.019.

343. Losso, J.N.; Truax, R.E.; Richard, G. trans-Resveratrol Inhibits HyperglycemiaInduced Inflammation and Connexin Downregulation in Retinal Pigment Epithelial Cells. Journal of Agricultural and Food Chemistry 2010, 58, 8246-8252, http://doi. org/10.1021/jf1012067.

344. Chen, Y.; Meng, J.; Li, H.; Wei, H.; Bi, F.; Liu, S.; Tang, K.; Guo, H.; Liu, W. Resveratrol exhibits an effect on attenuating retina inflammatory condition and damage of diabetic retinopathy via PON1. Experimental Eye Research 2019, 181, 356-366, http://doi.org/10.1016/j.exer.2018.11.023.

345. Jiménez-Osorio, A.S.; González-Reyes, S.; Pedraza-Chaverri, J. Natural Nrf2 activators in diabetes. Clinica Chimica Acta 2015, 448, 182-192, http://doi. org/10.1016/j.cca.2015.07.009

346. Joint Expert Committee on Food Additives Evaluation of certain food additives and contaminants: eightieth report of the Joint FAO/WHO Expert Committee on Food Additives: Rome, 16-25 June 2015; WHO technical report series; WHO: Geneva, 2016; ISBN 978-92-4-120995-3.

347. Radomska-Leśniewska, D.M.; Osiecka-Iwan, A.; Hyc, A.; Góźdź, A.; Dąbrowska, A.M.; Skopiński, P. Therapeutic potential of curcumin in eye diseases. Cent Eur J Immunol 2019, 44, 181-189, http://doi.org/10.5114/ceji.2019.87070.

348. Platania, C.B.M.; Fidilio, A.; Lazzara, F.; Piazza, C.; Geraci, F.; Giurdanella, G.; Leggio, G.M.; Salomone, S.; Drago, F.; Bucolo, C. Retinal Protection and Distribution of Curcumin in Vitro and in Vivo. Front Pharmacol 2018, 9, 670-670, http://doi. org/10.3389/fphar.2018.00670

349. Premanand, C.; Rema, M.; Sameer, M.Z.; Sujatha, M.; Balasubramanyam, M. Effect of Curcumin on Proliferation of Human Retinal Endothelial Cells under In Vitro Conditions. Investigative Opthalmology \& Visual Science 2006, 47, 2179, http://doi. org/10.1167/iovs.05-0580.

350. Woo, J.M.; Shin, D.-Y.; Lee, S.J.; Joe, Y.; Zheng, M.; Yim, J.H.; Callaway, Z.; Chung, H.T. Curcumin protects retinal pigment epithelial cells against oxidative stress via induction of heme oxygenase- 1 expression and reduction of reactive oxygen. Mol Vis $2012,18,901-908$

351. Li, Y.; Zou, X.; Cao, K.; Xu, J.; Yue, T.; Dai, F.; Zhou, B.; Lu, W.; Feng, Z.; Liu, J. Curcumin analog 1, 5-bis (2-trifluoromethylphenyl)-1, 4-pentadien-3-one exhibits enhanced ability on Nrf2 activation and protection against acrolein-induced ARPE19 cell toxicity. Toxicology and Applied Pharmacology 2013, 272, 726-735, http://doi. org/10.1016/j.taap.2013.07.029

352. Yang, C.; Zhang, X.; Fan, H.; Liu, Y. Curcumin upregulates transcription factor Nrf2, HO-1 expression and protects rat brains against focal ischemia. Brain Research 2009, 1282, 133-141, http://doi.org/10.1016/j.brainres.2009.05.009.

353. Zuo, Z.-F.; Zhang, Q.; Liu, X.-Z. Protective effects of curcumin on retinal Müller cell in early diabetic rats. Int J Ophthalmol 2013, 6, 422-424, http://doi.org/10.3980/j. issn.2222-3959.2013.04.02

354. Gupta, S.K.; Kumar, B.; Nag, T.C.; Agrawal, S.S.; Agrawal, R.; Agrawal, P.; Saxena, R.; Srivastava, S. Curcumin Prevents Experimental Diabetic Retinopathy in Rats Through Its Hypoglycemic, Antioxidant, and Anti-Inflammatory Mechanisms. Journal of Ocular Pharmacology and Therapeutics 2011, 27, 123-130, http://doi. org/10.1089/jop.2010.0123.

355. Kowluru, R.A.; Kanwar, M. Effects of curcumin on retinal oxidative stress and inflammation in diabetes. Nutr Metab (Lond) 2007, 4, 8-8, http://doi. org/10.1186/1743-7075-4-8
356. Bone, R.A.; Landrum, J.T.; Hime, G.W.; Cains, A.; Zamor, J. Stereochemistry of the human macular carotenoids. Invest. Ophthalmol. Vis. Sci. 1993, 34, 2033-2040.

357. Jia, Y.-P.; Sun, L.; Yu, H.-S.; Liang, L.-P.; Li, W.; Ding, H.; Song, X.-B.; Zhang, L.-J. The Pharmacological Effects of Lutein and Zeaxanthin on Visual Disorders and Cognition Diseases. Molecules 2017, 22, 610, http://doi.org/10.3390/molecules22040610.

358. Bone, R.A.; Landrum, J.T.; Tarsis, S.L. Preliminary identification of the human macular pigment. Vision Research 1985, 25, 1531-1535, http://doi.org/10.1016/00426989(85)90123-3.

359. Bone, R.A.; Landrum, J.T.; Fernandez, L.; Tarsis, S.L. Analysis of the macular pigment by HPLC: retinal distribution and age study. Invest. Ophthalmol. Vis. Sci. 1988, 29, 843-849.

360. Kijlstra, A.; Tian, Y.; Kelly, E.R.; Berendschot, T.T.J.M. Lutein: More than just a filter for blue light. Progress in Retinal and Eye Research 2012, 31, 303-315, http://doi. org/10.1016/j.preteyeres.2012.03.002.

361. Zhang, P.-C.; Wu, C.-R.; Wang, Z.-L.; Wang, L.-Y.; Han, Y.; Sun, S.-L.; Li, Q.-S.; $\mathrm{Ma}$, L. Effect of lutein supplementation on visual function in nonproliferative diabetic retinopathy. Asia Pac J Clin Nutr 2017, 26, 406-411, http://doi.org/10.6133/ apjen.032016.13.

362. Kowluru, R.A.; Menon, B.; Gierhart, D.L. Beneficial Effect of Zeaxanthin on Retinal Metabolic Abnormalities in Diabetic Rats. Investigative Opthalmology \& Visual Science 2008, 49, 1645, http://doi.org/10.1167/iovs.07-0764

363. Sasaki, M.; Ozawa, Y.; Kurihara, T.; Kubota, S.; Yuki, K.; Noda, K.; Kobayashi, S. Ishida, S.; Tsubota, K. Neurodegenerative influence of oxidative stress in the retina of a murine model of diabetes. Diabetologia 2010, 53, 971-979, http://doi.org/10.1007/ s00125-009-1655-6.

364. Hu, B.-J.; Hu, Y.-N.; Lin, S.; Ma, W.-J.; Li, X.-R. Application of Lutein and Zeaxanthin in nonproliferative diabetic retinopathy. Int J Ophthalmol 2011, 4, 303-306, http:// doi.org/10.3980/j.issn.2222-3959.2011.03.19.

365. Sila, A.; Ghlissi, Z.; Kamoun, Z.; Makni, M.; Nasri, M.; Bougatef, A.; Sahnoun, Z. Astaxanthin from shrimp by-products ameliorates nephropathy in diabetic rats. European Journal of Nutrition 2014, 54, 301-307, http://doi.org/10.1007/s00394014-0711-2.

366. Yeh, P.-T.; Huang, H.-W.; Yang, C.-M.; Yang, W.-S.; Yang, C.-H. Astaxanthin Inhibits Expression of Retinal Oxidative Stress and Inflammatory Mediators in Streptozotocin-Induced Diabetic Rats. PLoS One 2016, 11, e0146438-e0146438, http://doi.org/10.1371/journal.pone.0146438

367. Zhou, X.; Zhang, F.; Hu, X.; Chen, J.; Wen, X.; Sun, Y.; Liu, Y.; Tang, R.; Zheng, K.; Song, Y. Inhibition of inflammation by astaxanthin alleviates cognition deficits in diabetic mice. Physiology \& Behavior 2015, 151, 412-420, http://doi.org/10.1016/j. physbeh.2015.08.015.

368. Will, J.C.; Byers, T. Does Diabetes Mellitus Increase the Requirement for Vitamin C? Nutrition Reviews 2009, 54, 193-202, http://doi.org/10.1111/j.1753-4887.1996. tb03932.x.

369. Sinclair, A.J.; Girling, A.J.; Gray, L.; Le Guen, C.; Lunec, J.; Barnett, A.H. Disturbed handling of ascorbic acid in diabetic patients with and without microangiopathy during high dose ascorbate supplementation. Diabetologia 1991, 34, 171-175, http:// doi.org/10.1007/bf00418271

370. Park, S.W.; Ghim, W.; Oh, S.; Kim, Y.; Park, U.C.; Kang, J.; Yu, H.G. Association of vitreous vitamin $\mathrm{C}$ depletion with diabetic macular ischemia in proliferative diabetic retinopathy. PLoS One 2019, 14, e0218433-e0218433, http://doi.org/10.1371/journal pone. 0218433

371. Duarte, T.L.; Lunec, J. ReviewPart of the Series: From Dietary Antioxidants to Regulators in Cellular Signalling and Gene ExpressionReview: When is an antioxidant not an antioxidant? A review of novel actions and reactions of vitamin C. Free Radical Research 2005, 39, 671-686, http://doi.org/10.1080/10715760500104025.

372. Sorice, A.; Guerriero, E.; Capone, F.; Colonna, G.; Castello, G.; Costantini, S. Ascorbic Acid: Its Role in Immune System and Chronic Inflammation Diseases. Mini-Reviews in Medicinal Chemistry 2014, 14, 444-452, http://doi.org/10.2174/13895575146661 40428112602 .

373. Wang, H.; Zhang, Z.; Wen, R.; Chen, J. Experimental and clinical studies on the reduction of erythrocyte sorbitol-glucose ratios by ascorbic acid in diabetes mellitus. Diabetes Research and Clinical Practice 1995, 28, 1-8, http://doi.org/10.1016/01688227(95)01059-m 
374. May, J.M.; Jayagopal, A.; Qu, Z.-C.; Parker, W.H. Ascorbic acid prevents high glucoseinduced apoptosis in human brain pericytes. Biochem Biophys Res Commun 2014, 452, 112-117, http://doi.org/10.1016/j.bbrc.2014.08.057.

375. Ulker, E.; Parker, W.H.; Raj, A.; Qu, Z.; May, J.M. Ascorbic acid prevents VEGFinduced increases in endothelial barrier permeability. Mol Cell Biochem 2016, 412, 73-79, http://doi.org/10.1007/s11010-015-2609-6.

376. Gomes, M.B.; Negrato, C.A. Alpha-lipoic acid as a pleiotropic compound with potential therapeutic use in diabetes and other chronic diseases. Diabetol Metab Syndr 2014, 6, 80-80, http://doi.org/10.1186/1758-5996-6-80.

377. Santos, J.M.; Kowluru, R.A. Role of mitochondria biogenesis in the metabolic memory associated with the continued progression of diabetic retinopathy and its regulation by lipoic acid. Invest Ophthalmol Vis Sci 2011, 52, 8791-8798, http://doi. org/10.1167/iovs.11-8203.

378. Lin, J.; Bierhaus, A.; Bugert, P.; Dietrich, N.; Feng, Y.; vom Hagen, F.; Nawroth, P.; Brownlee, M.; Hammes, H.-P. Effect of R-(+)-a-lipoic acid on experimental diabetic retinopathy. Diabetologia 2006, 49, 1089-1096, http://doi.org/10.1007/s00125-0060174-y.

379. Nebbioso, M.; Federici, M.; Rusciano, D.; Evangelista, M.; Pescosolido, N. Oxidative Stress in Preretinopathic Diabetes Subjects and Antioxidants. Diabetes Technology \& Therapeutics 2012, 14, 257-263, http://doi.org/10.1089/dia.2011.0172.

380. Kowluru, R.A.; Zhong, Q.; Santos, J.M.; Thandampallayam, M.; Putt, D.; Gierhart, D.L. Beneficial effects of the nutritional supplements on the development of diabetic retinopathy. Nutr Metab (Lond) 2014, 11, 8-8, http://doi.org/10.1186/1743-7075-118.

381. Waugh, N.; Loveman, E.; Colquitt, J.; Royle, P.; Yeong, J.L.; Hoad, G.; Lois, N. Treatments for dry age-related macular degeneration and Stargardt disease: a systematic review. Health Technol Assess 2018, 22, 1-168, http://doi.org/10.3310/ hta22270.

382. Pawlowska, E.; Szczepanska, J.; Koskela, A.; Kaarniranta, K.; Blasiak, J. Dietary Polyphenols in Age-Related Macular Degeneration: Protection against Oxidative Stress and Beyond. Oxid Med Cell Longev 2019, 2019, 9682318-9682318, http://doi. org/10.1155/2019/9682318.

383. Kauppinen, A.; Paterno, J.J.; Blasiak, J.; Salminen, A.; Kaarniranta, K. Inflammation and its role in age-related macular degeneration. Cell Mol Life Sci 2016, 73, 17651786, http://doi.org/10.1007/s00018-016-2147-8.

384. Wang, L.; Clark, M.E.; Crossman, D.K.; Kojima, K.; Messinger, J.D.; Mobley, J.A.; Curcio, C.A. Abundant lipid and protein components of drusen. PLoS One 2010, 5, e10329-e10329, http://doi.org/10.1371/journal.pone.0010329.

385. Wong, W.L.; Su, X.; Li, X.; Cheung, C.M.G.; Klein, R.; Cheng, C.-Y.; Wong, T.Y. Global prevalence of age-related macular degeneration and disease burden projection for 2020 and 2040: a systematic review and meta-analysis. The Lancet Global Health 2014, 2, e106-e116, http://doi.org/10.1016/s2214-109x(13)70145-1.

386. Sparrow, J.R.; Boulton, M. RPE lipofuscin and its role in retinal pathobiology. Experimental Eye Research 2005, 80, 595-606, http://doi.org/10.1016/j. exer.2005.01.007.

387. Abokyi, S.; To, C.-H.; Lam, T.T.; Tse, D.Y. Central Role of Oxidative Stress in Age-Related Macular Degeneration: Evidence from a Review of the Molecular Mechanisms and Animal Models. Oxid Med Cell Longev 2020, 2020, 79012707901270, http://doi.org/10.1155/2020/7901270.

388. Johnson, L.V.; Leitner, W.P.; Staples, M.K.; Anderson, D.H. Complement Activation and Inflammatory Processes in Drusen Formation and Age Related Macular Degeneration. Experimental Eye Research 2001, 73, 887-896, http://doi.org/10.1006/ exer.2001.1094.

389. Shaw PX, Stiles T, Douglas C, Ho D, Fan W, Du H, Xiao X. Oxidative stress, innate immunity, and age-related macular degeneration. AIMS Mol Sci. 2016, 3:196-221. http://doi.org/10.3934/molsci.2016.2.196.

390. Ho, L.; van Leeuwen, R.; de Jong, P.T.V.M.; Vingerling, J.R.; Klaver, C.C.W. Epidemiology of AMD. Age-related Macular Degeneration 2012, 3-32, http://doi. org/10.1007/978-3-642-22107-1_1.

391. Holz, F.G.; Strauss, E.C.; Schmitz-Valckenberg, S.; van Lookeren Campagne, M. Geographic Atrophy. Ophthalmology 2014, 121, 1079-1091, http://doi.org/10.1016/j. ophtha.2013.11.023.

392. Hanus, J.; Zhao, F.; Wang, S. Current therapeutic developments in atrophic age- related macular degeneration. Br J Ophthalmol 2016, 100, 122-127, http://doi. org/10.1136/bjophthalmol-2015-306972.

393. Brown, E.E.; DeWeerd, A.J.; Ildefonso, C.J.; Lewin, A.S.; Ash, J.D. Mitochondrial oxidative stress in the retinal pigment epithelium (RPE) led to metabolic dysfunction in both the RPE and retinal photoreceptors. Redox Biol 2019, 24, 101201-101201, http://doi.org/10.1016/j.redox.2019.101201.

394. Andreatta, W.; El-Sherbiny, S. Evidence-Based Nutritional Advice for Patients Affected by Age-Related Macular Degeneration. Ophthalmologica 2014, 231, 185190, http://doi.org/10.1159/000357528.

395. Morita, Y.; Miwa, Y.; Jounai, K.; Fujiwara, D.; Kurihara, T.; Kanauchi, O. Lactobacillus paracasei KW3110 Prevents Blue Light-Induced Inflammation and Degeneration in the Retina. Nutrients 2018, 10, 1991, http://doi.org/10.3390/nu10121991.

396. Khoo, H.E.; Ng, H.S.; Yap, W.-S.; Goh, H.J.H.; Yim, H.S. Nutrients for Prevention of Macular Degeneration and Eye-Related Diseases. Antioxidants (Basel) 2019, 8, 85, http://doi.org/10.3390/antiox8040085.

397. A Randomized, Placebo-Controlled, Clinical Trial of High-Dose Supplementation With Vitamins C and E, Beta Carotene, and Zinc for Age-Related Macular Degeneration and Vision Loss: AREDS Report No. 8. Arch Ophthalmol 2001, 119, 1417-1436, http://doi.org/10.1001/archopht.119.10.1417.

398. Lutein + Zeaxanthin and Omega-3 Fatty Acids for Age-Related Macular Degeneration: The Age-Related Eye Disease Study 2 (AREDS2) Randomized Clinical Trial. JAMA 2013, 309, 2005-2015, http://doi.org/10.1001/jama.2013.4997.

399. Carneiro, Â.; Andrade, J.P. Erratum to "Nutritional and Lifestyle Interventions for Age-Related Macular Degeneration: A Review." Oxid Med Cell Longev 2017, 2017, 2435963-2435963, http://doi.org/10.1155/2017/2435963.

400. Khoo, H.E.; Azlan, A.; Tang, S.T.; Lim, S.M. Anthocyanidins and anthocyanins: colored pigments as food, pharmaceutical ingredients, and the potential health benefits. Food Nutr Res 2017, 61, 1361779-1361779, http://doi.org/10.1080/165466 28.2017.1361779.

401. Sin, H.P.Y.; Liu, D.T.L.; Lam, D.S.C. Lifestyle modification, nutritional and vitamins supplements for age-related macular degeneration. Acta Ophthalmologica 2012, 91 , 6-11, http://doi.org/10.1111/j.1755-3768.2011.02357.x.

402. Matsumoto, H.; Nakamura, Y.; Tachibanaki, S.; Kawamura, S.; Hirayama, M. Stimulatory Effect of Cyanidin 3-Glycosides on the Regeneration of Rhodopsin Journal of Agricultural and Food Chemistry 2003, 51, 3560-3563, http://doi. org/10.1021/jf034132y.

403. Wang, Y.; Zhao, L.; Lu, F.; Yang, X.; Deng, Q.; Ji, B.; Huang, F. Retinoprotective Effects of Bilberry Anthocyanins via Antioxidant, Anti-Inflammatory, and AntiApoptotic Mechanisms in a Visible Light-Induced Retinal Degeneration Model in Pigmented Rabbits. Molecules 2015, 20, 22395-22410, http://doi.org/10.3390/ molecules201219785.

404. Silván, J.M.; Reguero, M.; de Pascual-Teresa, S. A protective effect of anthocyanins and xanthophylls on UVB-induced damage in retinal pigment epithelial cells. Food \& Function 2016, 7, 1067-1076, http://doi.org/10.1039/c5fo01368b.

405. Olmedilla-Alonso, B.; Estévez-Santiago, R.; Silván, J.-M.; Sánchez-Prieto, M.; de Pascual-Teresa, S. Effect of Long-Term Xanthophyll and Anthocyanin Supplementation on Lutein and Zeaxanthin Serum Concentrations and Macular Pigment Optical Density in Postmenopausal Women. Nutrients 2018, 10, 959, http:// doi.org/10.3390/nu10080959.

406. Chou, W.-W.; Wang, Y.-S.; Chen, K.-C.; Wu, J.-M.; Liang, C.-L.; Juo, S.-H.H. Tannic acid suppresses ultraviolet B-induced inflammatory signaling and complement factor B on human retinal pigment epithelial cells. Cellular Immunology 2012, 273, 79-84, http://doi.org/10.1016/j.cellimm.2011.11.003.

407. Hytti, M.; Piippo, N.; Salminen, A.; Honkakoski, P.; Kaarniranta, K.; Kauppinen, A. Quercetin alleviates 4-hydroxynonenal-induced cytotoxicity and inflammation in ARPE-19 cells. Experimental Eye Research 2015, 132, 208-215, http://doi. org/10.1016/j.exer.2015.02.001.

408. Kim, J.; Jin, H.L.; Jang, D.S.; Jeong, K.W.; Choung, S.-Y. Quercetin-3-O-a-larabinopyranoside protects against retinal cell death via blue light-induced damage in human RPE cells and Balb-c mice. Food \& Function 2018, 9, 2171-2183, http://doi. org/10.1039/c7fo01958k.

409. Cao, X.; Liu, M.; Tuo, J.; Shen, D.; Chan, C.-C. The effects of quercetin in cultured human RPE cells under oxidative stress and in $\mathrm{Ccl} 2 / \mathrm{Cx} 3 \mathrm{cr} 1$ double deficient mice. Exp Eye Res 2010, 91, 15-25, http://doi.org/10.1016/j.exer.2010.03.016. 
410. Koyama, Y.; Kaidzu, S.; Kim, Y.-C.; Matsuoka, Y.; Ishihara, T.; Ohira, A.; Tanito, M. Suppression of Light-Induced Retinal Degeneration by Quercetin via the AP-1 Pathway in Rats. Antioxidants (Basel) 2019, 8, 79, http://doi.org/10.3390/antiox8040079.

411. López-Malo, D.; Villarón-Casares, C.A.; Alarcón-Jiménez, J.; Miranda, M.; Díaz-Llopis, M.; Romero, F.J.; Villar, V.M. Curcumin as a Therapeutic Option in Retinal Diseases. Antioxidants (Basel) 2020, 9, 48, http://doi.org/10.3390/antiox9010048.

412. Mandal, M.N.A.; Patlolla, J.M.R.; Zheng, L.; Agbaga, M.-P.; Tran, J.-T.A.; Wicker, L.; Kasus-Jacobi, A.; Elliott, M.H.; Rao, C.V.; Anderson, R.E. Curcumin protects retinal cells from light-and oxidant stress-induced cell death. Free Radic Biol Med 2009, 46, 672-679, http://doi.org/10.1016/j.freeradbiomed.2008.12.006

413. Chan, C.-M.; Huang, J.-H.; Lin, H.-H.; Chiang, H.-S.; Chen, B.-H.; Hong, J.-Y.; Hung, C.-F. Protective effects of (-)-epigallocatechin gallate on UVA-induced damage in ARPE19 cells. Mol. Vis. 2008, 14, 2528-2534.

414. Sampath, C.; Zhu, Y.; Sang, S.; Ahmedna, M. Bioactive compounds isolated from apple, tea, and ginger protect against dicarbonyl induced stress in cultured human retinal epithelial cells. Phytomedicine 2016, 23, 200-213, http://doi.org/10.1016/j. phymed.2015.12.013.

415. Chan, C.-M.; Huang, C.-H.; Li, H.-J.; Hsiao, C.-Y.; Su, C.-C.; Lee, P.-L.; Hung, C.-F. Protective effects of resveratrol against UVA-induced damage in ARPE19 cells. Int J Mol Sci 2015, 16, 5789-5802, http://doi.org/10.3390/ijms16035789.

416. Nagai, N.; Kubota, S.; Tsubota, K.; Ozawa, Y. Resveratrol prevents the development of choroidal neovascularization by modulating AMP-activated protein kinase in macrophages and other cell types. J. Nutr. Biochem. 2014, 25, 1218-1225, http://doi. org/10.1016/j.jnutbio.2014.05.015.

417. Subramani, M.; Ponnalagu, M.; Krishna, L.; Jeyabalan, N.; Chevour, P.; Sharma, A.; Jayadev, C.; Shetty, R.; Begum, N.; Archunan, G.; Das, D. Resveratrol reverses the adverse effects of bevacizumab on cultured ARPE-19 cells. Scientific reports 2017, 7(1), 12242, https://doi.org/10.1038/s41598-017-12496-z.

418. Organisciak, D.T.; Darrow, R.M.; Rapp, C.M.; Smuts, J.P.; Armstrong, D.W.; Lang, J.C. Prevention of retinal light damage by zinc oxide combined with rosemary extract. Mol. Vis. 2013, 19, 1433-1445

419. Belmonte, M.A.; Santos, M.F.; Kihara, A.H.; Yan, C.Y.I.; Hamassaki, D.E. LightInduced Photoreceptor Degeneration in the Mouse Involves Activation of the Small GTPase Rac1. Investigative Opthalmology \& Visual Science 2006, 47, 1193, http://doi. org/10.1167/iovs.05-0446.

420. Haruta, M.; Bush, R.A.; Kjellstrom, S.; Vijayasarathy, C.; Zeng, Y.; Le, Y.-Z.; Sieving, P.A. Depleting Racl in mouse rod photoreceptors protects them from photo-oxidative stress without affecting their structure or function. Proc Natl Acad Sci U S A 2009, 106, 9397-9402, http://doi.org/10.1073/pnas.0808940106.

421. Ma, L.; Liu, R.; Du, J.H.; Liu, T.; Wu, S.S.; Liu, X.H. Lutein, Zeaxanthin and Mesozeaxanthin Supplementation Associated with Macular Pigment Optical Density. Nutrients 2016, 8, 426, http://doi.org/10.3390/nu8070426.

422. Bernstein, P.S.; Li, B.; Vachali, P.P.; Gorusupudi, A.; Shyam, R.; Henriksen, B.S. Nolan, J.M. Lutein, zeaxanthin, and meso-zeaxanthin: The basic and clinical science underlying carotenoid-based nutritional interventions against ocular disease. Prog Retin Eye Res 2016, 50, 34-66, http://doi.org/10.1016/j.preteyeres.2015.10.003.

423. Biswal, M.R.; Justis, B.D.; Han, P.; Li, H.; Gierhart, D.; Dorey, C.K.; Lewin, A.S. Daily zeaxanthin supplementation prevents atrophy of the retinal pigment epithelium (RPE) in a mouse model of mitochondrial oxidative stress. PLoS One 2018, 13, e0203816-e0203816, http://doi.org/10.1371/journal.pone.0203816.

424. Hammond, B.R.; Fletcher, L.M.; Roos, F.; Wittwer, J.; Schalch, W. A Double-Blind, Placebo-Controlled Study on the Effects of Lutein and Zeaxanthin on Photostress Recovery, Glare Disability, and Chromatic Contrast. Investigative Ophthalmology \& Visual Science 2014, 55, 8583-8589, http://doi.org/10.1167/iovs.14-15573.

425. Krinsky, N.I.; Landrum, J.T.; Bone, R.A. BIOLOGICMECHANISMS OF THEPROTECTIVEROLE OFLUTEIN ANDZEAXANTHIN IN THEEYE. Annual Review of Nutrition 2003, 23, 171-201, http://doi.org/10.1146/annurev. nutr.23.011702.073307.

426. Thurnham, D.I. Macular zeaxanthins and lutein - a review of dietary sources and bioavailability and some relationships with macular pigment optical density and agerelated macular disease. Nutrition Research Reviews 2007, 20, 163-179, http://doi. org/10.1017/s0954422407842235.

427. de Koning-Backus, A.P.M.; Buitendijk, G.H.S.; Kiefte-de Jong, J.C.; Colijn, J.M.; Hofman, A.; Vingerling, J.R.; Haverkort, E.B.; Franco, O.H.; Klaver, C.C.W. Intake of Vegetables, Fruit, and Fish is Beneficial for Age-Related Macular Degeneration. American Journal of Ophthalmology 2019, 198, 70-79, http://doi.org/10.1016/j. ajo.2018.09.036.

428. Zampatti, S.; Ricci, F.; Cusumano, A.; Marsella, L.T.; Novelli, G.; Giardina, E. Review of nutrient actions on age-related macular degeneration. Nutrition Research 2014, 34, 95-105, http://doi.org/10.1016/j.nutres.2013.10.011

429. Age-Related Eye Disease Study Research Group; SanGiovanni, J.P.; Chew, E.Y.; Clemons, T.E.; Ferris, F.L.; Gensler, G.; Lindblad, A.S.; Milton, R.C.; Seddon, J.M.; Sperduto, R.D. The relationship of dietary carotenoid and vitamin A, E, and C intake with age-related macular degeneration in a case-control study: AREDS Report No. 22 Arch. Ophthalmol. 2007, 125, 1225-1232, http://doi.org/10.1001/archopht.125.9.1225.

430. Robison, W.G.; Kuwabara, T.; Bieri, J.G. The roles of vitamin E and unsaturated fatty acids in the visual process. Retina (Philadelphia, Pa.) 1982, 2, 263-281.

431. Tanito, M.; Yoshida, Y.; Kaidzu, S.; Chen, Z.-H.; Cynshi, O.; Jishage, K.; Niki, E.; Ohira, A. Acceleration of Age-Related Changes in the Retina in $\alpha$-Tocopherol Transfer Protein Null Mice Fed a Vitamin E-Deficient Diet. Investigative Opthalmology \& Visual Science 2007, 48, 396, http://doi.org/10.1167/iovs.06-0872.

432. Katz, M.L.; Eldred, G.E. Failure of vitamin E to protect the retina against damage resulting from bright cyclic light exposure. Invest. Ophthalmol. Vis. Sci. 1989, 30, 2936 .

433. Belda, J.I.; Romá, J.; Vilela, C.; Puertas, F.J.; Di囚az-Llopis, M.; Bosch-Morell, F.; Romero, F.J. Serum vitamin E levels negatively correlate with severity of age-related macular degeneration. Mechanisms of Ageing and Development 1999, 107, 159-164, http://doi. org/10.1016/s0047-6374(98)00144-4.

434. Alsalem, J.A.; Patel, D.; Susarla, R.; Coca-Prados, M.; Bland, R.; Walker, E.A.; Rauz S.; Wallace, G.R. Characterization of vitamin D production by human ocular barrier cells. Invest. Ophthalmol. Vis. Sci. 2014, 55, 2140-2147, http://doi.org/10.1167/iovs.1313019 .

435. Kaarniranta, K.; Pawlowska, E.; Szczepanska, J.; Jablkowska, A.; Błasiak, J. Can vitamin $\mathrm{D}$ protect against age-related macular degeneration or slow its progression? Acta Biochimica Polonica 2019, http://doi.org/10.18388/abp.2018_2810.

436. Ugarte, M.; Osborne, N.N.; Brown, L.A.; Bishop, P.N. Iron, zinc, and copper in retinal physiology and disease. Survey of Ophthalmology 2013, 58, 585-609, http://doi. org/10.1016/j.survophthal.2012.12.002.

437. Arteel, G.E.; Sies H. The biochemistry of selenium and the glutathione system. Environ Toxicol Pharmacol. 2001, 10(4):153-158, http://doi.org/10.1016/s1382-6689(01)00078-3.

438. Erie, J.C.; Good, J.A.; Butz, J.A.; Pulido, J.S. Reduced Zinc and Copper in the Retinal Pigment Epithelium and Choroid in Age-related Macular Degeneration. American Journal of Ophthalmology 2009, 147, 276-282.e1, http://doi.org/10.1016/j. ajo.2008.08.014.

439. Farnsworth, C.C.; Stone, W.L.; Dratz, E.A. Effects of vitamin E and selenium deficiency on the fatty acid composition of rat retinal tissues. Biochimica et Biophysica Acta (BBA) - Biomembranes 1979, 552, 281-293, http://doi.org/10.1016/0005-2736(79)90283-9.

440. Sun, Y.-D.; Dong, Y.-D.; Fan, R.; Zhai, L.-L.; Bai, Y.-L.; Jia, L.-H. Effect of (R)-a-Lipoic Acid Supplementation on Serum Lipids and Antioxidative Ability in Patients with AgeRelated Macular Degeneration. Annals of Nutrition and Metabolism 2012, 60, 293-297, http://doi.org/10.1159/000338444.

441. Tao, Y.; Jiang, P.; Wei, Y.; Wang, P.; Sun, X.; Wang, H. a-Lipoic Acid Treatment Improves Vision-Related Quality of Life in Patients with Dry Age-Related Macular Degeneration. The Tohoku Journal of Experimental Medicine 2016, 240, 209-214, http://doi. org/10.1620/tjem.240.209

442. Querques, G.; Merle, B.M.J.; Pumariega, N.M.; Benlian, P.; Delcourt, C.; Zourdani, A.; Leisy, H.B.; Lee, M.D.; Smith, R.T.; Souied, E.H. Dynamic Drusen Remodelling in Participants of the Nutritional AMD Treatment-2 (NAT-2) Randomized Trial. PLoS One 2016, 11, e0149219-e0149219, http://doi.org/10.1371/journal.pone.0149219.

443. Cammalleri, M.: Dal Monte, M.; Locri, F; Lardner, E.; Kvanta, A.; Rusciano, D; André, H.; Bagnoli, P. Efficacy of a Fatty Acids Dietary Supplement in a Polyethylene GlycolInduced Mouse Model of Retinal Degeneration. Nutrients 2017, 9, 1079, http://doi. org/10.3390/nu9101079.

444. Williams, K.M.; Bertelsen, G.; Cumberland, P.; Wolfram, C.; Verhoeven, V.J.M.; Anastasopoulos, E.; Buitendijk, G.H.S.; Cougnard-Grégoire, A.; Creuzot-Garcher, C.; Erke, M.G.; et al. Increasing Prevalence of Myopia in Europe and the Impact of Education. Ophthalmology 2015, 122, 1489-1497, http://doi.org/10.1016/j. ophtha.2015.03.018. 
445. Flitcroft, D.I.; He, M.; Jonas, J.B.; Jong, M.; Naidoo, K.; Ohno-Matsui, K.; Rahi, J.; Resnikoff, S.; Vitale, S.; Yannuzzi, L. IMI - Defining and Classifying Myopia: A Proposed Set of Standards for Clinical and Epidemiologic Studies. Invest Ophthalmol Vis Sci 2019, 60, M20-M30, http://doi.org/10.1167/iovs.18-25957.

446. Bourne, R.R.A.; Stevens, G.A.; White, R.A.; Smith, J.L.; Flaxman, S.R.; Price, H.; Jonas, J.B.; Keeffe, J.; Leasher, J.; Naidoo, K.; et al. Causes of vision loss worldwide, 19902010: a systematic analysis. The Lancet Global Health 2013, 1, e339-e349, http://doi. org/10.1016/s2214-109x(13)70113-x.

447. Holden, B.A.; Fricke, T.R.; Wilson, D.A.; Jong, M.; Naidoo, K.S.; Sankaridurg, P.; Wong, T.Y.; Naduvilath, T.J.; Resnikoff, S. Global Prevalence of Myopia and High Myopia and Temporal Trends from 2000 through 2050. Ophthalmology 2016, 123, 1036-1042, http://doi.org/10.1016/j.ophtha.2016.01.006.

448. Dolgin, E. The myopia boom. Nature 2015, 519, 276-278, http://doi. org/10.1038/519276a.

449. Wang, Q.; Klein, B.E.; Klein, R.; Moss, S.E. Refractive status in the Beaver Dam Eye Study. Invest. Ophthalmol. Vis. Sci. 1994, 35, 4344-4347.

450. Verhoeven, V.J.M.; Hysi, P.G.; Wojciechowski, R.; Fan, Q.; Guggenheim, J.A.; Höhn, R.; MacGregor, S.; Hewitt, A.W.; Nag, A.; Cheng, C.-Y.; et al. Genome-wide meta-analyses of multi-ethnic cohorts identify multiple new susceptibility loci for refractive error and myopia. Nat Genet 2013, 45, 314-318, http://doi.org/10.1038/ng.2554.

451. Fan, Q.; Barathi, V.A.; Cheng, C.-Y.; Zhou, X.; Meguro, A.; Nakata, I.; Khor, C.-C.; Goh, L.-K.; Li, Y.-J.; Lim, W.; et al. Genetic variants on chromosome 1q41 influence ocular axial length and high myopia. PLoS Genet 2012, 8, e1002753-e1002753, http://doi. org/10.1371/journal.pgen.1002753.

452. Li, J.; Zhang, Q. Insight into the molecular genetics of myopia. Mol Vis 2017, 23, 10481080.

453. Young, F.A.; Leary, G.A.; Baldwin, W.R.; West, D.C.; Box, R.A.; Harris, E.; Johnson, C. THE TRANSMISSION OF REFRACTIVE ERRORS WITHIN ESKIMO FAMILIES. Optometry and Vision Science 1969, 46, 676-685, http://doi.org/10.1097/00006324196909000-00005.

454. Cai, X.-B.; Shen, S.-R.; Chen, D.-F.; Zhang, Q.; Jin, Z.-B. An overview of myopia genetics. Experimental Eye Research 2019, 188, 107778, http://doi.org/10.1016/j. exer.2019.107778

455. Zhang, X.; Qu, X.; Zhou, X. Association between parental myopia and the risk of myopia in a child. Exp Ther Med 2015, 9, 2420-2428, http://doi.org/10.3892/etm.2015.2415.

456. Mutti, D.O.; Mitchell, G.L.; Moeschberger, M.L.; Jones, L.A.; Zadnik, K. Parental myopia, near work, school achievement, and children's refractive error. Invest. Ophthalmol. Vis. Sci. 2002, 43, 3633-3640.

457. Huang, H.-M.; Chang, D.S.-T.; Wu, P.-C. The Association between Near Work Activities and Myopia in Children-A Systematic Review and Meta-Analysis. PLoS One 2015, 10, e0140419-e0140419, http://doi.org/10.1371/journal.pone.0140419.

458. Deng, L.; Pang, Y. Effect of Outdoor Activities in Myopia Control. Optometry and Vision Science 2019, 96, 276-282, http://doi.org/10.1097/opx.0000000000001357.

459. Rose, K.A.; Morgan, I.G.; Ip, J.; Kifley, A.; Huynh, S.; Smith, W.; Mitchell, P. Outdoor Activity Reduces the Prevalence of Myopia in Children. Ophthalmology 2008, 115, 1279-1285, http://doi.org/10.1016/j.ophtha.2007.12.019.

460. Guo, Y.; Liu, L.J.; Tang, P.; Lv, Y.Y.; Feng, Y.; Xu, L.; Jonas, J.B. Outdoor activity and myopia progression in 4-year follow-up of Chinese primary school children: The Beijing Children Eye Study. PLoS One 2017, 12, e0175921-e0175921, http://doi. org/10.1371/journal.pone.0175921.

461. Jin, J.-X.; Hua, W.-J.; Jiang, X.; Wu, X.-Y.; Yang, J.-W.; Gao, G.-P.; Fang, Y.; Pei, C.-L.; Wang, S.; Zhang, J.-Z.; et al. Effect of outdoor activity on myopia onset and progression in school-aged children in northeast China: the Sujiatun Eye Care Study. BMC Ophthalmol 2015, 15, 73-73, http://doi.org/10.1186/s12886-015-0052-9.

462. Zhou, X.; Pardue, M.T.; Iuvone, P.M.; Qu, J. Dopamine signaling and myopia development: What are the key challenges. Prog Retin Eye Res 2017, 61, 60-71, http:// doi.org/10.1016/j.preteyeres.2017.06.003.

463. Feldkaemper, M.; Schaeffel, F. An updated view on the role of dopamine in myopia. Experimental Eye Research 2013, 114, 106-119, http://doi.org/10.1016/j. exer.2013.02.007.

464. Rymer, J.; Wildsoet, C.F. The role of the retinal pigment epithelium in eye growth regulation and myopia: A review. Visual Neuroscience 2005, 22, 251-261, http://doi. org/10.1017/s0952523805223015.
465. Tan, J.; Deng, Z.; Liu, S.; Wang, J.; Huang, C. TGF- $\beta 2$ in Human Retinal Pigment Epithelial Cells: Expression and Secretion Regulated by Cholinergic Signals In Vitro. Current Eye Research 2009, 35, 37-44, http://doi.org/10.3109/02713680903374190.

466. Cristaldi, M.; Olivieri, M.; Pezzino, S.; Spampinato, G.; Lupo, G.; Anfuso, C.D.; Rusciano, D. Atropine Differentially Modulates ECM Production by Ocular Fibroblasts, and Its Ocular Surface Toxicity Is Blunted by Colostrum. Biomedicines 2020, 8, 78, http://doi. org/10.3390/biomedicines8040078.

467. Cooper, J.; Tkatchenko, A.V. A Review of Current Concepts of the Etiology and Treatment of Myopia. Eye Contact Lens 2018, 44, 231-247, http://doi.org/10.1097/ ICL.0000000000000499.

468. Vagge, A.; Ferro Desideri, L.; Nucci, P.; Serafino, M.; Giannaccare, G.; Traverso, C.E. Prevention of Progression in Myopia: A Systematic Review. Diseases 2018, 6, 92, http:// doi.org/10.3390/diseases6040092.

469. Chua, W.-H.; Balakrishnan, V.; Chan, Y.-H.; Tong, L.; Ling, Y.; Quah, B.-L.; Tan, D Atropine for the Treatment of Childhood Myopia. Ophthalmology 2006, 113, 22852291, http://doi.org/10.1016/j.ophtha.2006.05.062.

470. Chia, A.; Chua, W.-H.; Cheung, Y.-B.; Wong, W.-L.; Lingham, A.; Fong, A.; Tan, D. Atropine for the Treatment of Childhood Myopia: Safety and Efficacy of $0.5 \%, 0.1 \%$, and $0.01 \%$ Doses (Atropine for the Treatment of Myopia 2). Ophthalmology 2012, 119, 347-354, http://doi.org/10.1016/j.ophtha.2011.07.031

471. Hodge, W.; Barnes, D.; Schachter, H.M.; Pan, Y.; Lowcock, E.C.; Zhang, L.; Sampson, M.; Morrison, A.; Tran, K.; Miguelez, M.; et al. Effects of Omega-3 Fatty Acids on Eye Health: Summary; Agency for Healthcare Research and Quality (US), 2005;

472. Kim, H.; Seo, J.S.; Yoo, W.-S.; Kim, G.-N.; Kim, R.B.; Chae, J.E.; Chung, I.; Seo, S.-W.; Kim, S.J. Factors associated with myopia in Korean children: Korea National Health and nutrition examination survey 2016-2017 (KNHANES VII). BMC Ophthalmol 2020, 20, 31-31, http://doi.org/10.1186/s12886-020-1316-6.

473. Lim, L.S.; Gazzard, G.; Low, Y.-L.; Choo, R.; Tan, D.T.H.; Tong, L.; Yin Wong, T.; Saw, S.M. Dietary Factors, Myopia, and Axial Dimensions in Children. Ophthalmology 2010, 117, 993-997.e4, http://doi.org/10.1016/j.ophtha.2009.10.003.

474. Jacobsen, N.; Jensen, H.; Lund-Andersen, H.; Goldschmidt, E. Is poor glycaemic control in diabetic patients a risk factor of myopia? Acta Ophthalmologica 2008, 86, 510-514, http://doi.org/10.1111/j.1600-0420.2007.01104.x.

475. Yarbağ, A.; Yazar, H.; Akdoğan, M.; Pekgör, A.; Kaleli, S. Refractive errors in patients with newly diagnosed diabetes mellitus. Pak J Med Sci 2015, 31, 1481-1484, http://doi. org/10.12669/pjms.316.8204

476. Fedor, M.; Socha, K.; Urban, B.; Soroczyńska, J.; Matyskiela, M.; Borawska, M.H.; Bakunowicz-Łazarczyk, A. Serum Concentration of Zinc, Copper, Selenium, Manganese, and $\mathrm{Cu} / \mathrm{Zn}$ Ratio in Children and Adolescents with Myopia. Biol Trace Elem Res 2017, 176, 1-9, http://doi.org/10.1007/s12011-016-0805-1.

477. Burke, N.; Butler, J.S.; Flitcroft, I.; McCartney, D.; Loughman, J. Association of Total Zinc Intake with Myopia in U.S. Children and Adolescents. Optometry and Vision Science 2019, 96, 647-654, http://doi.org/10.1097/opx.0000000000001418.

478. Mutti,D.O.; Marks, A.R. Blood levels of vitamin D in teens and young adults with myopia Optom Vis Sci 2011, 88, 377-382, http://doi.org/10.1097/OPX.0b013e31820b0385.

479. Yazar, S.; Hewitt, A.W.; Black, L.J.; McKnight, C.M.; Mountain, J.A.; Sherwin, J.C.; Oddy, W.H.; Coroneo, M.T.; Lucas, R.M.; Mackey, D.A. Myopia Is Associated With Lower Vitamin D Status in Young Adults. Investigative Opthalmology \& Visual Science 2014, 55, 4552, http://doi.org/10.1167/iovs.14-14589.

480. Tideman, J.W.L.; Polling, J.R.; Voortman, T.; Jaddoe, V.W.V.; Uitterlinden, A.G.; Hofman, A.; Vingerling, J.R.; Franco, O.H.; Klaver, C.C.W. Low serum vitamin D is associated with axial length and risk of myopia in young children. Eur J Epidemiol 2016, 31, 491-499, http://doi.org/10.1007/s10654-016-0128-8.

481. Kwon, J.-W.; Choi, J.A.; La, T.Y.; Epidemiologic Survey Committee of the Korean Ophthalmological Society Serum 25-hydroxyvitamin D level is associated with myopia in the Korea national health and nutrition examination survey. Medicine (Baltimore) 2016, 95, e5012-e5012, http://doi.org/10.1097/MD.0000000000005012.

482. PubChem 7-Methylxanthine Available online: https://pubchem.ncbi.nlm.nih.gov/ compound/68374.

483. Hung, L.-F.; Arumugam, B.; Ostrin, L.; Patel, N.; Trier, K.; Jong, M.; Smith, E.L., III The Adenosine Receptor Antagonist, 7-Methylxanthine, Alters Emmetropizing Responses in Infant Macaques. Invest Ophthalmol Vis Sci 2018, 59, 472-486, http://doi. org/10.1167/iovs.17-22337. 
484. Trier, K.; Olsen, E.B.; Kobayashi, T.; Ribel-Madsen, S.M. Biochemical and ultrastructural changes in rabbit sclera after treatment with 7-methylxanthine, theobromine, acetazolamide, or L-ornithine. Br J Ophthalmol 1999, 83, 1370-1375, http://doi.org/10.1136/bjo.83.12.1370.

485. Trier, K.; Munk Ribel-Madsen, S.; Cui, D.; Brøgger Christensen, S. Systemic 7-methylxanthine in retarding axial eye growth and myopia progression: a 36-month pilot study. J Ocul Biol Dis Infor 2008, 1, 85-93, http://doi.org/10.1007/s12177-008-9013-3.

486. Umigai, N.; Murakami, K.; Ulit, M.V.; Antonio, L.S.; Shirotori, M.; Morikawa, H.; Nakano, T. The pharmacokinetic profile of crocetin in healthy adult human volunteers after a single oral administration. Phytomedicine 2011, 18, 575-578, http://doi. org/10.1016/j.phymed.2010.10.019.

487. G. Gutheil, W.; Reed, G.; Ray, A.; Anant, S.; Dhar, A. Crocetin: an Agent Derived from Saffron for Prevention and Therapy for Cancer. Current Pharmaceutical Biotechnology 2012, 13, 173-179, http://doi.org/10.2174/138920112798868566.

488. Mori, K.; Kurihara, T.; Miyauchi, M.; Ishida, A.; Jiang, X.; Ikeda, S.-I.; Torii, H.; Tsubota, K. Oral crocetin administration suppressed refractive shift and axial elongation in a murine model of lens-induced myopia. Sci Rep 2019, 9, 295-295, http://doi. org/10.1038/s41598-018-36576-w.

489. Mori, K.; Torii, H.; Fujimoto, S.; Jiang, X.; Ikeda, S.-I.; Yotsukura, E.; Koh, S.; Kurihara, T.; Nishida, K.; Tsubota, K. The Effect of Dietary Supplementation of Crocetin for Myopia Control in Children: A Randomized Clinical Trial. J Clin Med 2019, 8, 1179, http://doi.org/10.3390/jcm8081179.

490. Allen D. Cataract. BMJ Clin Evid. 2011;2011:0708. PMID: 21718561.

491. Kaur, J.; Kukreja, S.; Kaur, A.; Malhotra, N.; Kaur, R. The Oxidative Stress in Cataract Patients. J Clin Diagn Res 2012, 6, 1629-1632, http://doi.org/10.7860/ JCDR/2012/4856.2626.

492. Shiels A, Hejtmancik JF. Molecular Genetics of Cataract. Prog Mol Biol Transl Sci. 2015;134:203-218. http://doi.org/10.1016/bs.pmbts.2015.05.004.

493. Christen WG, Glynn RJ, Manson JE, MacFadyen J, Bubes V, Schvartz M, Buring JE, Sesso HD, Gaziano JM. Effects of multivitamin supplement on cataract and age-related macular degeneration in a randomized trial of male physicians. Ophthalmology. 2014;121:525-34. http://doi.org/10.1016/j.ophtha.2013.09.038.

494. Rautiainen S, Lindblad BE, Morgenstern R, Wolk A. Total antioxidant capacity of the diet and risk of age-related cataract: a population-based prospective cohort of women. JAMA Ophthalmol. 2014;132:247-252. http://doi.org/10.1001/ jamaophthalmol.2013.6241.

495. Mares JA, Voland R, Adler R, Tinker L, Millen AE, Moeller SM, Blodi B, Gehrs KM, Wallace RB, Chappell RJ, Neuhouser ML, Sarto GE; CAREDS Group. Healthy diets and the subsequent prevalence of nuclear cataract in women. Arch Ophthalmol. 2010;128:738-49. http://doi.org/10.1001/archophthalmol.2010.84.

496. Tan AG, Mitchell P, Flood VM, Burlutsky G, Rochtchina E, Cumming RG, Wang JJ. Antioxidant nutrient intake and the long-term incidence of age-related cataract: the Blue Mountains Eye Study. Am J Clin Nutr. 2008;87:1899-905. http://doi.org/10.1093/ ajcn/87.6.1899.

497. Moeller SM, Voland R, Tinker L, Blodi BA, Klein ML, Gehrs KM, Johnson EJ, Snodderly DM, Wallace RB, Chappell RJ, Parekh N, Ritenbaugh C, Mares JA; CAREDS Study Group; Women's Health Initiative. Associations between age-related nuclear cataract and lutein and zeaxanthin in the diet and serum in the Carotenoids in the AgeRelated Eye Disease Study, an Ancillary Study of the Women's Health Initiative. Arch Ophthalmol. 2008;126:354-64. http://doi.org/10.1001/archopht.126.3.354.

498. Mathew MC, Ervin AM, Tao J, Davis RM. Antioxidant vitamin supplementation for preventing and slowing the progression of age-related cataract. Cochrane Database Syst Rev. 2012;6:CD004567. http://doi.org/10.1002/14651858.CD004567.pub2

499. Tunis SW, Brownlow R, Schmidt EE. The Post-Vitrectomy Lenstatin ${ }^{\text {Tm }}$ Study: A Randomized Double Blind Human Clinical Trial Testing the Efficacy of Lenstatin, an Oral Antioxidant Nutritional Supplement, in Inhibiting Nuclear Cataract Progression After Pars Plana Vitrectomy. EC Ophthalmology 9.5 (2018): 299-307.

500. Weikel KA, Garber C, Baburins A, Taylor A. Nutritional modulation of cataract. Nutr Rev. 2014;72:30-47. http://doi.org/10.1111/nure.12077.
501. Varma, S.D.; Richards, R.D. Ascorbic acid and the eye lens. Ophthalmic Res. 1988, 20, 164-173, http://doi.org/10.1159/000266579.

502. Varma, S.D.; Srivastava, V.K.; Richards, R.D. Photoperoxidation in lens and cataract formation: preventive role of superoxide dismutase, catalase and vitamin C. Ophthalmic Res. 1982, 14, 167-175, http://doi.org/10.1159/000265189.

503. Lohmann, W., Schmehl, W., \& Strobel, J. (1986). Nuclear cataract: Oxidative damage to the lens. Experimental Eye Research, 43(5), 859-862. http://doi.org/10.1016/s00144835(86)80015-x

504. Taylor, A.; Jacques, P.F.; Nadler, D.; Morrow, F.; Sulsky, S.I.; Shepard, D. Relationship in humans between ascorbic acid consumption and levels of total and reduced ascorbic acid in lens, aqueous humor, and plasma. Curr. Eye Res. 1991, 10, 751-759, http://doi. org/10.3109/02713689109013869.

505. Simon, J.A.; Hudes, E.S. Serum ascorbic acid and other correlates of self-reported cataract among older Americans. J Clin Epidemiol 1999, 52, 1207-1211, http://doi. org/10.1016/s0895-4356(99)00110-9.

506. Jacques, P.F.; Chylack, L.T.; Hankinson, S.E.; Khu, P.M.; Rogers, G.; Friend, J.; Tung W.; Wolfe, J.K.; Padhye, N.; Willett, W.C.; et al. Long-term nutrient intake and early age-related nuclear lens opacities. Arch. Ophthalmol. 2001, 119, 1009-1019, http://doi. org/10.1001/archopht.119.7.1009.

507. Mares-Perlman, J.A.; Lyle, B.J.; Klein, R.; Fisher, A.I.; Brady, W.E.; VandenLangenberg, G.M.; Trabulsi, J.N.; Palta, M. Vitamin Supplement Use and Incident Cataracts in a Population-Based Study. Arch Ophthalmol 2000, 118, 1556-1563, http://doi. org/10.1001/archopht.118.11.1556.

508. Chylack, L.T.; Brown, N.P.; Bron, A.; Hurst, M.; Köpcke, W.; Thien, U.; Schalch, W. The Roche European American Cataract Trial (REACT): a randomized clinical trial to investigate the efficacy of an oral antioxidant micronutrient mixture to slow progression of age-related cataract. Ophthalmic Epidemiol 2002, 9, 49-80, http://doi. org/10.1076/opep.9.1.49.1717.

509. Ravindran, R.D.; Vashist, P.; Gupta, S.K.; Young, I.S.; Maraini, G.; Camparini, M.; Jayanthi, R.; John, N.; Fitzpatrick, K.E.; Chakravarthy, U.; et al. Inverse Association of Vitamin C with Cataract in Older People in India. Ophthalmology 2011, 118, 19581965.e2, http://doi.org/10.1016/j.ophtha.2011.03.016.

510. Yonova-Doing, E.; Forkin, Z.A.; Hysi, P.G.; Williams, K.M.; Spector, T.D.; Gilbert, C.E.; Hammond, C.J. Genetic and Dietary Factors Influencing the Progression of Nuclear Cataract. Ophthalmology 2016, 123, 1237-1244, http://doi.org/10.1016/j. ophtha.2016.01.036.

511. Chasan-Taber L, Willett WC, Seddon JM, Stampfer MJ, Rosner B, Colditz GA, Speizer FE, Hankinson SE. A prospective study of carotenoid and vitamin A intakes and risk of cataract extraction in US women. Am J Clin Nutr. 1999;70:509-16. http://doi. org/10.1093/ajcn/70.4.509.

512. Delcourt C, Carrière I, Delage M, Barberger-Gateau P, Schalch W; POLA Study Group. Plasma lutein and zeaxanthin and other carotenoids as modifiable risk factors for age-related maculopathy and cataract: the POLA Study. Invest Ophthalmol Vis Sci. 2006;47:2329-2335. http://doi.org/10.1167/iovs.05-1235.

513. Vu HT, Robman L, Hodge A, McCarty CA, Taylor HR. Lutein and zeaxanthin and the risk of cataract: the Melbourne visual impairment project. Invest Ophthalmol Vis Sci. 2006;47:3783-3786. http://doi.org/10.1167/iovs.05-0587.

514. Age-Related Eye Disease Study 2 (AREDS2) Research Group, Chew EY, SanGiovanni JP, Ferris FL, Wong WT, Agron E, Clemons TE, Sperduto R, Danis R, Chandra SR, Blodi BA, Domalpally A, Elman MJ, Antoszyk AN, Ruby AJ, Orth D, Bressler SB, Fish GE, Hubbard GB, Klein ML, Friberg TR, Rosenfeld PJ, Toth CA, Bernstein P. Lutein/zeaxanthin for the treatment of age-related cataract: AREDS2 randomized trial report no. 4. JAMA Ophthalmol. 2013 Jul;131(7):843-50. http://doi.org/10.1001/ jamaophthalmol.2013.4412.

515. Sella R, Afshari NA. Nutritional effect on age-related cataract formation and progression. Curr Opin Ophthalmol. 2019;30(1):63-69. http://doi.org/10.1097/ ICU.0000000000000537.

516. Pache M, Flammer J. A sick eye in a sick body? Systemic findings in patients with primary open-angle glaucoma. Surv Ophthalmol. 2006;51:179-212. http://doi. org/10.1016/j.survophthal.2006.02.008

\section{Citation:}

Dario Rusciano, Salvatore Pezzino, Melania Olivieri, Martina Cristaldi, Giorgia Spampinato (2020) Food Supplements in the Treatment of Ophthalmic Diseases: Preclinical and Clinical Studies. J Pharmacol Pharm Res Volume 3(2): 1-34. 